\title{
Petrophysical Tutorial, Lessons Learned, and Evaluation Workflow: A Case Study in the Power River Basin
}

\author{
Stephanie E. Perry, Matthew White
}

GeoMark Research, Houston, TX, USA

Correspondence to: Stephanie E. Perry, sperry@geomarkresearch.com

Keywords: Petrophysics, Wireline, Workflow, Niobrara, Power River

Received: March 31, $2021 \quad$ Accepted: May 28, $2021 \quad$ Published: May 31, 2021

Copyright $\odot 2021$ by author(s) and Scientific Research Publishing Inc.

This work is licensed under the Creative Commons Attribution International License (CC BY 4.0).

http://creativecommons.org/licenses/by/4.0/

\section{(c) (i) Open Access}

\section{ABSTRACT}

The objective is to empower the reader and scientific community with the knowledge and specific applicable equations to then reproduce the critical rock and fluid attributes in the Powder River Basin. To then continue to unravel the basin and its potential (both conventionally and unconventionally). The overall goal is to ensure the transfer of knowledge and communication of a petrophysical workflow that can then also influence application to other basins worldwide. The Powder River Basin is in southeast Montana and northeast Wyoming and is a prolific oil and gas (hydrocarbon-prone) sedimentary basin related to the greater Rockies chain/series of hydrocarbon-bearing basins (ex. Big Horn, Greater Green River, Denver-Jules). In this study, we briefly set-up the geological background of the Powder River Basin and the importance/ relevance to then tackling subsurface petrophysical evaluation on a regional scale. Approximately, 200 wells were evaluated petrophysically by a combined deterministic and inversion-based workflow representing an effort to share best practices, approaches, and the relative trends to apply in the basin to unravel the stratigraphic hydrocarbon potential in place. An extensive workflow involving basic petrophysical approaches such as raw log applicable cutoffs and volume of clay determination are shared as well as extending knowledge and application into advanced petrophysics through geochemical property derivation and impact of those derived properties as well as bound versus free water and hydrocarbon understanding. Results of the petrophysical analysis highlight the varying properties in conventional and unconventional formations (example Niobrara). The results of how and why the petrophysical approach was calibrated and then applied are the primary efforts accomplished.

\section{INTRODUCTION}

Petrophysicists are often referred to as one of the primary links or bridges between the geosciences and engineering disciplines (Figure 1). 
In this study, we focus on educating and communicating a multi-avenue approach and resulting workflow to petrophysical evaluation in the Powder River Basin. The Powder River Basin is in southeast Montana and northeast Wyoming and has historically been known for its coal bed methane potential and production [1-3]. In this study, we utilize 200 wells for petrophysical evaluation and several wells with accessible subsurface rock property measured constraint to calibrate and tie the stratigraphic core to log evaluation of properties (Figure 2). In addition to the coal bed methane potential, the basin has been utilized for conventional vertical wellbore production since the early 1980's. Then into the early 2010's has transitioned to a conventional and unconventional focus with the advent of deviated as well as horizontal-drilling capabilities [4-6]. Historically deeper vertical targets for conventional gas-prone production included the Minnelusa, Morrison, Dakota, and Lakota formations [1-3]. For the purposes of this study, while we recognize the continued potential and need for further characterization of the pre-Cretaceous stratigraphy, we focus our evaluation on the Cretaceous to present primarily liquids-bearing hydrocarbon stratigraphy whose base/lower depth zone we will define as the Muddy formation and at its shallowest we will define as the Teckla formation (Figure 3, i.e., Stratigraphic type log section with wireline response defined).

\begin{tabular}{|llcl}
\hline & \multicolumn{2}{c}{ Business Life Cycle } \\
Pre-Screen \& Capture $\quad$ Exploration $\quad$ Appraisa-Exploitation & Development & Production & Post-Production
\end{tabular}

Figure 1. Business life cycle schematic relative to the application of petrophysics in the oil and gas industry.

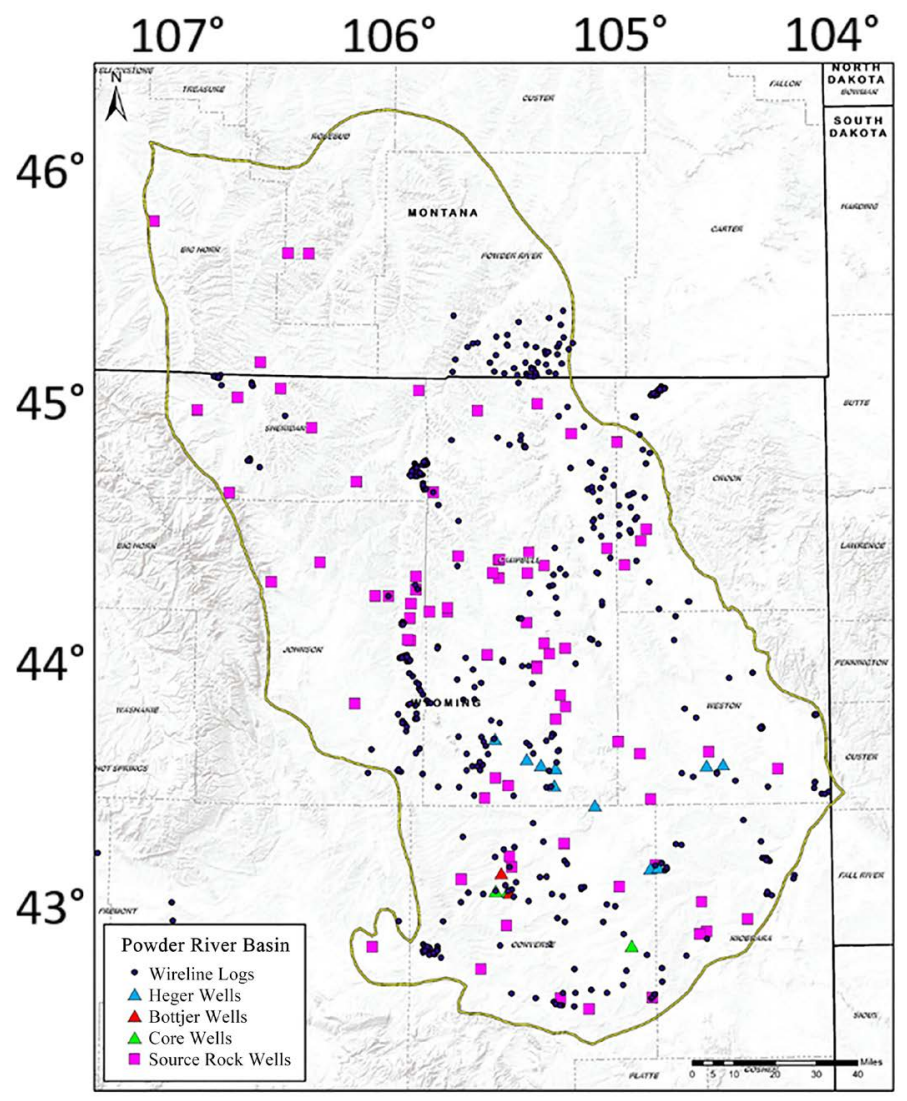

Figure 2. Spatial map of the Powder River basin showing the rock property constraint locations utilized from two published references $[4,5]$, source rock data and last the physical location of the wireline data evaluated for this study. 


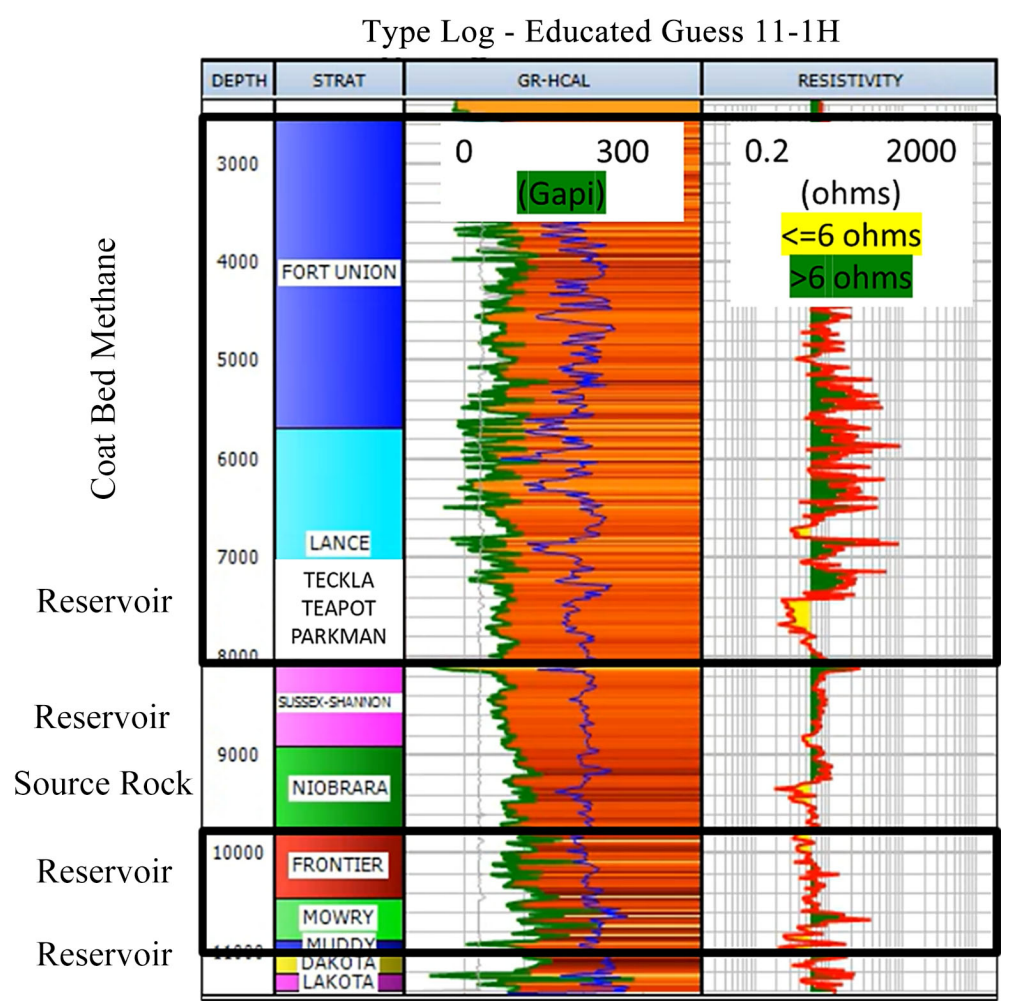

Figure 3. Wireline type log stratigraphic section. Tracks left to right: Depth (MD')-StratigraphyGamm Ray (GR Gapi) and Caliper (HCAL inches)-Resistivity (RDEEP ohms).

The basin has experienced more than one episode of tectonic contraction, then overprinted by Eocene to Miocene aged Basin and Range extension which has complicated the hydrocarbon system understanding and charge and migration reconstruction [1-3]. Focusing on the Cretaceous stratigraphy to present the Cretaceous hydrocarbon generation and expulsion from the Mowry and Niobrara (i.e., also includes the Belle Fourche member underlying the Niobrara) formations are the main source rocks that have generated and expelled the hydrocarbon that has charged the Cretaceous and younger stratigraphic reservoirs [6]. The source rock potential and intercalated as well as primary reservoir characteristics will be discussed in detail in the results and interpretation section of this study. Based on the prolific source rock potential and the Laramide Orogeny tectonic setting, the basin experienced contraction in the NW-SE orientation [1-3], which provides the interpretation to the primary observation of the orientation one can observe in most of the known conventional fields in the basin (Figure 4). Late-stage basin and range extension might have allowed existing "leaky seals" (such as the Pierre Shale unit) to provide a pathway for migration of hydrocarbon out of the more overpressured and "tighter" $(<1 \mathrm{mD}$ permeability) formations, directionally off to the eastern flank of the basin where you find other identified and produced conventional fields (i.e. Finn Shirley) [6]. Evidence for Mowry sourced long-distance migration (defined as $>5-10 \mathrm{~km}$ from point source) can be found in comparison of the fluids in situ versus hydrocarbon-produced oil fingerprints (see [6] Sonnenberg 2011). By contrast, the Niobrara sourced fluids stayed more "locally" home (defined as $<5$ - $10 \mathrm{~km}$ from point source) with a lack of migratory component to the fluids generated in situ (see [6]). It is important to understand the timing of hydrocarbon movement and therefore charge to these fields to delineate their quality as well as the remaining hydrocarbon potential as any scientist tries to exploit horizontal and conventional targets and research and studies continue to be conducted on various components of the stratigraphy and its rock and fluid properties. The importance and development of subsurface features, such as the Belle Fourche arc [6,7], as well as the timing and basin configuration and heat flow related to the inter-Cretaceous seaway formation and timing are also critical aspects of the basin evolution and history to understand [6]. Basement composition is primarily granites intra-cratonic PreCambrian 
metamorphic and igneous rocks, however the location of surrounding granitic basement plutons and the variation in basement composition can significantly impact the wicking or distribution of heat flow across the asymmetric Powder River Basin through time [6]. The influence of the Ancestral Rockies prior to Laramie Orogeny tectonic timing will not be discussed in this study.

Subsurface stratigraphic challenges in the basin include overcoming the impact of bentonites throughout the column which can impact the ability to stimulate and generate significant height or complexity related to unconventional completions (Figure 5). The stratigraphy transitions in the south from carbonate dominated to clastic dominated (from distal to proximal) as you move northward through Campbell county and towards a northwestern acreage position. Mapping of historic conventional fields is critical to understand the $\mathrm{HC}$ system and how that sets up the questions subsurface operators are facing.

Petrophysics in the basin has been and continues to be very challenging as most known opportunities and any future potential efforts focus on the presence of low resistivity low contrast pay such as would define the Shannon and Sussex, Turner and other sandstone plays. The defined source rocks of the Mowry and Niobrara have additional petrophysical challenges to understand and evaluate properties beyond the typical total organic carbon and maturity assessment and will be discussed in more detail forthcoming. From here, as we have set-up the aspects of the basin setting, hydrocarbon system evolution and geological context that are relevant and critical to now evaluate the basin petrophysically. We advocate that in any study of a stratigraphic zone on a regional or development scale $(\sim 1-2$ miles), subsurface disciplines should integrate all aspects of their understanding to further define and refine subsurface characterization efforts. These components, incorporating the applicable criteria that follow.

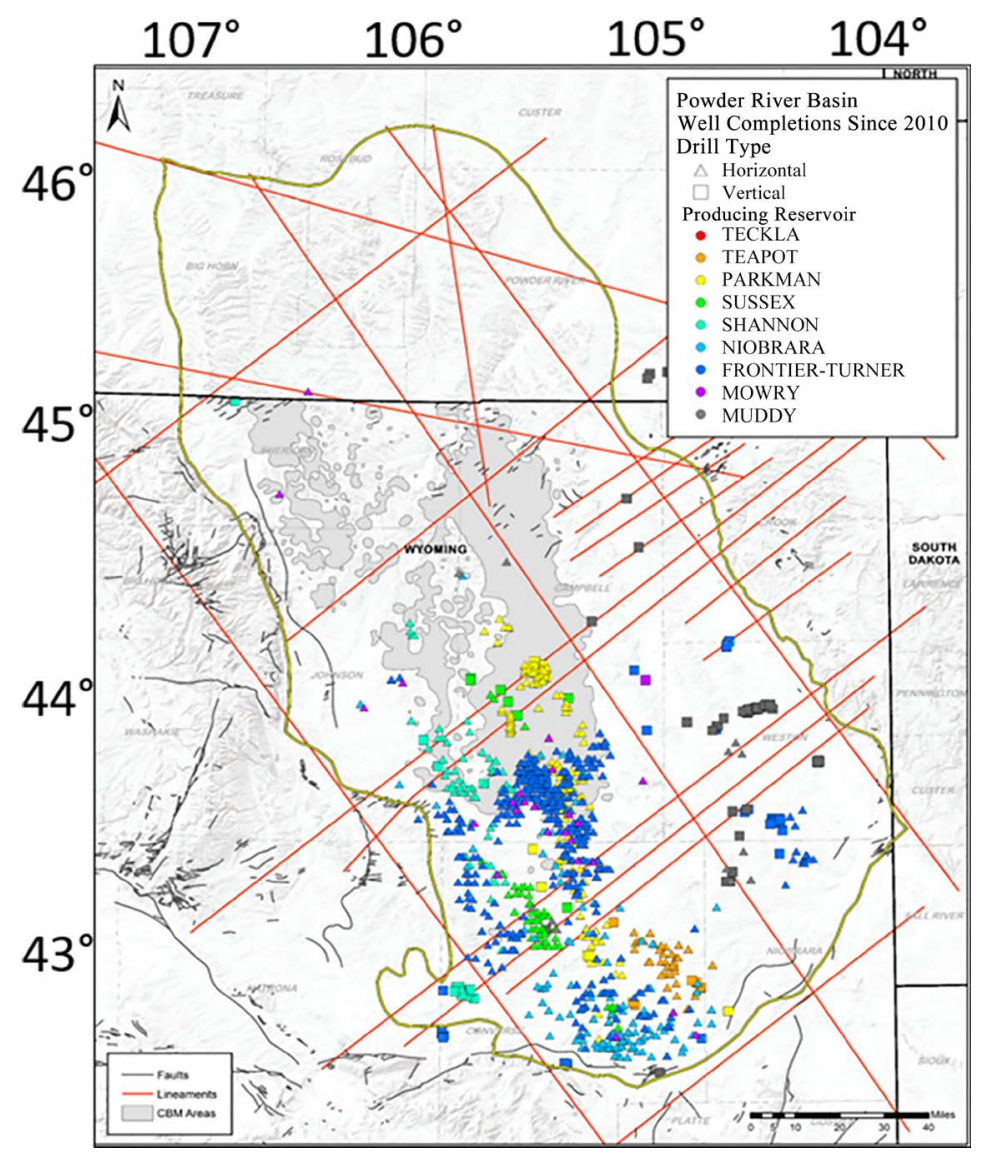

Figure 4. Spatial overview map of the Powder River basin with major structural, geographical features defined. Map highlights by stratigraphic interval the horizontal evolution of drilling since 2010 . Also noted are vertical producing locations and the main coal bed methane trend in the basin. 


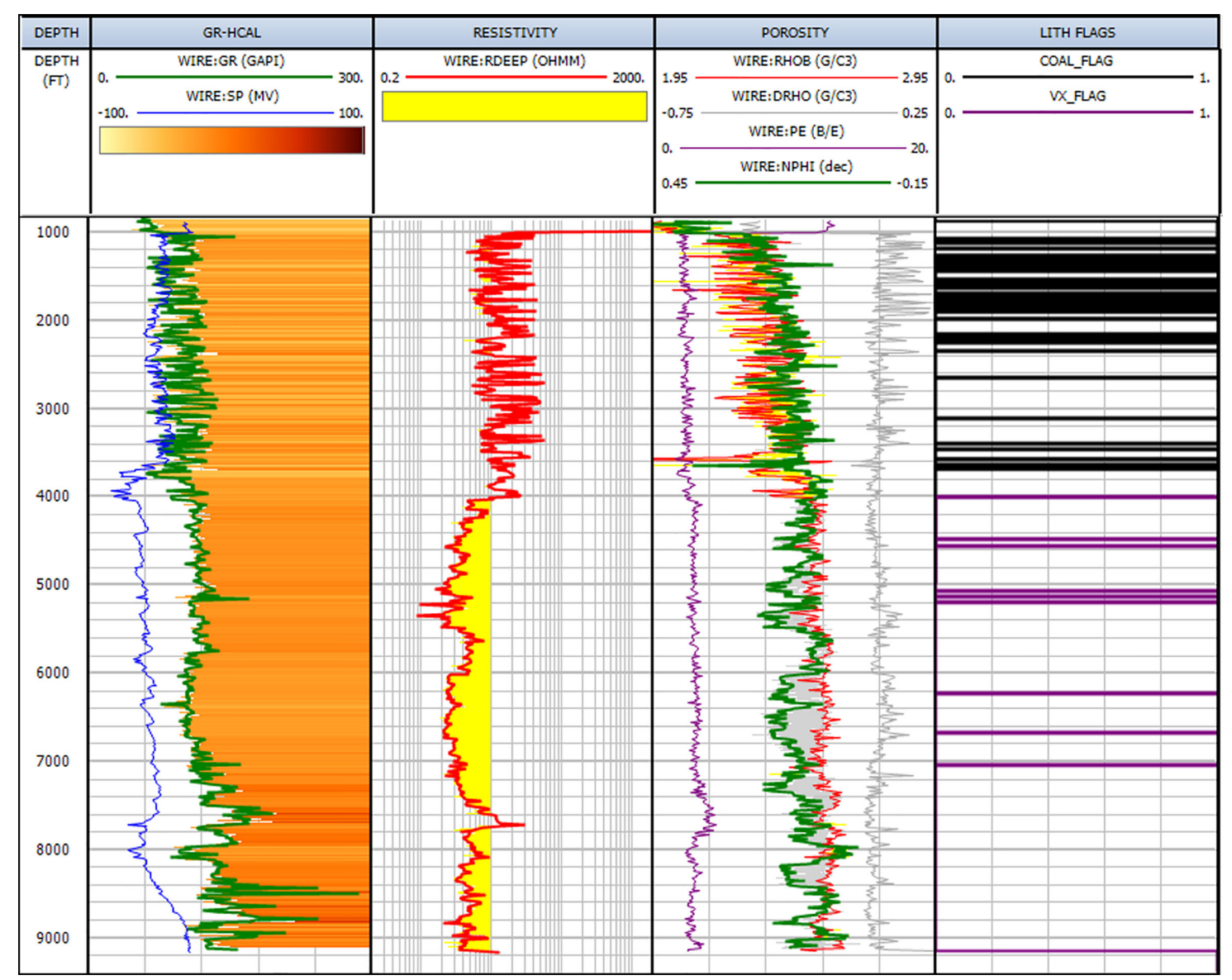

Figure 5. Iberlin 1-10 ${ }^{\text {th }}$ example of lithological coal and volcanics flags generated along the length of the wellbore. COAL_FLAG $=1$, where neutron porosity (NPHI) $\geq 0.35$ and bulk density (RHOB) $\leq$ 2.4 from 0 - 5000 MD' ELSE 0. VX_FLAG = 1, where RHOB $\leq 2.45$ from 4000-TD MD' ELSE 0.

\section{METHODS AND TUTORIAL}

In this study we approach the petrophysical model and integration from both a conventional and unconventional methodology and understanding. As the primary legacy targets in the Powder River Basin (PRB) have been conventional sandstones with porosity $>8 \%$ and permeability $>1 \mathrm{mD}$, we calibrate and investigate these known reservoirs and fields in our analysis. We utilize historic data to build on and identify play extensions and "halo" opportunities. In addition, we identify and approach the unconventional stratigraphy with an appropriate petrophysical approach including all the source rock quality and potential components to support unraveling the full hydrocarbon system analysis. We recognize one of the legacy hydrocarbon potential targets was related to coal bed methane primarily in the shallow Lewis shale unit as well as deeper gas-rich potential in the pre-Cretaceous stratigraphy. For this analysis and study, we focus on the main oil-bearing column spanning the Muddy sandstone and equivalents upward to the Teckla sandstone, now also known for its water-injection capacity.

Multiple petrophysical model approaches were taken in this study including both deterministic (empirically driven) methodology, as well as an inversion-based (i.e., probabilistic) approach with the development and application of a multi-mineral model utilizing more than linear regression analysis at its core logical engine. In addition, we applied hierarchical cluster analysis through a least mean squares approach to electrofacies rock typing efforts. The combination of the deterministic and inversion-based methods allows the applicability to investigate the exploration to development scale questions they are addressing. 


\section{Wireline Basic Nomenclature to Know}

- Gamma Ray, Spectral Gamma Ray (Uranium, Thorium, Potassium), Caliper, Spontaneous Potential, Bulk Density, Density Correction, Photoelectric Factor, Neutron Porosity, Resistivity, Compressional Sonic, Shear Sonic, Nuclear Magnetic Resonance, Dielectric Resistivity, Triaxial Resistivity, Resistivity Imager, Acoustic Imager, Fluid and Pressure Sampling, Telemetry, Orientation Tools

- Triple Combo (Gamma Ray-Caliper-Resistivity-Neutron Porosity-Photoelectric Factor and Bulk Density)

- Quad Combo (Gamma Ray-Caliper-Resistivity-Neutron Porosity-Photoelectric Factor-Bulk Density and Sonic)

Below is a generalized example of the petrophysical approach and workflow taken for wells that had subsequent data to interpret derivative properties (Figure 6).

Legacy core data was used to constrain all the mineralogical, total porosity and total water saturation interpretations presented within this study. Calibration for interpretation was extrapolated in between known calibration points and therefore uncertainty does exist in these property evaluations. In each section the uncertainty in the applied methodology and resulting derivatives are documented for the purposes of this study and to take into consideration and utilize when then evaluating outside of the study presented here. In this study, subsurface core, rotary sidewall core and cuttings measured properties were used to calibrate and constrain understanding, trends and the petrophysical approach and evaluation. We recognize the value and criticality of the subsurface constraint and calibration to further integration. In this study we do not review any stratigraphic, sedimentologic or structure-based core descriptions. However, we do encourage and communicate the value added by the additional context to the evaluation that is therefore presented here (Figure 7).

\subsection{Raw Wireline Logs}

For the regional efforts presented here two sources of raw wireline data were utilized. The first set of data was chosen from a non-public wireline database where any well in the Powder River Basin having a triple combo log suite (i.e., GR, RDEEP, NPHI and RHOB) was filtered and utilized in our efforts. The second set of data utilized was accessed from the Wyoming Oil and Gas Commission -WYOGC [8] by asking for the digital records of the wireline logged wells in the basin. Here again, wells utilized in this study were filtered for depth (wells with the most significant continuous logged coverage) as well as a minimum of a GR (gapi), RDEEP (ohms) and NPHI (dec) were utilized. These were the base wireline suites required however we note several wells did include PE (b/e), DT (us/ft), and some advanced wireline logs for our integrated efforts.

All raw wireline logs were quality controlled for borehole washout, casing points, poor log quality due to stick/slip. A borehole quality flag based on a DRHO threshold of $0.2 \geq \mathrm{DRHO} \leq-0.005$ was generated for use and often aids the petrophysicist and geologist by visually demonstrating where wireline data might not be able to be used for property assessment (Figure 8). In addition, all raw wireline logs were environmentally corrected for logging vendor variation, tool vintage and lithological scale. For this study, all neutron porosity (NPHI) logs were set to a limestone end member matrix scale assuming limestone equals $2.71 \mathrm{~g} / \mathrm{cc}$ (Figure 9).

As the Powder River Basin log response is challenged by the lithologic presence of coals and volcanics, additional flags were generated to identify these wireline responses in the stratigraphic column. The flags can be utilized by a geoscientist wanting to then map petrophysical properties varying the accuracy of the VCL (v/v), PHIT (\%) and SWT (\%) statistical values. For example, in the Mowry, a geoscientist may not want to include the interpretation of VCL, PHIT and SWT of the volcanics in the section as this will create a bimodal distribution of these properties and therefore inaccurately represent the shales average properties. Flags generated here (known as COAL_FLAG and VX_FLAG) can be used as cut-off values and applied to regional or local-scaled mapping efforts (see Figure 5).

- COAL_FLAG $=1$ where NPHI $\geq 0.35$ and RHOB $\leq 2.4$ from 0 - 5000 MD' ELSE 0

- VX_FLAG $=1$ where $\mathrm{RHOB} \leq 2.45$ from 4000 -TD MD' ELSE 0 
1. Calibrate all Logs to Limestone Matrix Scale

2. Run Flags for:

Badhole, Coal, Volcanics

3. Electrofacies Hierarchial Clustering Raw Log Approach

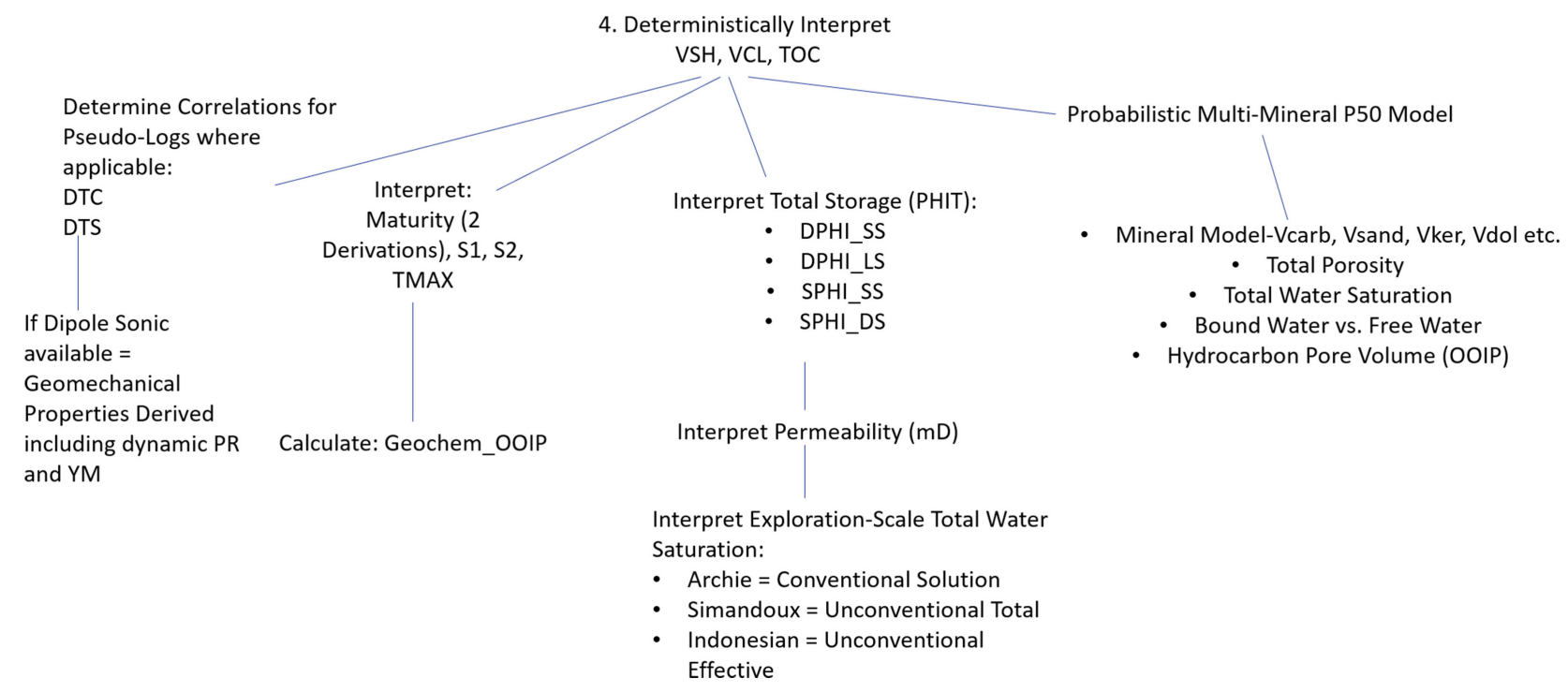

Figure 6. Generalized example of the wireline based petrophysical workflow applied in this study.

White Light Photography

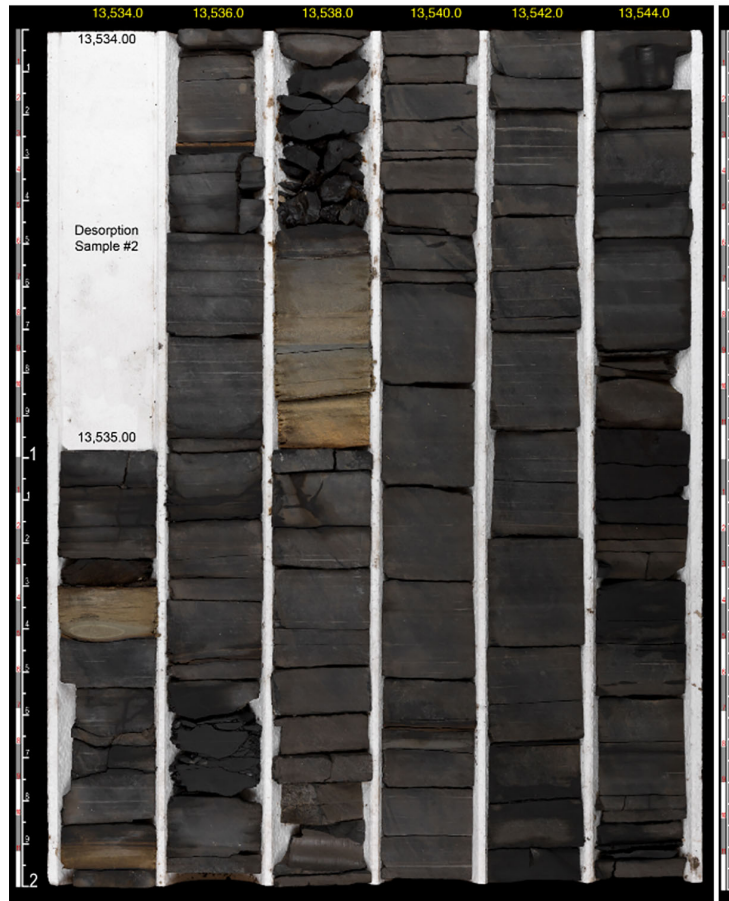

Ultraviolet Photography

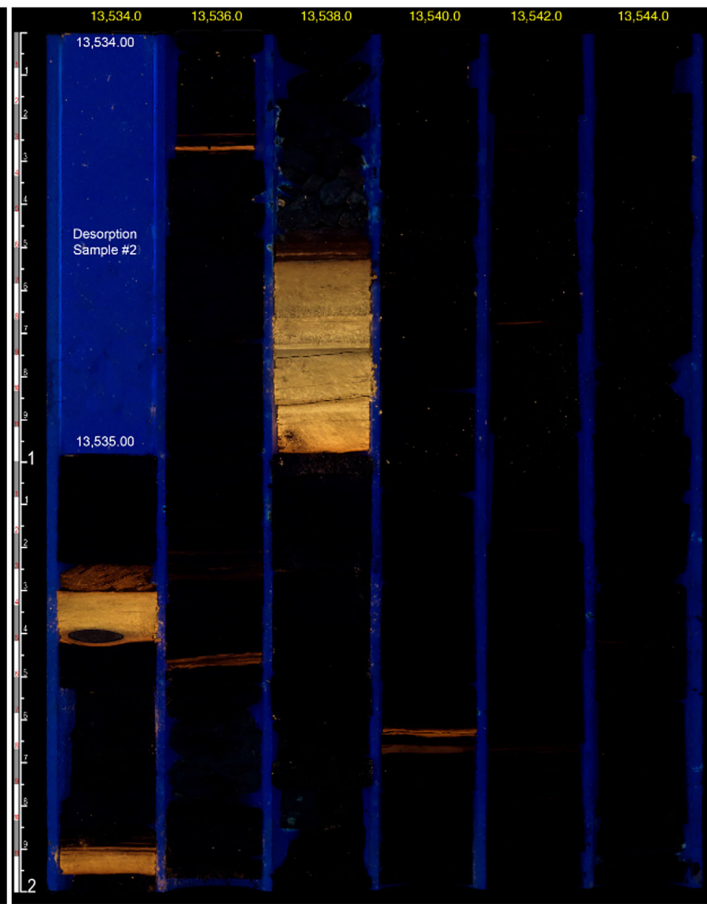

Figure 7. White and ultraviolet light box photography of the Mowry formation from northwestern Converse county. Subsurface core descriptions and geological context is critical to understand and help constrain the integration of petrophysics in a given play or basin study. 


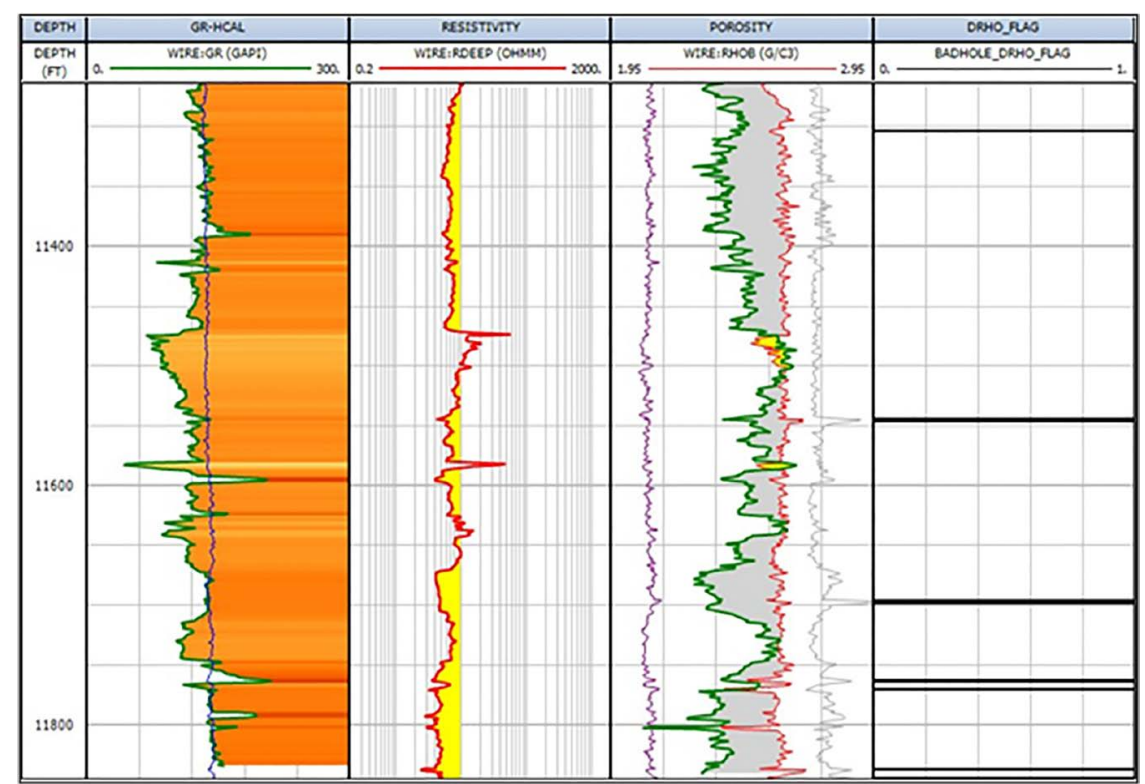

Figure 8. Iberlin $1-10^{\text {th }}$ example of a borehole quality flag based on a DRHO threshold.

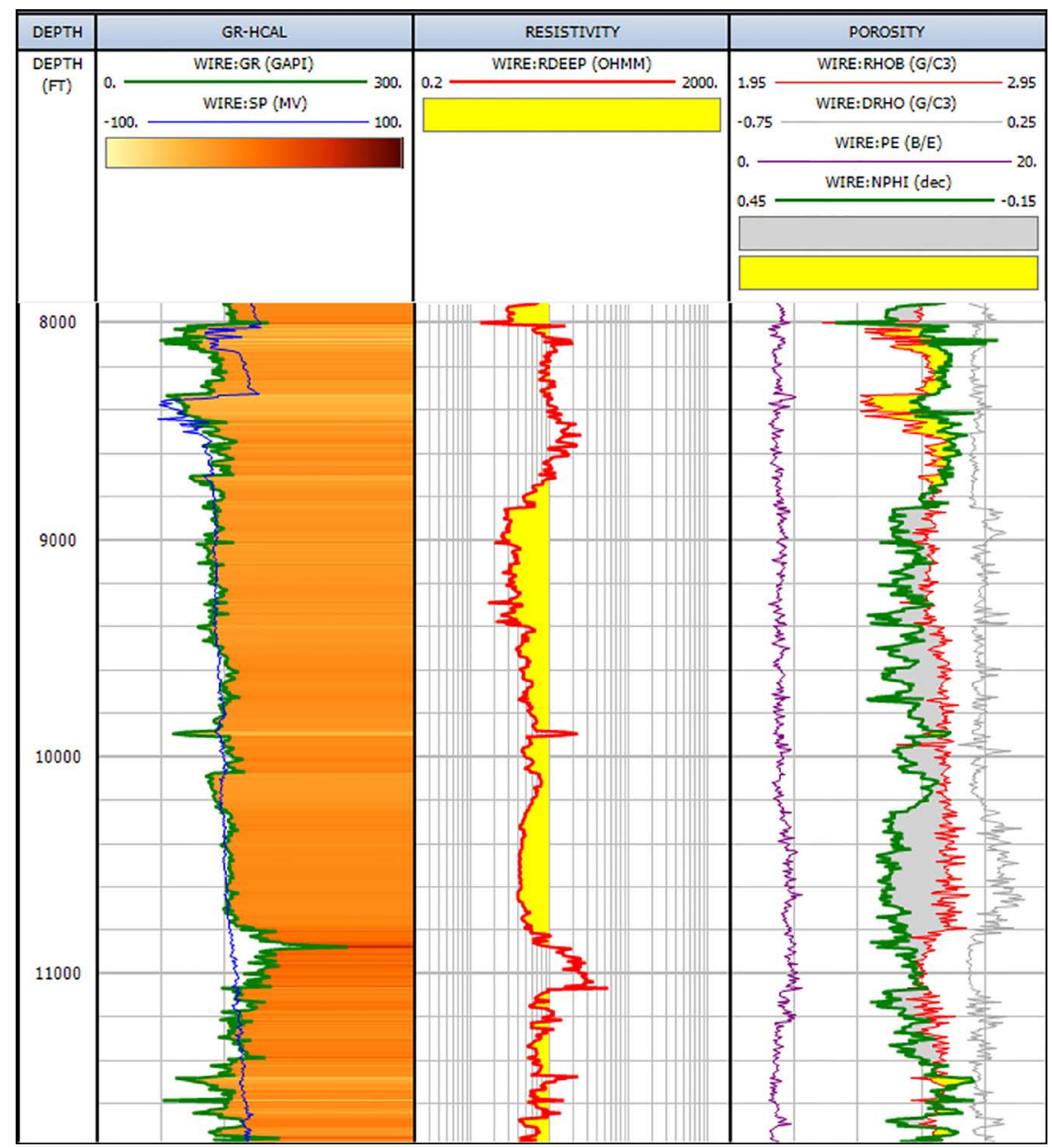

Figure 9. Iberlin $1-10^{\text {th }}$ plot demonstrating the neutron porosity (dec) and bulk density (g/cc) wireline curves scaled for a limestone matrix end member. 
Finally, raw wireline log responses were utilized as an independent way to then interpret the geological context since the basin wireline coverage could be infilled with wells containing just a gamma ray (GR) and neutron porosity (NPHI) log etc. bypassing the need for a triple combo suite to execute a full petrophysical evaluation. Raw wireline averages applied cutoff summations and footage of cutoffs were utilized to highlight depositional and property-based trends that are then interpreted in the context of the basin history. These wireline maps also supplement the petrophysical evaluation since any given property is a derivation of the raw digits. The effort is an effective quality control check on the petrophysical evaluation principles as we derive the properties from these log suites. For example, applying cutoffs or mapping bins of GR ranges, we can interpret those maps as net sandstone, net silty-sand and net shale representative maps. Deep resistivity cutoffs applied for these efforts include the footage of deep resistivity (defined by $>$ than 90-inch investigation radius) RDEEP $\leq 8,6$, and 4 ohms. These cutoffs can be interpreted to represent variation in low resistivity, low contrast pay potential as well as what has increased water-filler versus hydrocarbon-filled pore volume. Therefore, when mapped can highlight the proximal to distal trends of the stratigraphy. As well as where low resistivity, low contrast pay can be observed. Raw wireline cutoffs were also utilized for bulk density (RHOB) and sonic/acoustic (DT) (supplements by pseudo-DT logs) to represent trends in total storage as well as lithology and the overpressure presence in the basin (Figure 10). Petrophysical wireline-based interpretation across a regional set of wells results in our ability to map rock properties and provide hydrocarbon system context to disciplines. Below is an example of how a petrophysical evaluation in the Powder River Basin can then be mapped in 2D space for a given formation and property of interest (Figure 11).

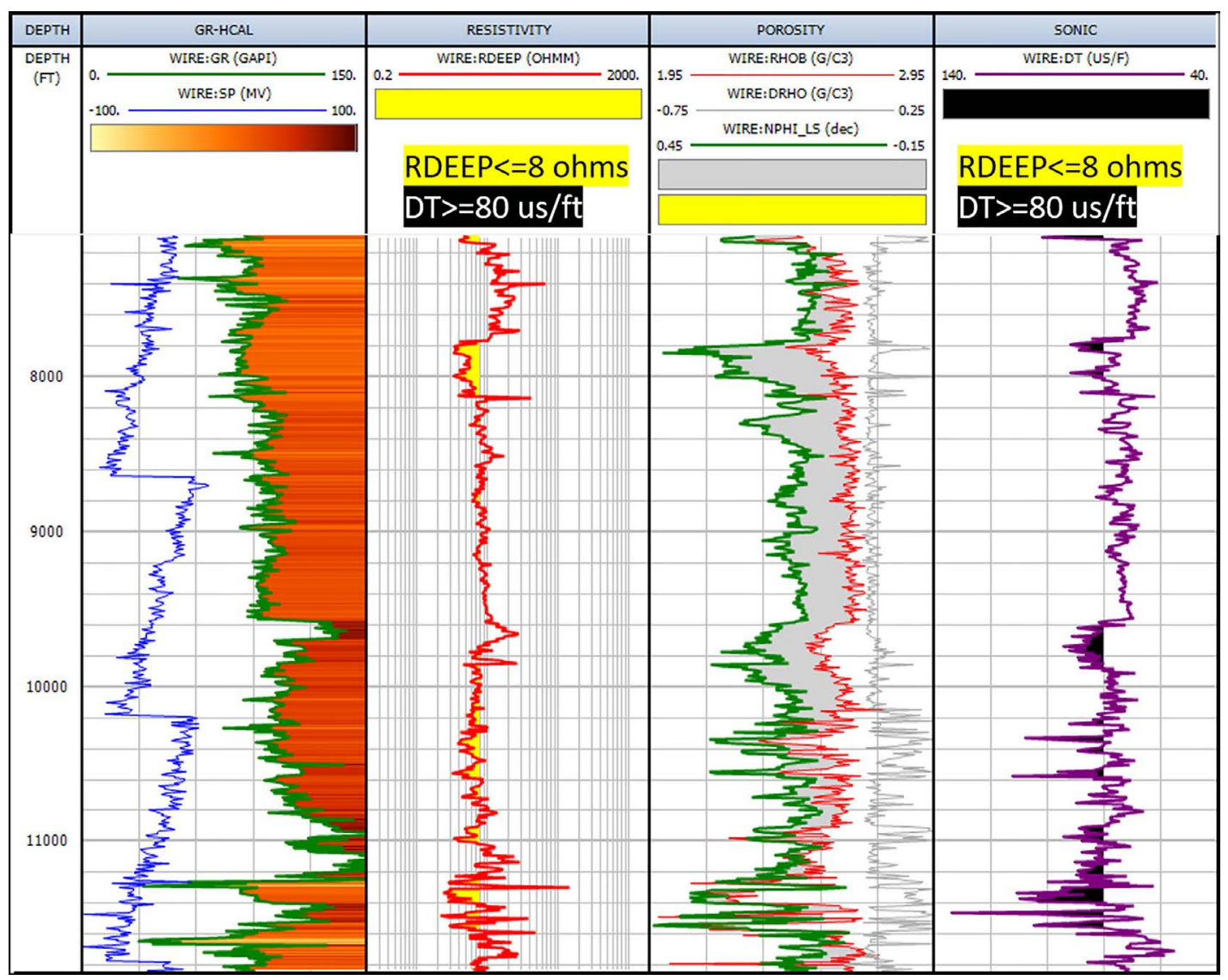

Figure 10. Little Bugher Draw unit 1 wireline display, highlighting the impact of raw wireline thresholds to capture trends in the stratigraphic properties that can be utilized for geological mapping. Here, we show deep resistivity (ohms) and delta acoustic travel time (us/ft) thresholds. 


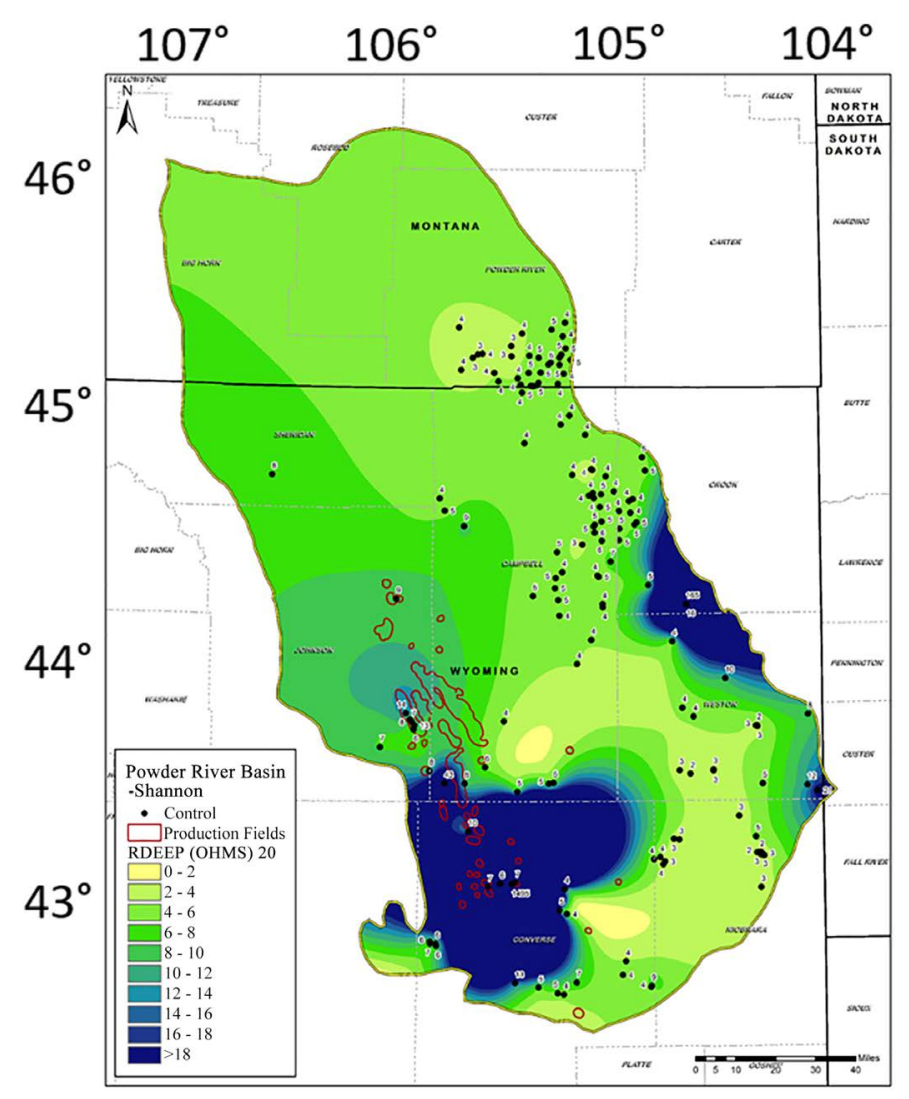

Figure 11. Shannon footage of RDEEP geological map, demonstrating how we take the petrophysically determined raw log cutoffs and translate them into meaningful geological maps. Here, we are attempting to highlight the sandstone depositional fairway in the basin. Combined with an understanding of the absolute deep resistivity value being mapped, we can interpret the map to represent the hydrocarbon-prone trend based on the data to constrain the spatial distribution.

Debate within the petrophysical discipline is still prevalent regarding the approach and application of normalized log efforts. For this study, we focused on the normalization of the GR and RHOB raw wireline logs as a deliverable for the geologist or stratigrapher correlating well tops across the basin. As such, a single point bulk shift normalization effort was conducted with the end member well being chosen based on basin position and log suite available. Below we demonstrate the impact graphically as well as in wireline format of the normalization effort (Figure 12 and Figure 13). Post normalization, these logs were not utilized in the following petrophysical evaluation efforts presented here. The justification being the potential impact in muting or skewing any true geological end member changes in the basin.

In any given basin investigated petrophysically there will always be some scarcity of coverage regarding the wireline data available or vintage etc. There is no exception in this case study presented here. While we attempted to include as complete of raw wireline log suites as possible, we did need to generate log curves that are a derivative of a correlation to another log that is more commonly measured regionally. For example, there is a lack of monopole and dipole acoustics in the PRB according to our ability to search and utilize log suites in our efforts. The same can be said for the presence of photoelectric (PE) logs.

As such, pseudo correlation for these logs specifically were generated. A correlation of photoelectric factor ( $\mathrm{PE} \mathrm{b} / \mathrm{e}$ ) to bulk density (RHOB $\mathrm{g} / \mathrm{cc}$ ) was generated and therefore a pseudo-PE utilized in a few wells to allow a multi-mineral model approach to be executed. See correlation below (Figure 14).

In addition, correlation between deep resistivity and neutron porosity can be established for wells that lack a raw measured wireline based NPHI (dec) (Figure 15). Neutron porosity is a critical input to mul- 
tiple petrophysical property derivations. In leu of a lack of physically measured logs we can apply the pseudo-correlation as established for a best fit correlation and go from there. Of course, any time we are honoring a regressive analysis through a distribution of data, the resulting pseudo-curves lack the entire spectrum of variability that does exist geologically. The end members of which are not captured in the pseudo-log application. However, much of the rock property distribution is honored and maintained as valid and represented through the stratigraphic column. Additional efforts were focused towards establishing a more robust multi-linear regression correlation and solution. However, the impact to the predictive pseudo-curves generated was minimal and therefore not justified versus the business case uplift. If a client would like additional work to be performed applying a more advanced statistical approach to infill data holes and generate/establish curve relationships (i.e., Random Forest, Clustering, Self-Organized Maps, Non-Linear Curvature etc.).

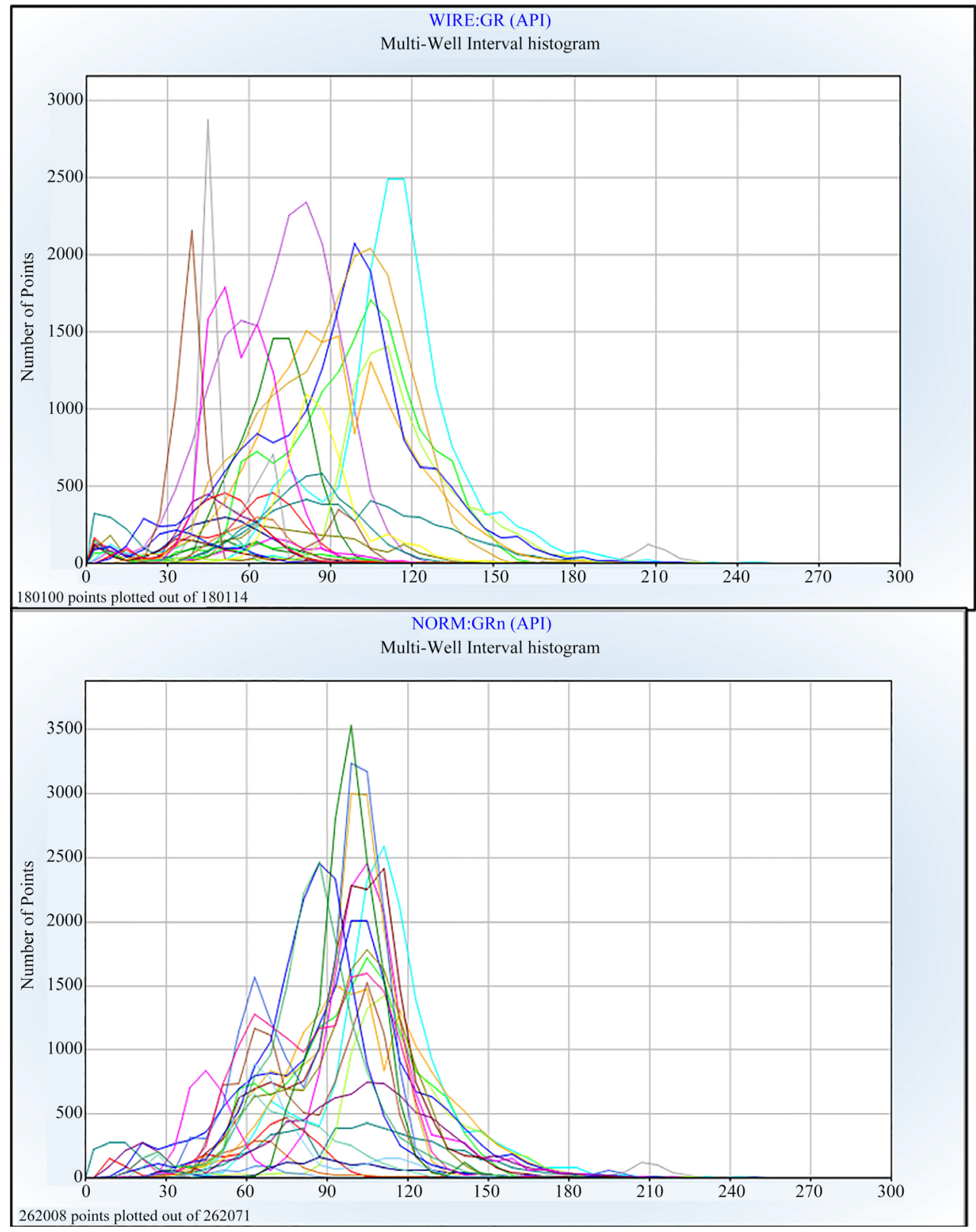

Figure 12. Top: Shows raw data distributions, no normalization. Bottom: Shows normalized distributions. 


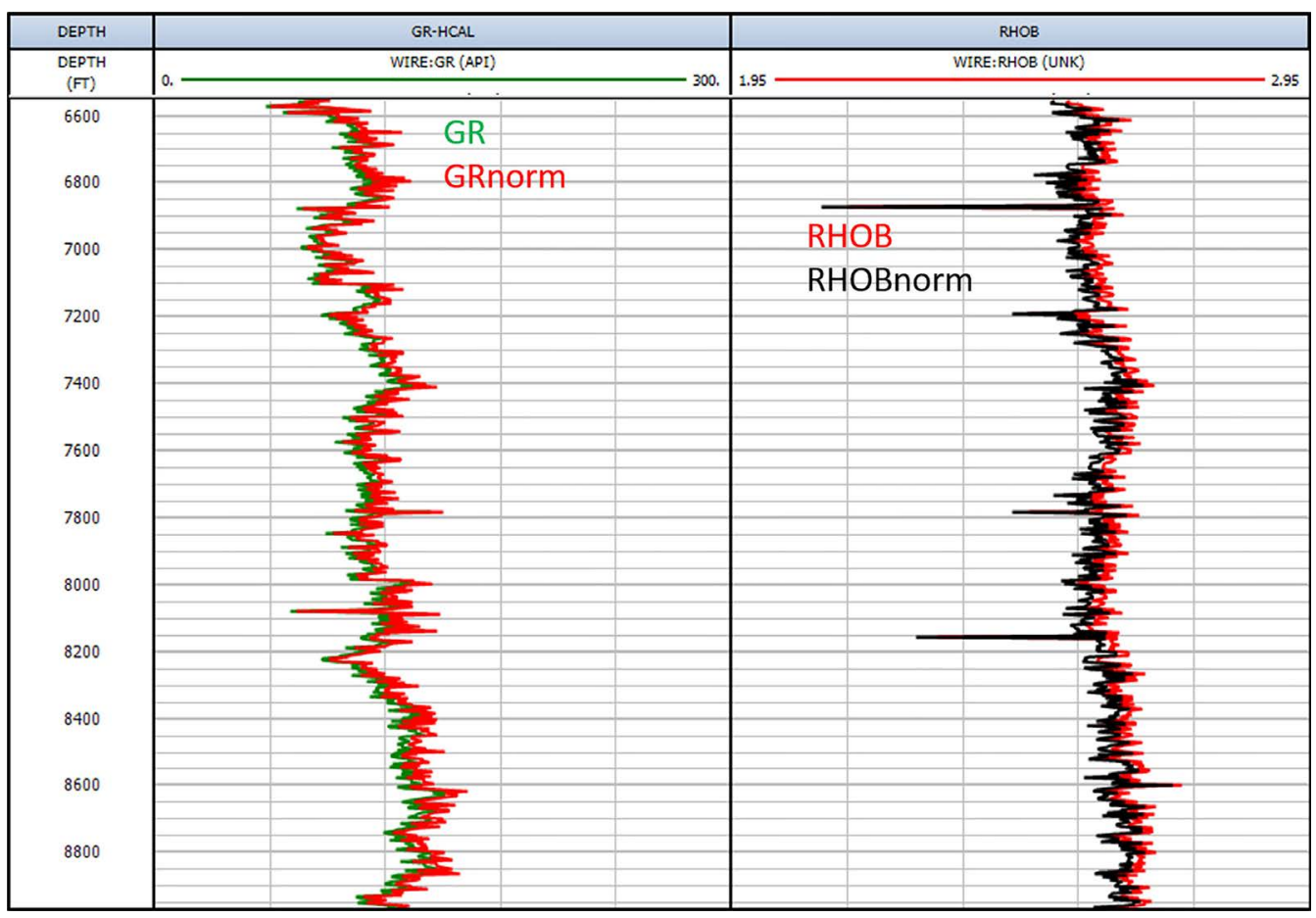

Figure 13. Wireline display of normalized GR and RHOB. Minimal corrections were applied from a one-point constant normalization effort.

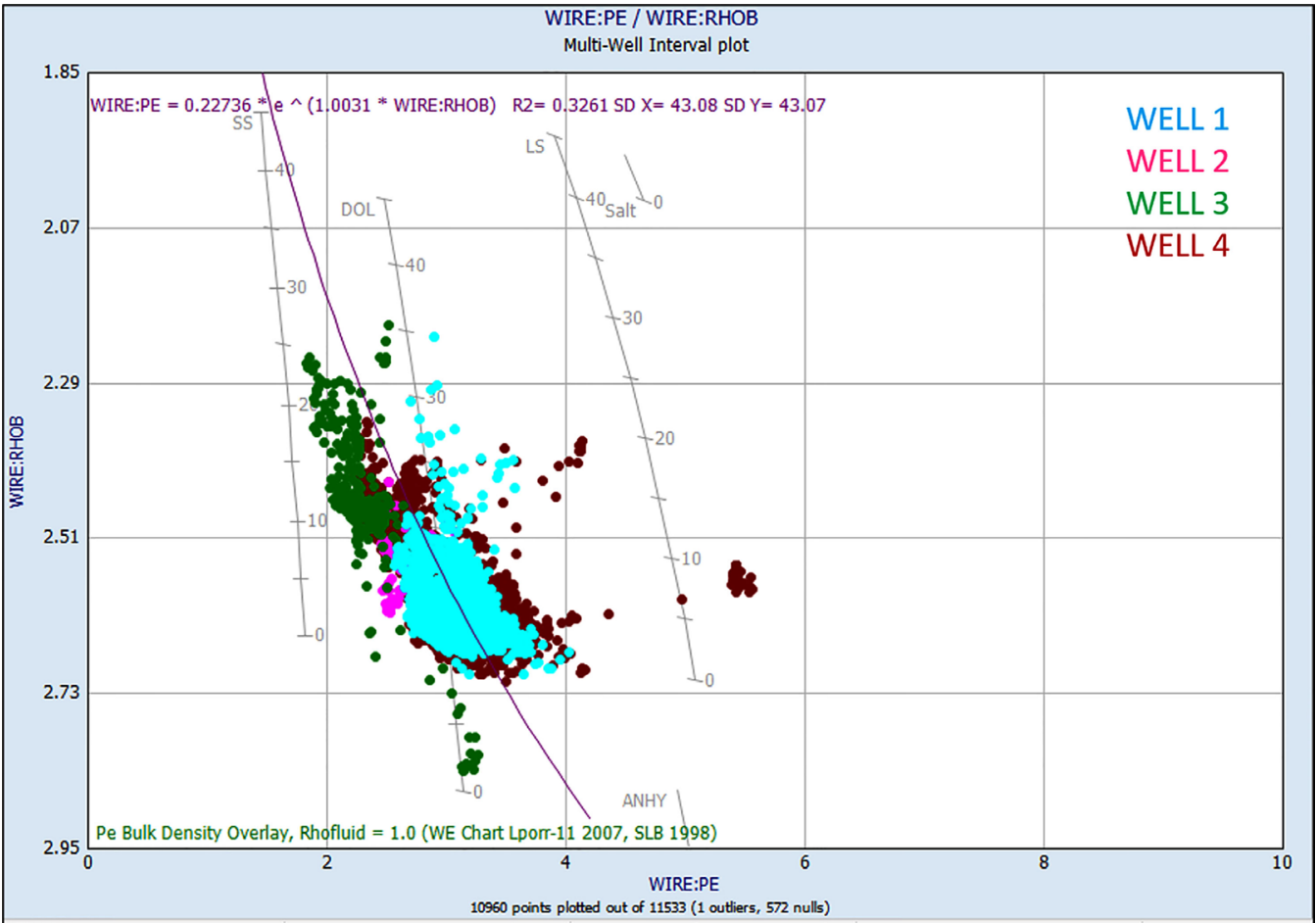

Figure 14. Cross-plot of multiple wells measured raw wireline photoelectric factor (b/e) versus bulk density $(\mathrm{g} / \mathrm{cc})$. The correlation allows a pseudo-PE to be generated, where absent, from the presence of the measured bulk density wireline log. $\mathrm{PE}$ is a required input for a multi-mineral petrophysical model approach. 


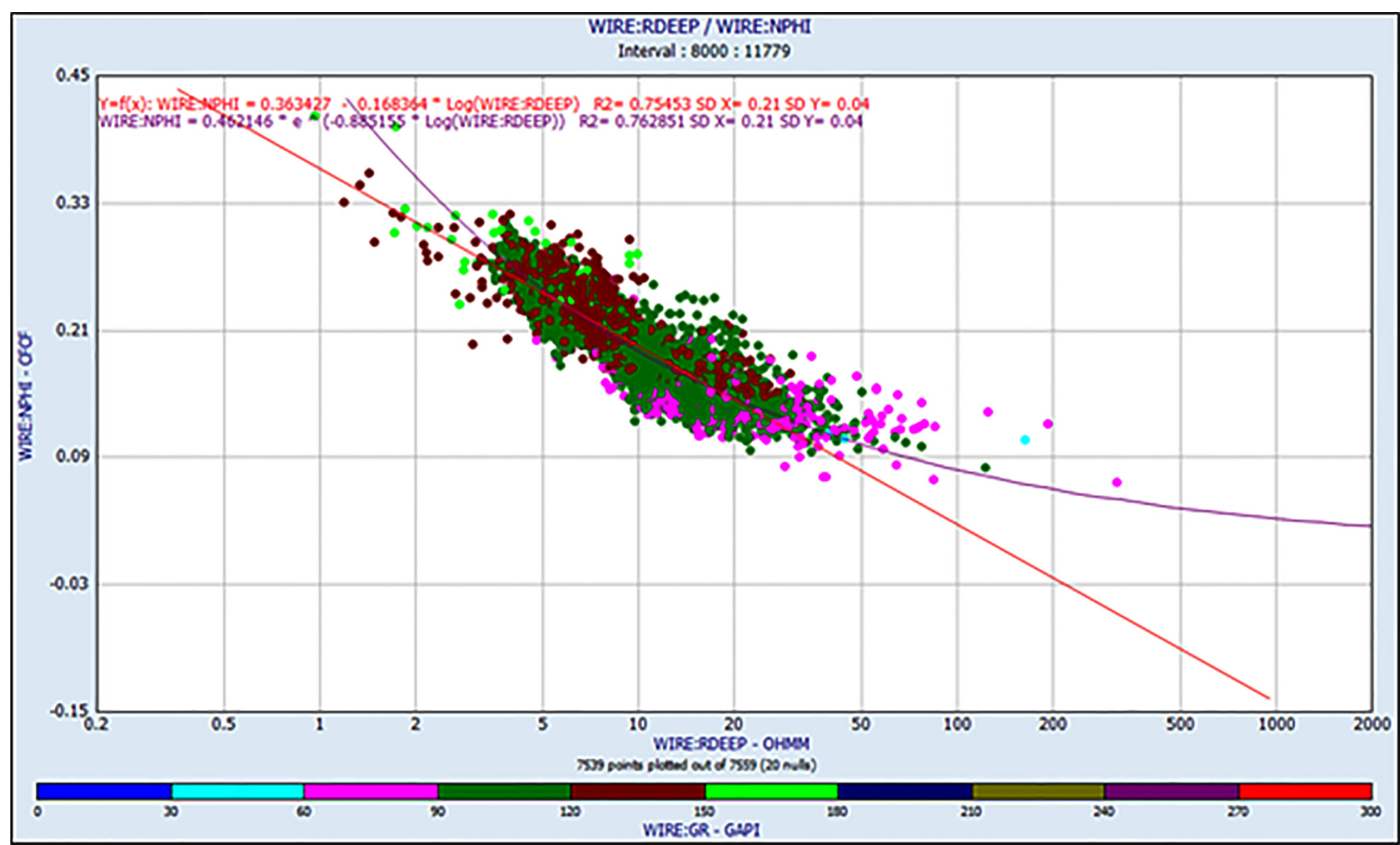

Figure 15. Cross-plot of wireline deep resistivity (RDEEP ohms) versus wireline neutron porosity (NPHI dec). Linear versus exponential correlations can be utilized to generate pseudo-logs where only one or the other wireline log is present/available.

Likewise, to extrapolate the sonic monopole and dipole DT, DTC and DTS log presence, first a correlation of DT/DTC was observed and generated. Next, the correlation between DTC to DTS was generated. Thereby allowing us to generate a pseudo-DTC and DTS (Figure 16 and Figure 17). This effort was focused on to provide the necessary inputs to utilize acoustics for the following properties. For example, acoustic based porosity on a carbonate and sandstone end members, identification of top overpressure, pore pressure prediction, rock typing electrofacies variations and geomechanical properties.

In this study, raw wireline-based electrofacies models were developed following the below methodology. Due to the lack of acoustics and additional advanced logs suites in the basin either publicly or for purchase now, the electrofacies models developed focused on triple combo inputs including. Including GR (gapi), RDEEP (ohms), RHOB (g/cc), and NPHI (dec). A series of unsupervised models were developed using hierarchical cluster statistical logic with the minimum of the least square's regression distance applied to reduce probabilistic overlap in the cluster association. No discriminators were applied and no petrophysically derived properties were input to train the model.

Cluster-based models were run allowing for identification of $20,18,16,14,12,10,8$ and 6 overall populations therefore resulting in electrofacies rock type associations that correspond. The deliverables can be utilized by geologists to readily identify major, as well as minor, changes in the wireline signatures across the stratigraphic column. Stratigraphic tops can be correlated based on these models. Geological maps can be generated as well, however would require interpretation of what each rock type tied to a sedimentological or structural context means (i.e. Bioturbated siltstone versus organic-rich mudstone). Without the additional environmental context leading to that interpretation, the electrofacies can be used to communicate observed changes in the triple combo wireline set and context provided in that way. For example, electrofacies A has high GR, high RDEEP, low RHOB and therefore could be interpreted as a "shale" (Figure 18 and Figure 19). 


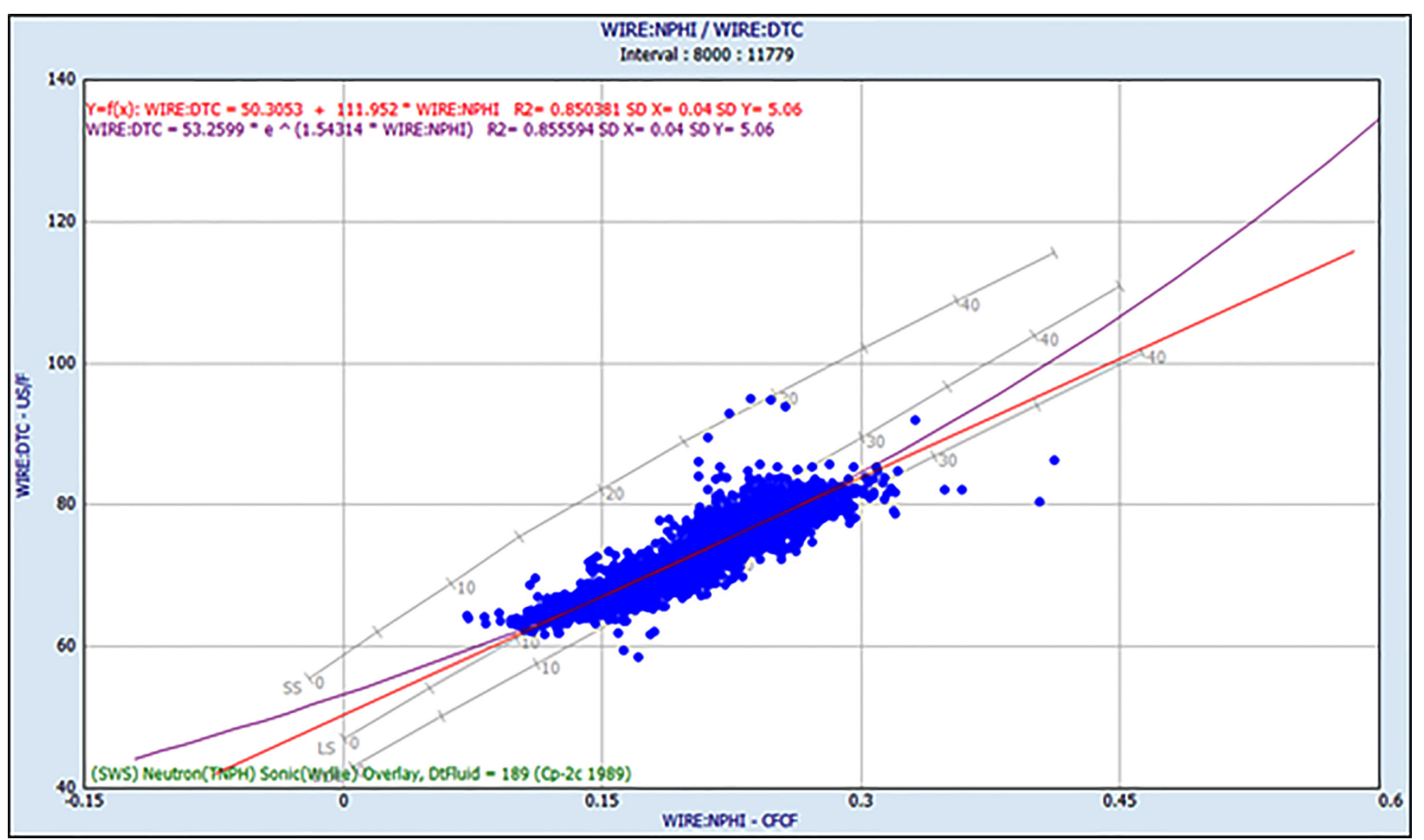

Figure 16. Cross-plot of neutron porosity $(\mathrm{dec})$ versus compressional sonic (us/ft) with Wyllie correlation overlay, where DTf $=189 \mathrm{us} / \mathrm{ft}$.

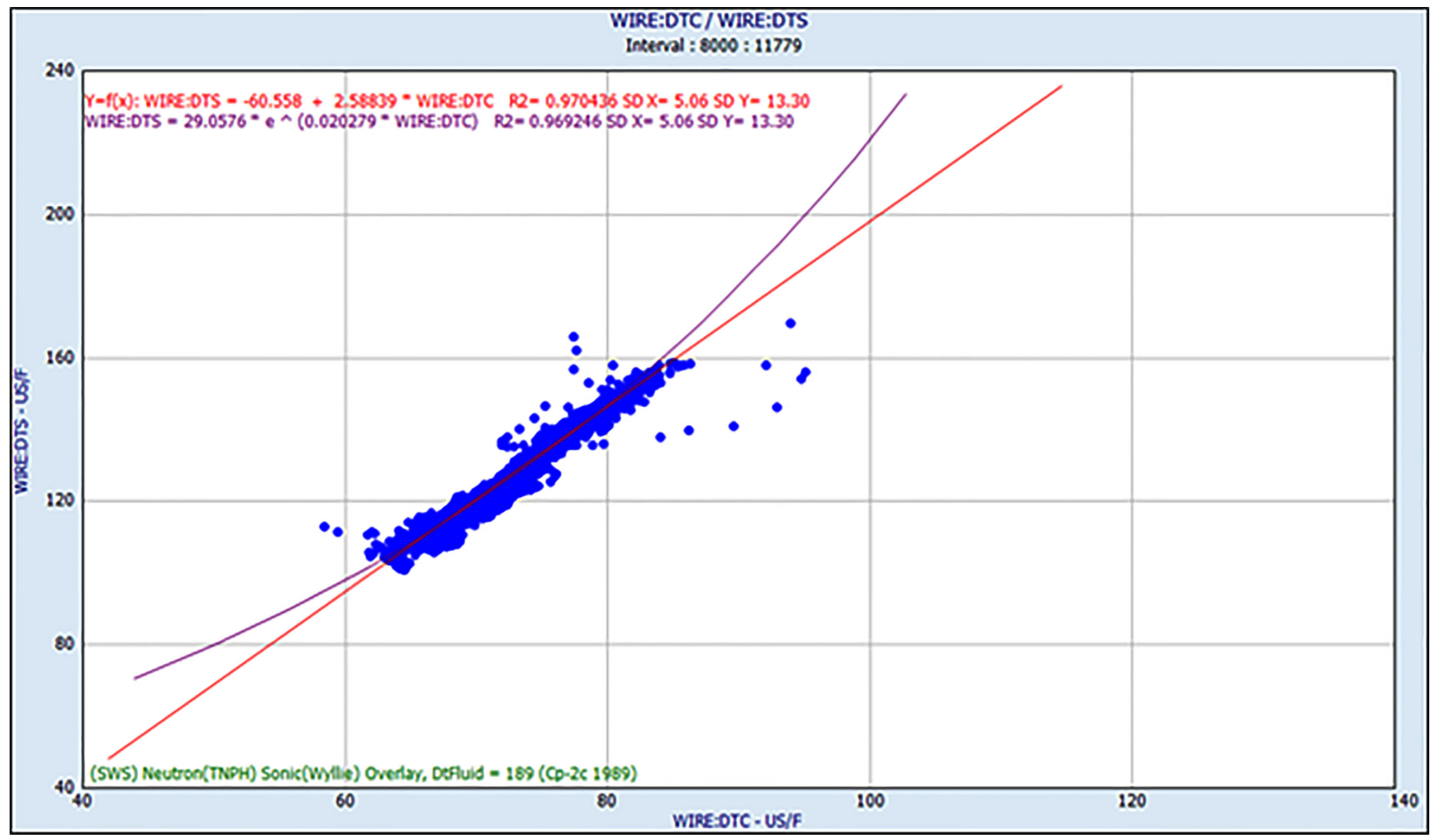

Figure 17. Cross-plot of compressional sonic ( $\mathrm{us} / \mathrm{ft}$ ) versus shear sonic (us/ft). Both an exponential and linear regression are provided, so the client can choose the correlation principle they see is best fit for prediction. 


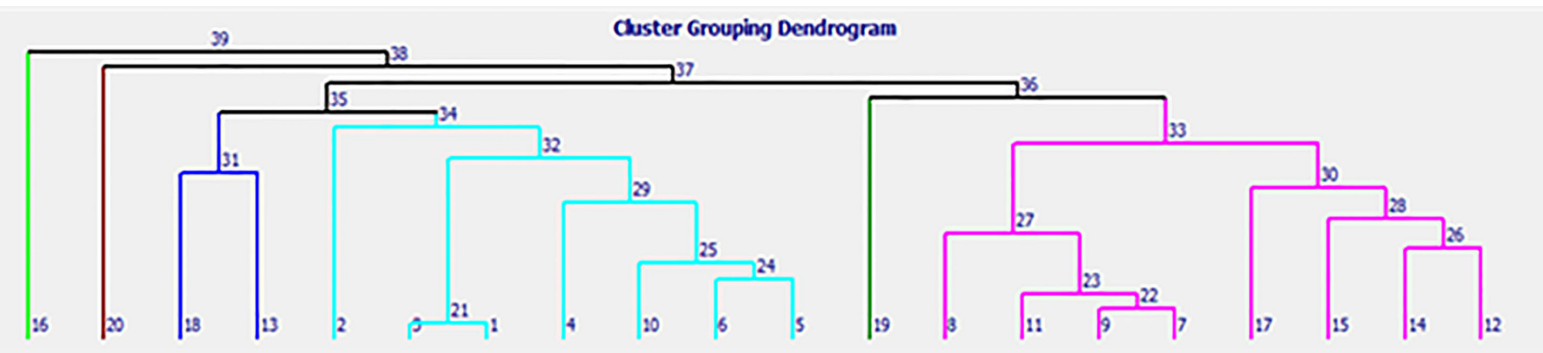

Figure 18. Example of a cluster dendrogram for a six electrofacies model.

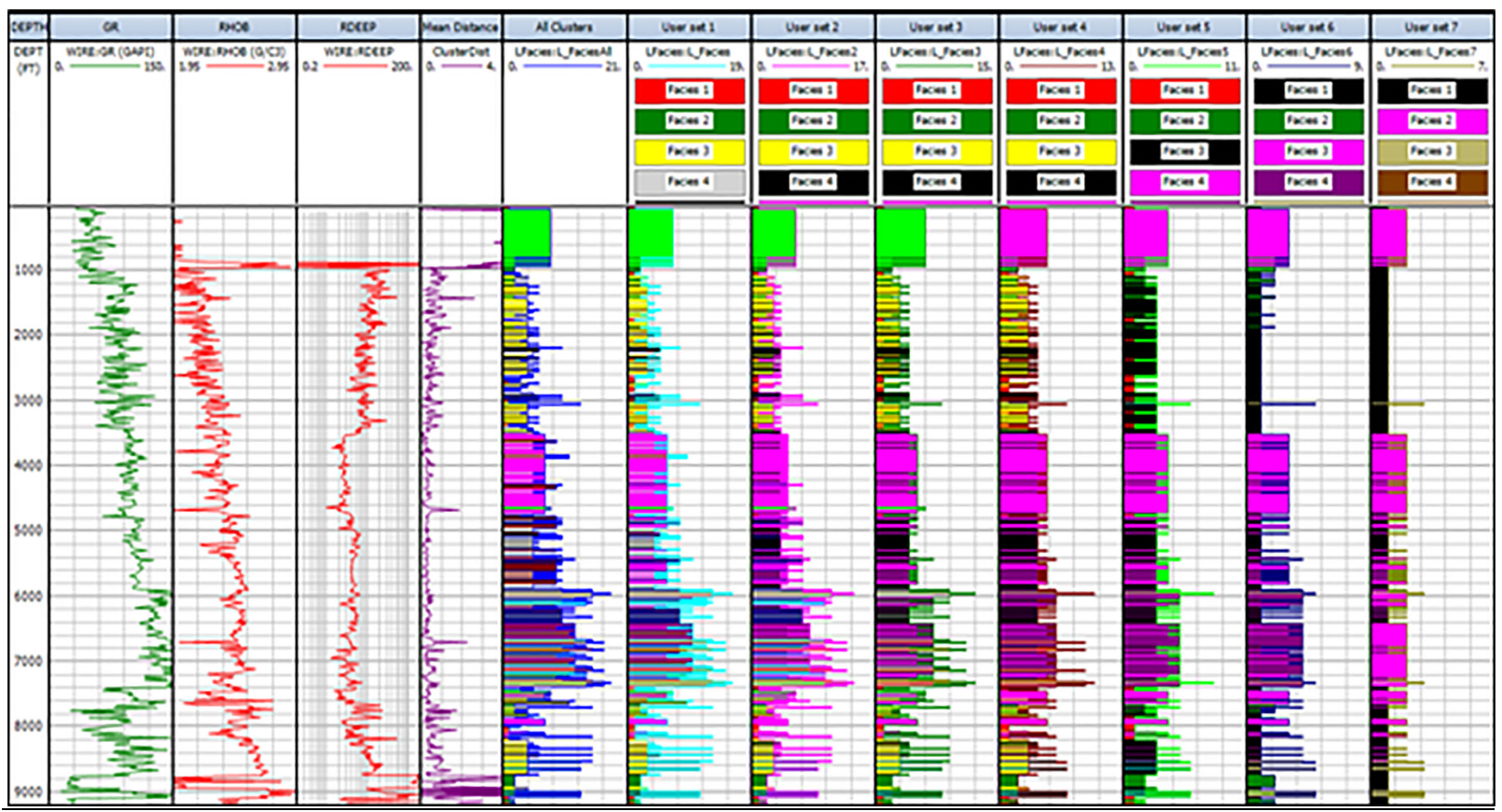

Figure 19. Display of various electrofacies models, ranging from 20 down to six rock typing hierarchical cluster-based results.

\subsection{Volume of Shale}

The volume of shale is an interpretation derived with the assumption that the mineralogy of the stratigraphy being invested is binary. Meaning the stratigraphy is either sand or shale with no deviations. That assumption is often valid in many conventionally targeted reservoirs and does therefore apply to the shallower historic legacy targets in the Powder River basin (i.e., Lewis Shale, Teckla, Teapot, Parkman, Shannon, and Sussex formations). As such, a volume of shale interpretation was derived in every well of this study and extrapolated across the stratigraphic column (Figure 20). The curve should only be applied for mapping purposes where applicable.

The volume of shale can be interpreted by the single curve use of GR, SP, RDEEP, NPHI or DT wireline logs where a baseline of end member shale and baseline of clean sand are determined. Or logs can also be used in combination such as NPHI and RHOB after Thomas and Steiber, 1975. In this study, we used a deterministic approach where only the GR was utilized for the interpretation. A clean sand baseline of 45 gapi was applied and an end member shale baseline of 180 gapi. Then the following equation is applied, and the volume of shale interpreted. We assumed a linear relationship between depth, GR value and the volume of shale, no Clavier or formation age dependent correction was applied.

$$
\text { Volume of Shale }(\mathrm{Vsh})=\text { GRfromlog }- \text { GRminimum/GRmaximum }- \text { GRminimum }
$$




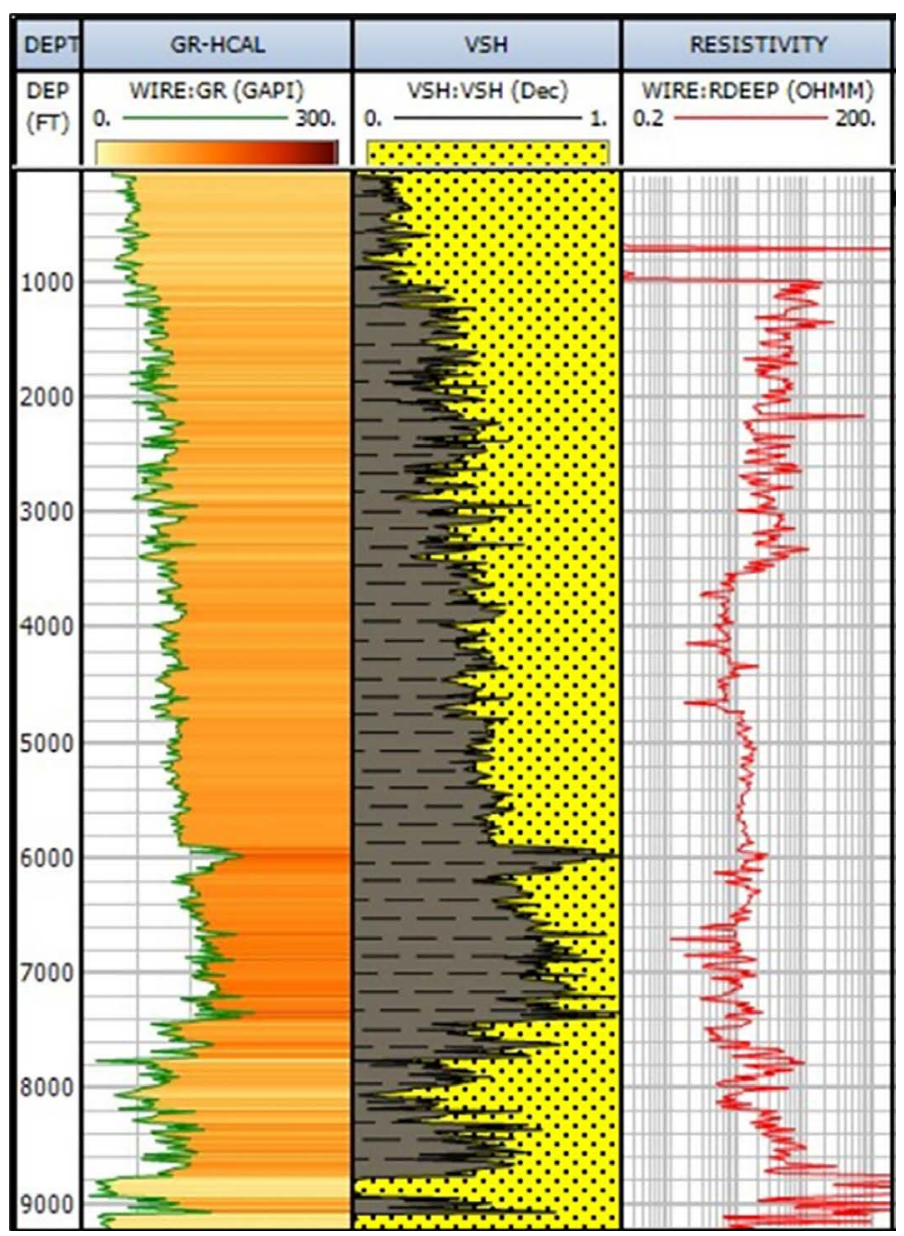

Figure 20. Callaway 15-5 interpretation of the volume of shale, assuming a binary lithological system.

\subsection{Volume of Clay}

The volume of clay is a critical interpretation solved for independent of the multi-mineral model applied in this study. Multiple approaches were taken to calibrate and constrain the resulting extrapolated VCL interpretation across the basin. These methods include 1) the volume of clay correlated to spectral gamma ray thorium ( $\mathrm{ppm}$ ) data where present; 2) An interpretation that is derived from gamma ray after calibrating baselines for the shale versus clay end members 3) An interpretation based on the neutron porosity and bulk density separation method (1/3 - 2/3 rule implied) (Figure 21). Neutron logs must be scaled by the given matrix they are relative too. A petrophysicist must ensure utilizing the interpreted neutron log on a limestone versus sandstone matrix accordingly. Is appropriately corrected and end member lithology matrices applied, the log by itself can be utilized for a total fluid-filled porosity estimate (note that the fluid medium can impact the log itself, for example brine versus hydrocarbon). When the neutron $\log$ moves to lower neutron values, this is often indicative of a carbonate lithology with little to no fluid-filled porosity. When the log increases this is often indicative of a sandstone or shaley-sandstone with fluid filled porosity present. The log is typically used in combination with a density porosity for an integrated interpretation (Figure 22).

To aid in calibrating and constraining methods 2 and 3 noted above, the neutron-density cross-plot approach was applied and measured x-ray diffraction result for the weight of total clay volume were employed. Variation in wells where a gamma ray, neutron and density were available to utilize for interpretation were worked individually to cross-check independent solutions. In the case where all curves were a 
present, they were all utilized by taking the minimum solution for the final VCL determination. The VCL curves were then used as an independent input into the multi-mineral model (Figure 23).

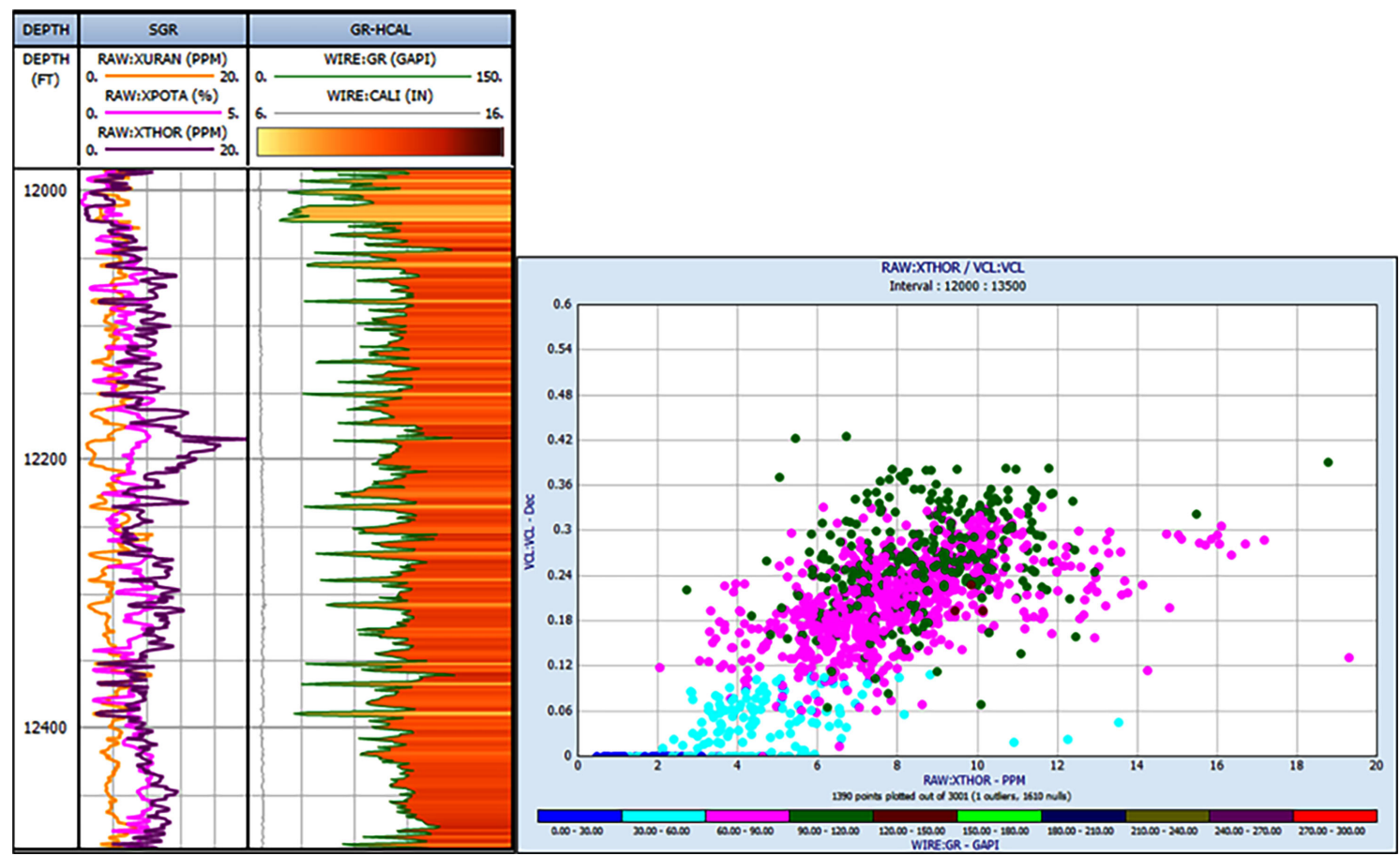

Figure 21. Left: Wireline display of spectral gamma ray thorium (purple), potassium (pink), and uranium (orange). Right: Cross-plot of spectral gamma ray thorium distribution versus correlation to the volume of clay interpreted.

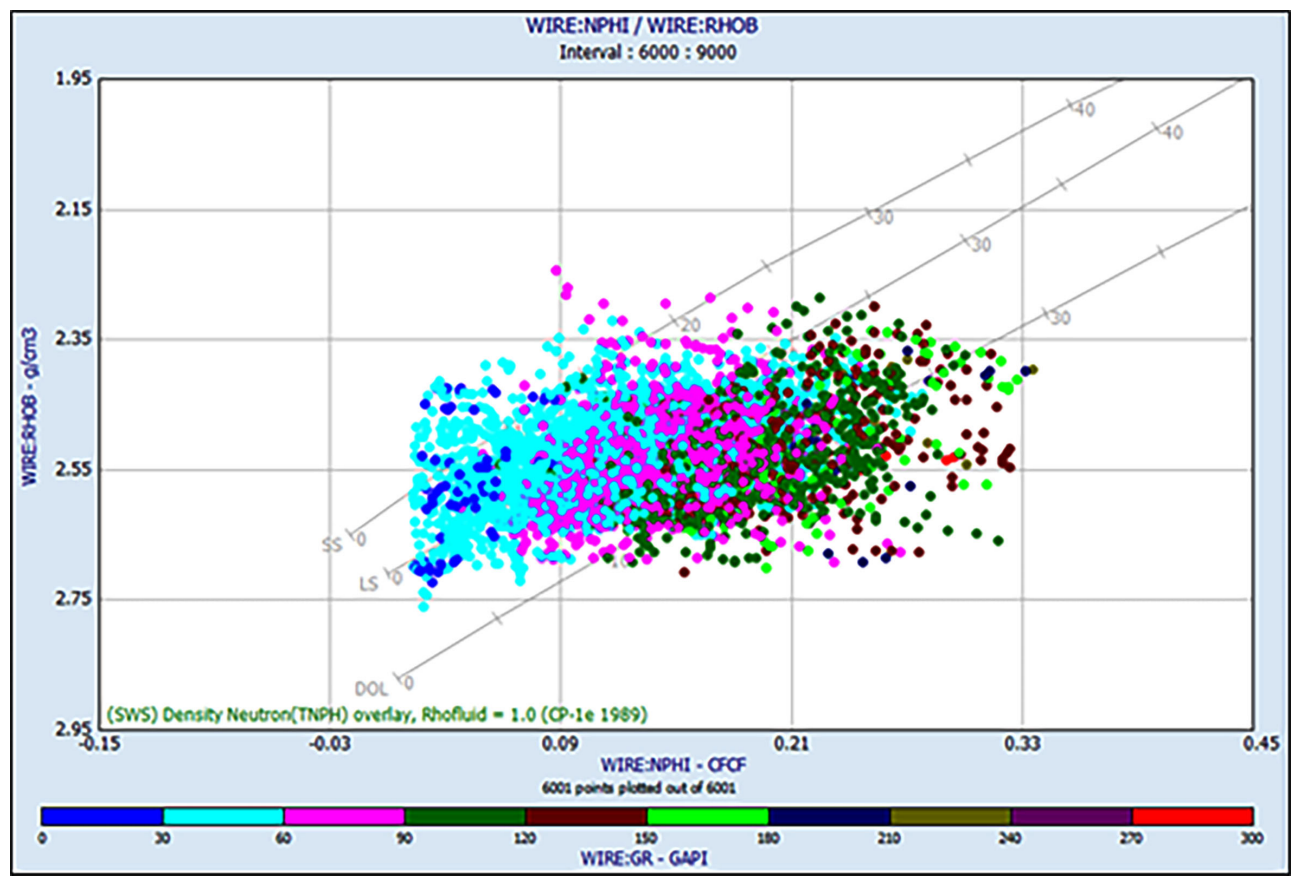

Figure 22. Neutron porosity (dec) versus bulk density $(\mathrm{g} / \mathrm{cc})$ cross-plot, assuming rhofluid $=1.0 \mathrm{~g} / \mathrm{cc}$ and with density-neutron overlay lines for lithological end member determination. 


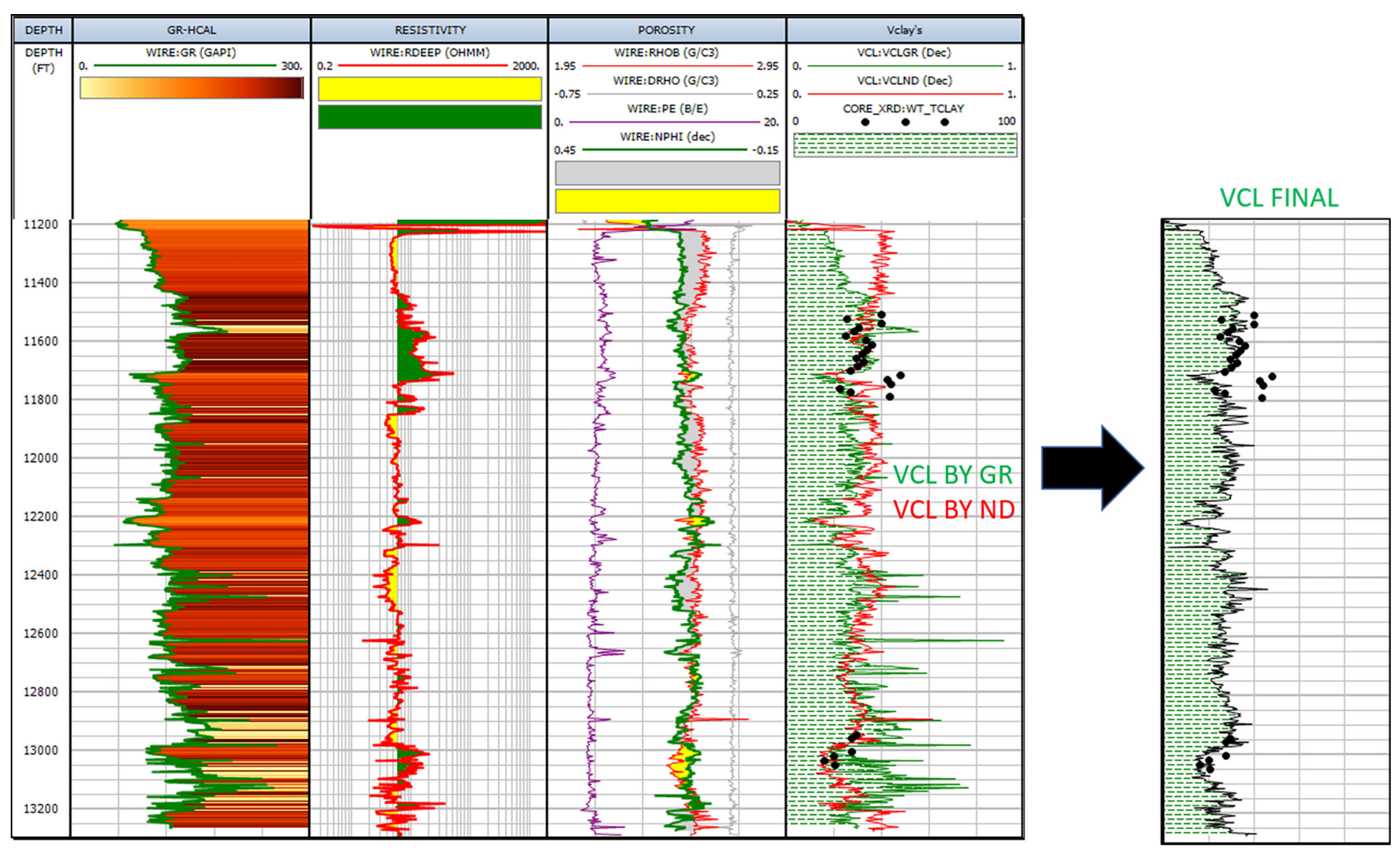

Figure 23. Wireline based volume of clay interpretation. Demonstrates the variance in a gamma ray (gapi) versus neutron-density (ND) derived solution. Then, taking the minimum solution from the combination of techniques to result in a final volume of clay stratigraphic interpretation.

Clay speciation is also important to note, and notes vary throughout the basin. Most important to note is the presence of chlorite in portions of the stratigraphy and basin that is otherwise Illite-mica dominated. There are spatial trends in the clay specification as related to the time-temperature history and therefore conversion of Smectite to Illite in the basin. The speciation is of importance to petrophysics to ensure the grain densities associated with the clay volume are accurate. Heavier clays, such as chlorite, can have impact to the calibrated clay and therefore multi-mineral model which in turn impacts the calibration of the total storage and other properties in the evaluation.

\subsection{Geochemical Properties}

Thermal maturity integration can be done by a few techniques to then interpret a wireline based continuous maturity log. Here is an example from the Powder River basin where a cross-plot of measured Vro versus depth and colored by county displays two distinct trends (Figure 24). The same can be done for a correlation between measured vitrinite reflectance (Vro) and thermal maximum from the S2 (mg/g) peak as defined by programmed pyrolysis measurements (TMAX). The defined functions can then be used in wireline interpretation. The assumption with any correlation such as this, is that the stratigraphy did not experience any significant uplift events through time and that a simple depth to burial to thermal maturity relationship is valid.

TMAX as a VRo equivalent can also be calculated continuously along the length of a stratigraphic section derived from correlations to the source rock dataset. In this study an association of total organic carbon (wt\%) (TOC) correlated with programmed pyrolysis S1 (mg/g) was established (Figure 25):

$$
\mathrm{S} 1=0.3851 * \text { TOC OR S1 }=0.1042 \mathrm{E} 0.8358 \mathrm{x}
$$




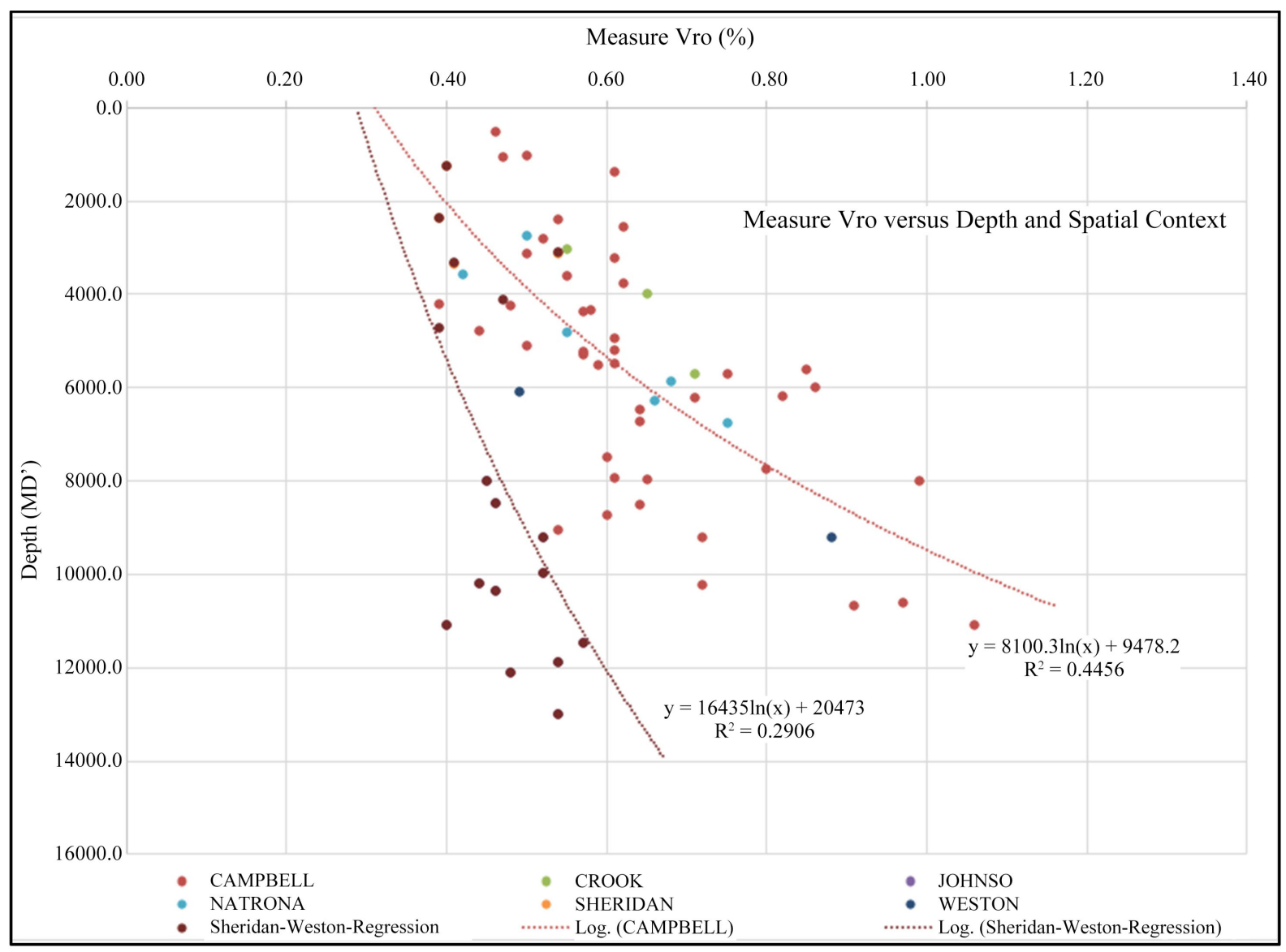

Figure 24. Cross-plot of measured Vro (\%) versus depth for the Powder River Basin.

WELL 1 EXAMPLE

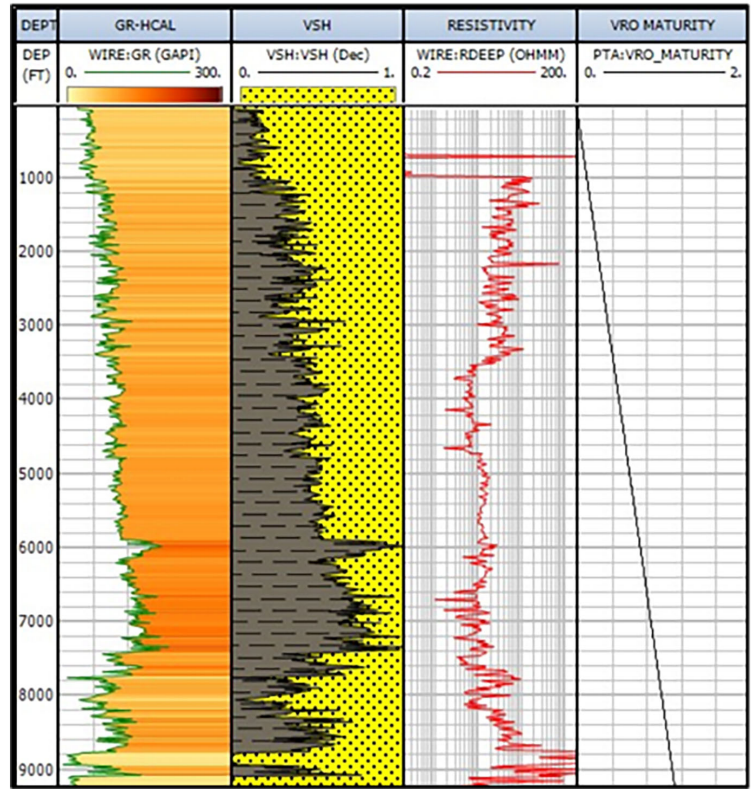

WELL 2 EXAMPLE

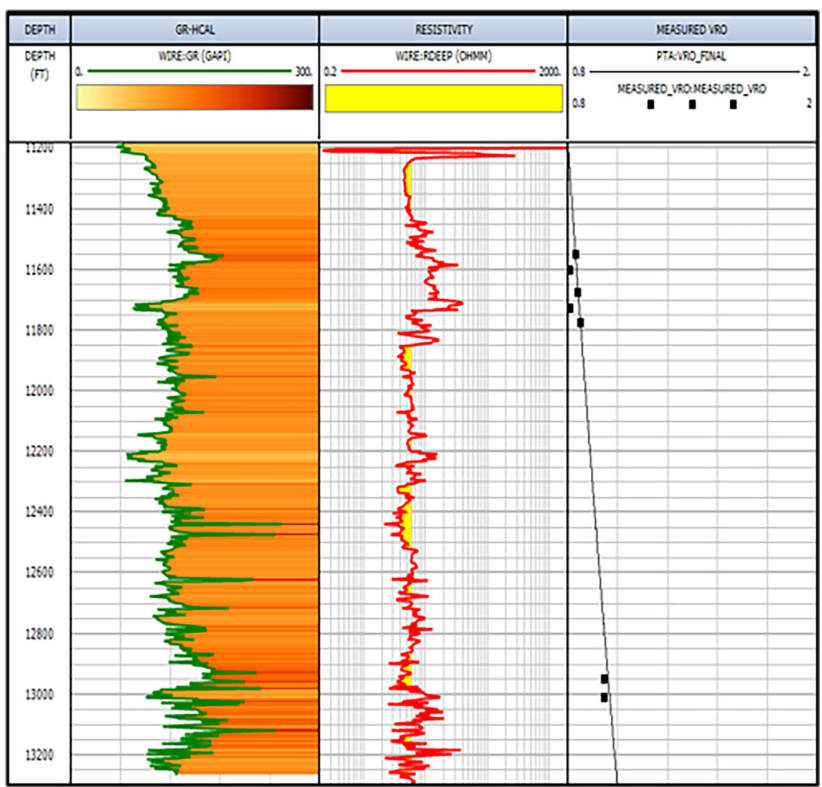

Figure 25. Wireline displays of two wells, one with measured Vro and one without demonstrating the correlation to wireline-derived continuous solutions. 
Then

$$
\mathrm{S} 2=0.2589 \mathrm{E} 1.2268 *(\mathrm{TOC})
$$

Then

$$
\operatorname{TMAX}=431.273+3.63636 * \mathrm{~S} 2
$$

And Finally

$$
\text { JARVIE_VROEQ }=\text { TMAX } * 0.018-7.16
$$

Both applied interpretations provide the petrophysicist with the maturity estimate needed to estimate hydrocarbon phase (oil versus gas) as well as constrain inputs for other property evaluations (ex. Level of Metamorphism) [9]. The maturity estimates that can be derived allow the geologist to generate 2D maps for any stratigraphic horizon and flex to their defined isopach in include the impact of structure and therefore stratigraphic thickness variation on the log-derived estimates presented here. The log-derived solutions will also allow a comparison between in situ mapped maturity and formation produced gasoil-ratios.

Total Organic Carbon determination is critical to the petrophysical evaluation of an unconventional play. Wireline based total organic carbon interpretation is step 2 of the overall petrophysical workflow (second to interpretation of the volume of clay). In unconventional plays, the determination of total organic carbon (TOC wt\%), can be conducted by several different calculations. Schmoker's Law/Principle is one such relationship where the correlation of bulk density $(\mathrm{RHOB} \mathrm{g} / \mathrm{cc})$ to measured total organic carbon can be utilized [10] (Figure 26).

$$
\text { SCHMOKER_TOC }=51.3291-19.3217 * \text { RHOB }(\text { Bulk Density g/cc })
$$

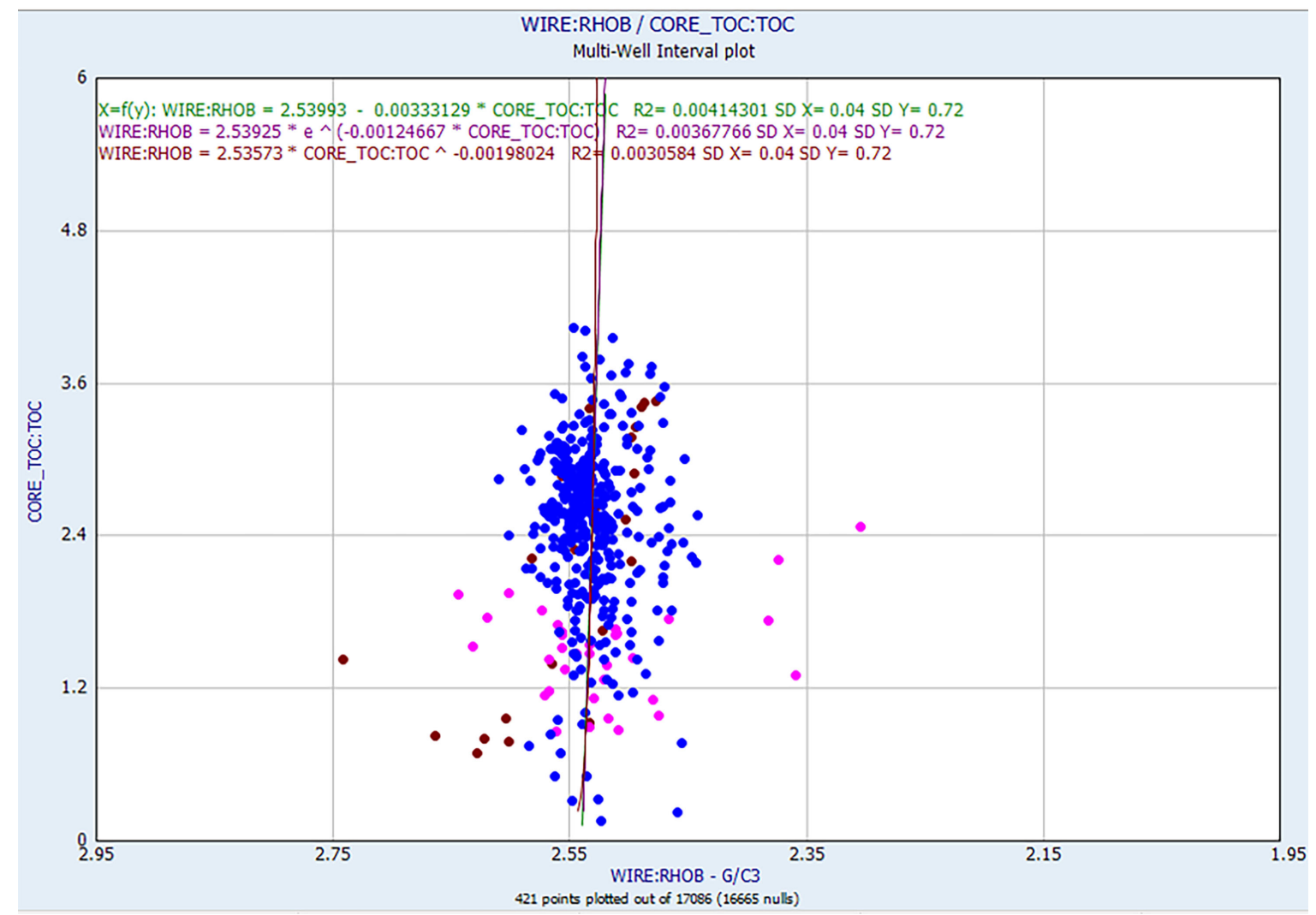

Figure 26. Correlation of bulk density $(\mathrm{g} / \mathrm{cc}$ ) to measured total organic carbon (TOC-wt\%) that is used to then apply Schmoker's principle to deliver a continuous wireline-based TOC (wt\%). 
An alternative method from Schmoker to interpret Total Organic carbon (wt\%) relies on Passey et al.'s principle $[9,11]$. When formation resistivity and sonic are linearly scaled relative to one another, the degree of resistive deflection off an acoustic baseline represents the degree of the log of resistivity difference (DlogR) between 0 to an associated total organic carbon quantification. There is an impact of maturity on the degree of deflection, and this is considered through the level of metamorphism constant that is assumed when the Passey's method is applied [9]. The method can also be applied relative to neutron porosity or bulk density. An empirical relationship between maturity and sonic logs can also be utilized. An example of a wireline based total organic carbon interpretation via Passey's DLOGR (1990) approach with cuttings LECO ${ }^{\circledR}$ total organic carbon (TOC) plotted on top for calibration is below (two different wells for reference, Figure 27).

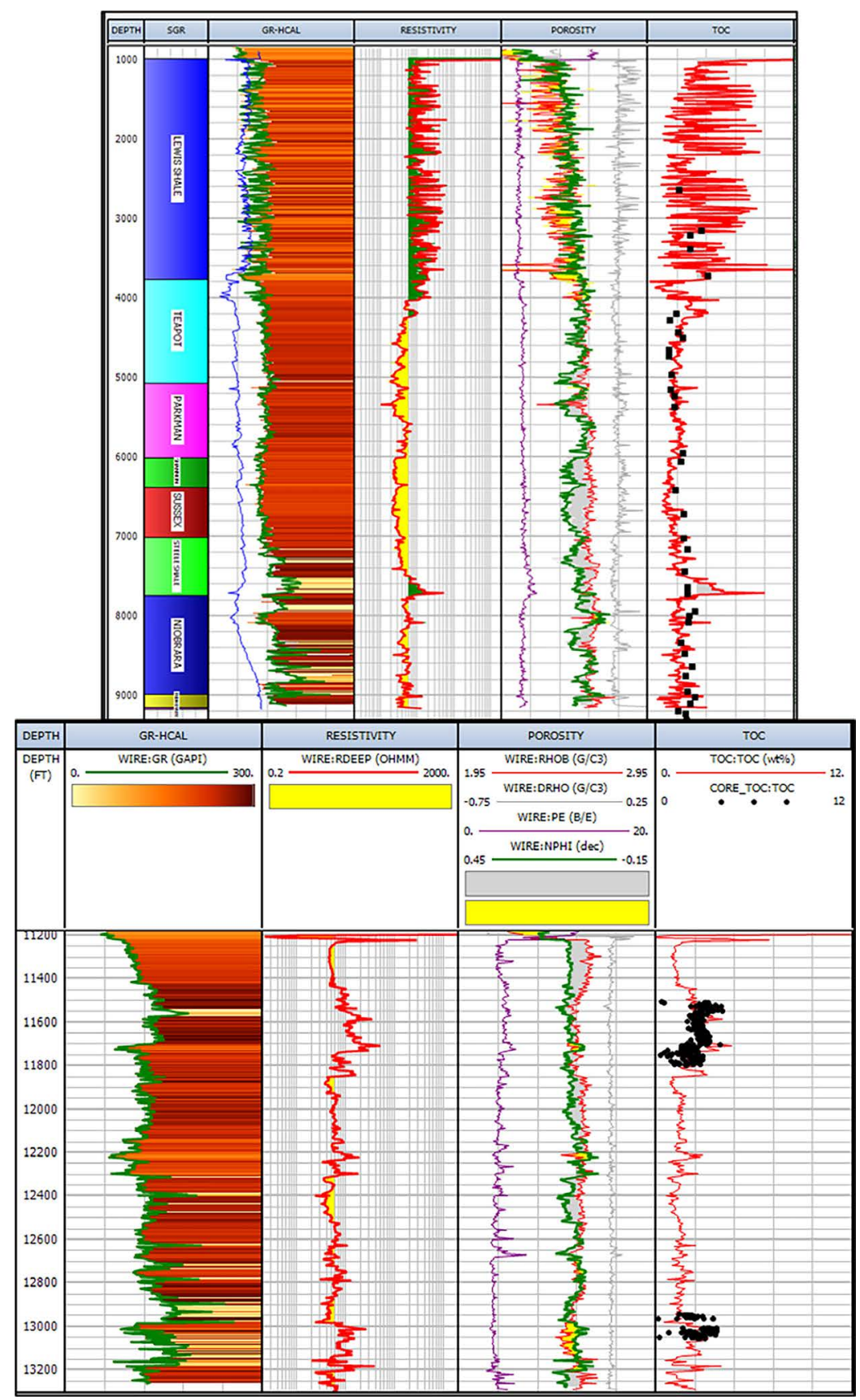

Figure 27. Example of whole core constraint and correlation. 
In this study the following criteria were used in the below order to expand total organic carbon interpretation as extensively as possible extrapolating away from known constraint and assess uncertainty in the extrapolated solution (Figure 28):

1) If RDEEP, DT, RHOB and NPHI present utilize all curves for DLOGR_TOC

2) ELSE Use RDEEP, DT and RHOB

3) Else Use RDEEP, DT OR RHOB dependent on which is present

The analysis along a wellbore was also baselined by subdividing on the following stratigraphy where significant change required a baseline change in the DLOGR approach:

1) Lewis Shale Baseline

2) Teckla through Mowry Baseline

3) Muddy to TD Baseline (includes Dakota and Minnelusa where present)

Resulting final curve is PASSEY_TOC where

- $\quad$ LOM ranges from 9.8 - 11 (stratigraphy dependent)

- $\quad$ DT offset $=0$ (stratigraphy dependent)

- $\quad$ RHOB offset $\sim 0.215$ ranging up to 2 in the Lewis Shale (stratigraphy dependent)

- NPHI offset $\sim-0.594$ (stratigraphy dependent)

Programmed pyrolysis data is utilized by petrophysics to correlate interpreted total organic carbon with S1, S2 and TMAX constraints. S1 is used as a direct hydrocarbon indicator and when compared to mineralogy, porosity and saturation is a good approach to obvious "pay". S2 (utilized as remaining generative capacity by comparing the as received versus extracted measurements), correlates with total organic carbon as well and can be derived then by wireline-based interpretation (Figure 29). TMAX correlates with Vro and often Vro correlates with depth (Figure 30). So TMAX can also be derived via wireline logs. All utilized in estimates of wireline based thermal maturity, source rock quality and direct hydrocarbon indicators. The S1, S2 and TMAX continuous logs can then also be utilized to approach "oil mobility" from the integration with geochemistry (Figure 31 ).

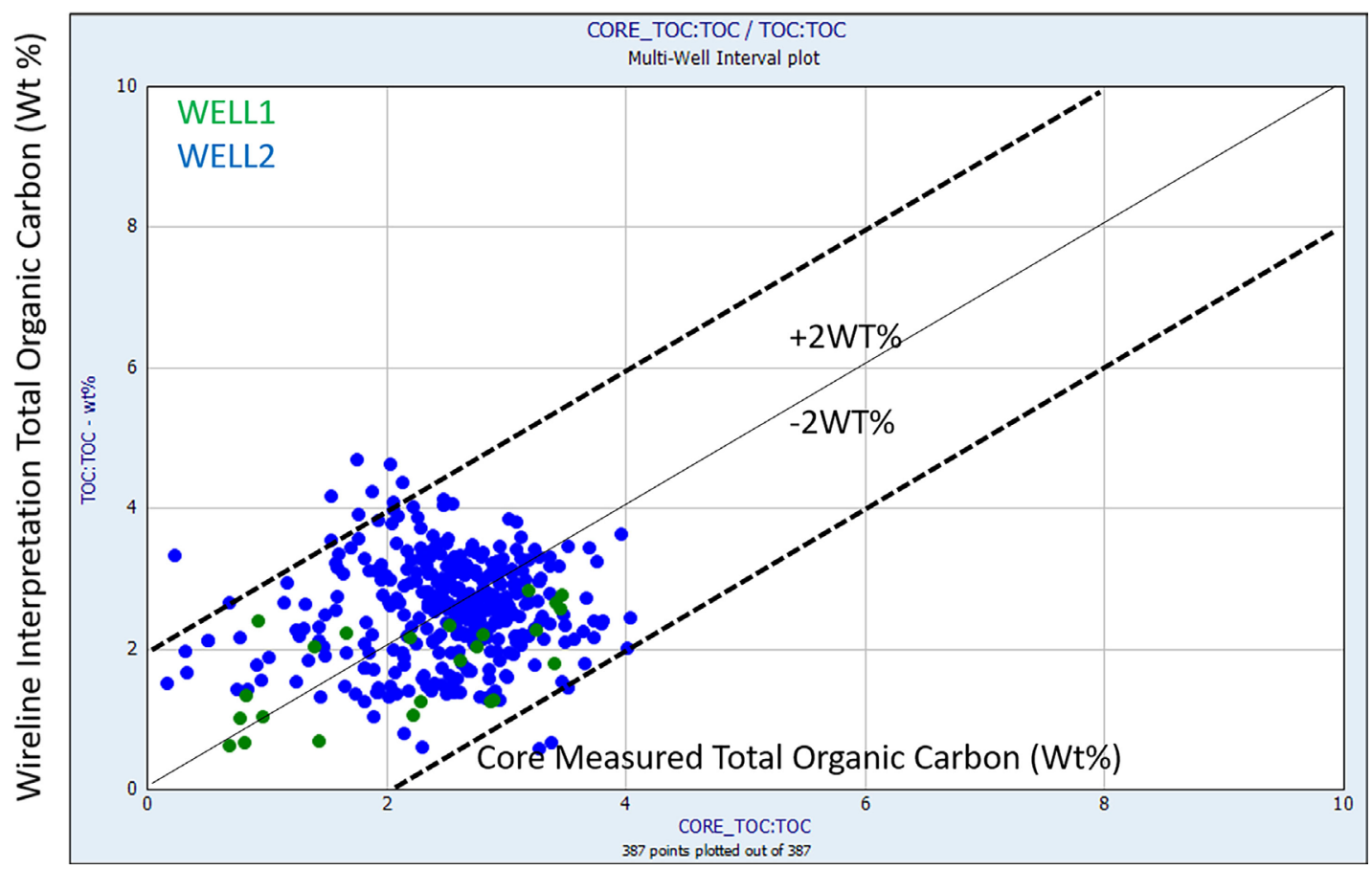

Figure 28. Cross-plot of measured total organic carbon versus wireline-derived total organic carbon interpretation. Plot demonstrates the agreement $\pm 2 \mathrm{wt} \%$ error to the association. 


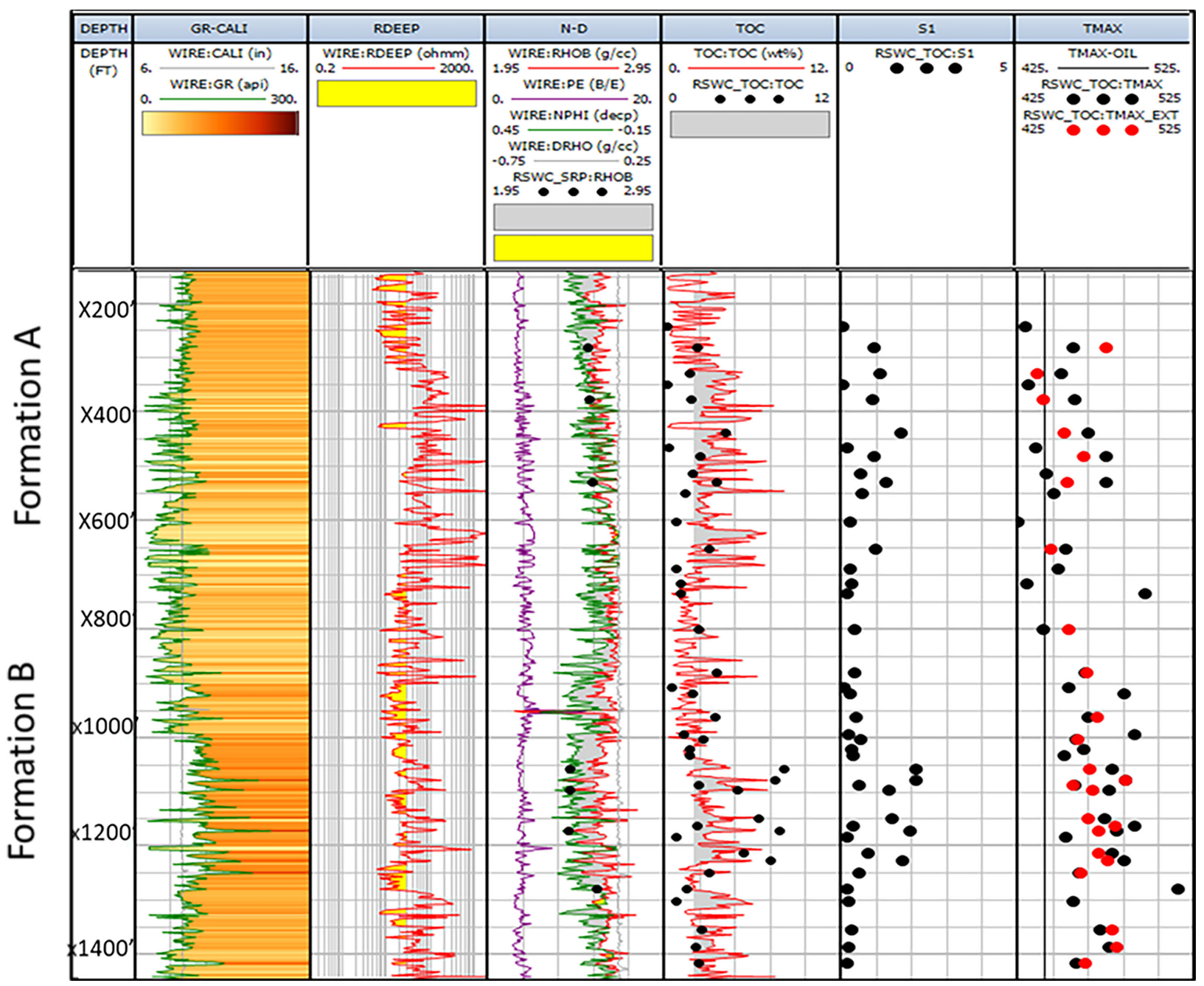

Figure 29. Demonstration of source rock total organic carbon and programmed pyrolysis integration. In this example, we show the programmed pyrolysis $S 1(\mathrm{mg} / \mathrm{g})$ data that is used as a volatile hydrocarbon indicator. In addition, we co-locate the as received versus the extracted TMAX data with a minimum threshold baseline for organically enriched potential. By integrating the source rock quality with the wireline-based attributed, a client can constrain the uncertainty in these properties across formations and lower the risk associated with the uncertainty.

General Trends:

As mentioned previously in the "Maturity" section of this study, correlations between the total organic carbon (wt\%), S1 (mg/g), S2 (mg/g) and therefore TMAX (degrees C) were established. The equations were applied to all wells where wireline logs existed to derive the interpretation of the programmed pyrolysis geochemical parameters (Figure 32).

Here we utilize the $\mathrm{S} 1 \mathrm{~g} / \mathrm{cc}$ as a direct $\mathrm{HC}$ indicator and replace the classic use of a resistivity dependent total water saturation to then calculate an OOIP. The use of S1 since it is an in situ reflective measurement also bypasses the need for a Formation Volume Factor input (Figure 33).

$$
\text { where OOIP/640 }=\left(4965.36{ }^{*} \mathrm{pb}{ }^{*} \mathrm{~S} 1{ }^{*} \mathrm{pOil}{ }^{*} 0.5^{\prime}\right)[20]
$$

Assume pOil $=0.85$

$$
\text { Curve = OOIP_GEOCHEM }
$$




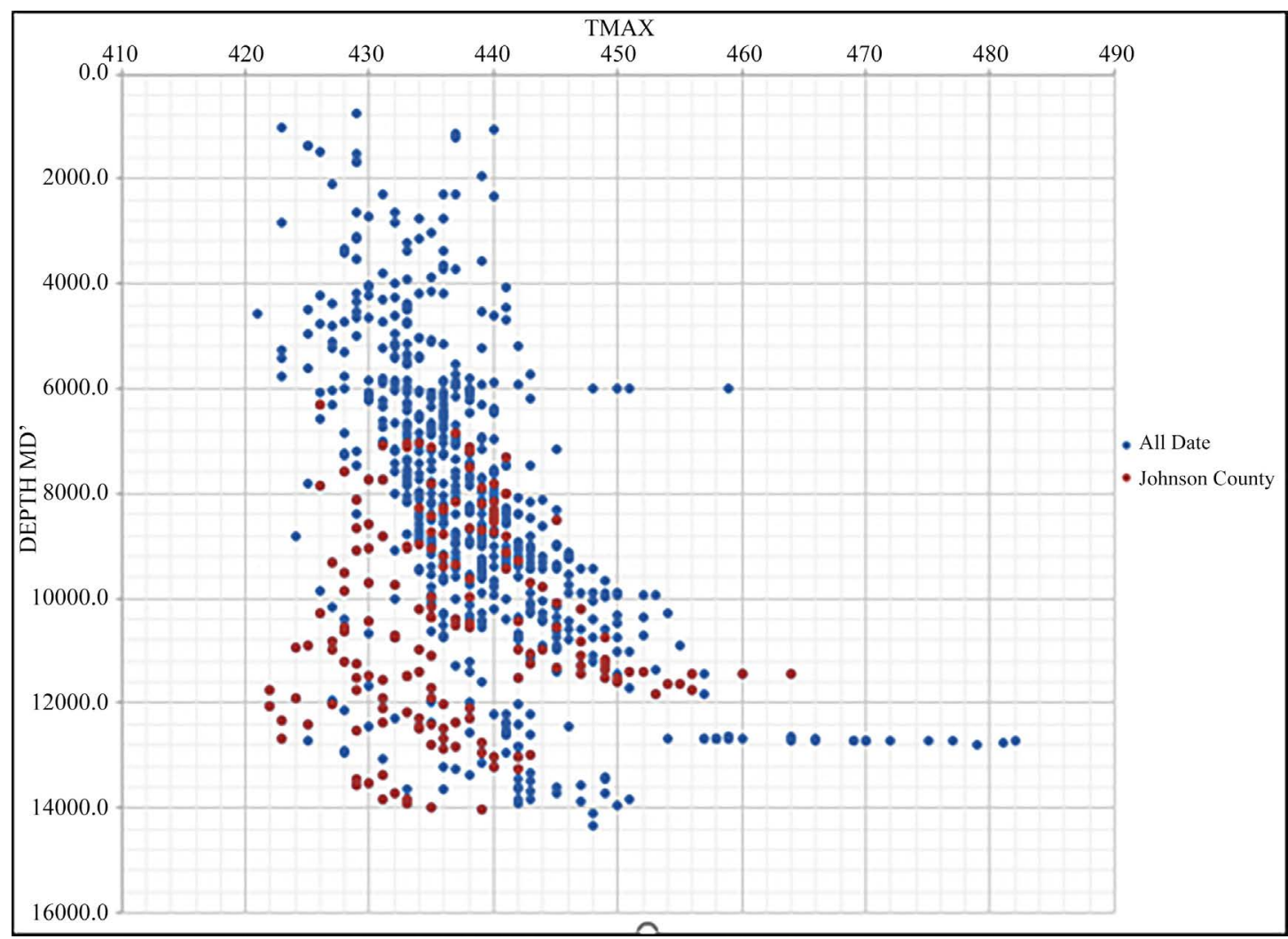

Figure 30. Cross-plot of regional dataset, where the $\mathrm{X}$-axis shows TMAX (degrees $\mathrm{C}$ ) versus the $\mathrm{Y}$-axis, which is depth in MD'. In the Powder River Basin, we note there is more than one population/correlation of TMAX with depth, with the main trend denoted in the blue circles and demonstrating an increase in TMAX (maturity indicator) versus depth. There is a second correlation that is dominated by samples from Johnson county, where at deeper depths the TMAX values are lower than the correlation in the main trend. The observation can be interpreted to suggest that across Johnson County there is significant change in the depth versus maturity relationship. Going a little further, we can also suggest that the equivalent temperature-related maturity scale would correlate to a significant change or variation in clay species present in the deeper formations, as well. Where the main trend in the basin is dominated by illite-smectite with a $40 \%-10 \%$ ratio, illite-mica, and chlorite rich clays, Johnson County may have more smectite present in the illite-smectite ratio $(20 \%$ $-30 \%)$.

In addition, the correlation between total organic carbon (weight \%) and programmed pyrolysis S2 $(\mathrm{mg} / \mathrm{g})$ can be established based on the cross-plot below (Figure 34). From the cross-plot the derivation of a continuous log-based S2 is established and provided as part of the derivative products for this study. Lastly, the correlation between S2 (mg/g) and TMAX as well as TOC (wt\%) versus TMAX was established. A continuous TMAX log-derived curve was interpreted.

From these derivative curves Jarvie's equation [12] was applied.

VROEQ curve:

$$
\text { where VROEQ }=\text { TMAX } * 0.018-7.16
$$

The above VROeq estimate can then be compared to additional maturity estimates derived from oil-based interpretations, vitrinite reflectance measurements as well as any association of known produced gas-oil-ratio to in situ maturity. 


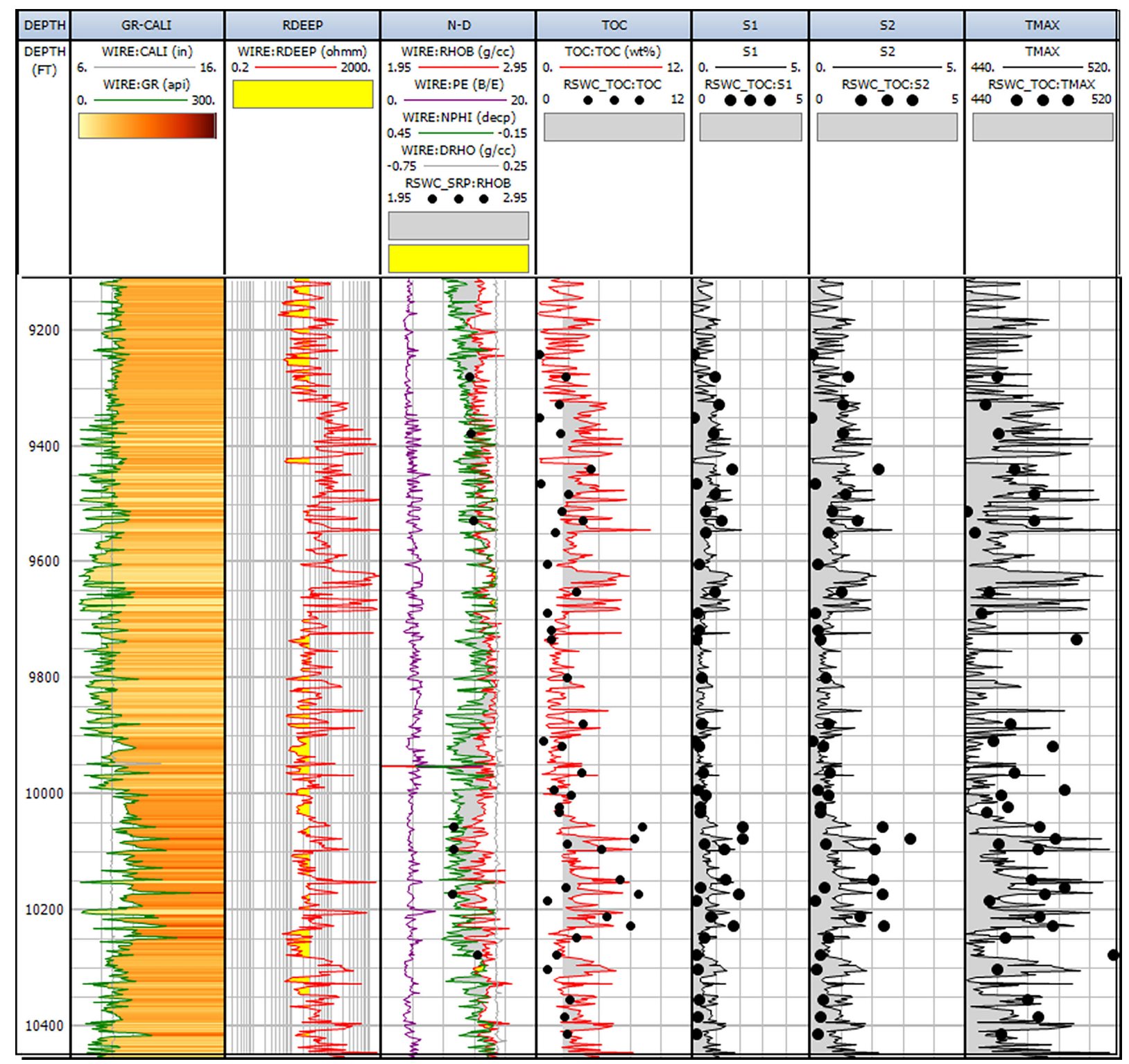

Figure 31. Building on the example from Figure A (above), correlations between total organic carbon (wt\%), S1 (mg/g), S2 (mg/g), and TMAX (degrees C) were established. Based on those exponential correlations' continuous wireline-based source rock, property attributes can be calculated (see above).

Two Ways to Approach a Petrophysical Model:

1) Deterministically

2) Probabilistically (Inversion)

Deterministic: IF GR $\leq 45$ GAPI then Carbonate

Inversion: Based on multiple inputs (GR, RHOB, NPHI, PE, VCL and TOC) solve for Carbonate, Sand and Dolomite based on the ranges/assumptions given.

Multi-Mineral Models are typically inversion-based. The benefit of a multi-mineral model is that at every 0.5 foot increment the mineralogy is resolved for the most accurate grain density representation based on the mineral model applied. Rather than assuming a constant mineral matrix (for example 2.65 $\mathrm{g} / \mathrm{cc}$ ), the multi-mineral model is solving for that matrix input variably across the applied model interval. Therefore, presenting a better representative mineralogy, total porosity, and total water saturation. 


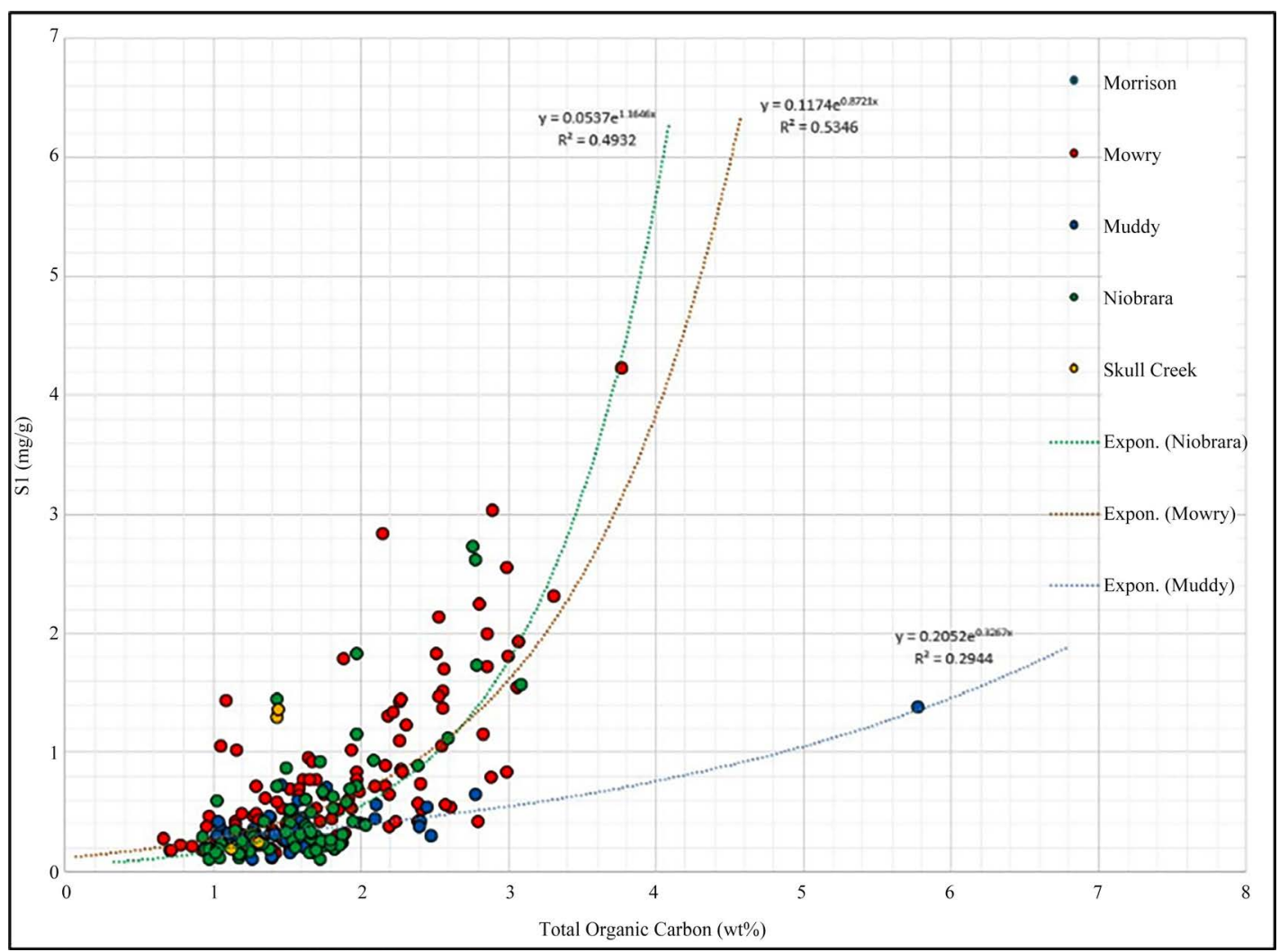

Figure 32. Integration of programmed pyrolysis S1 to petrophysical wireline interpretation.

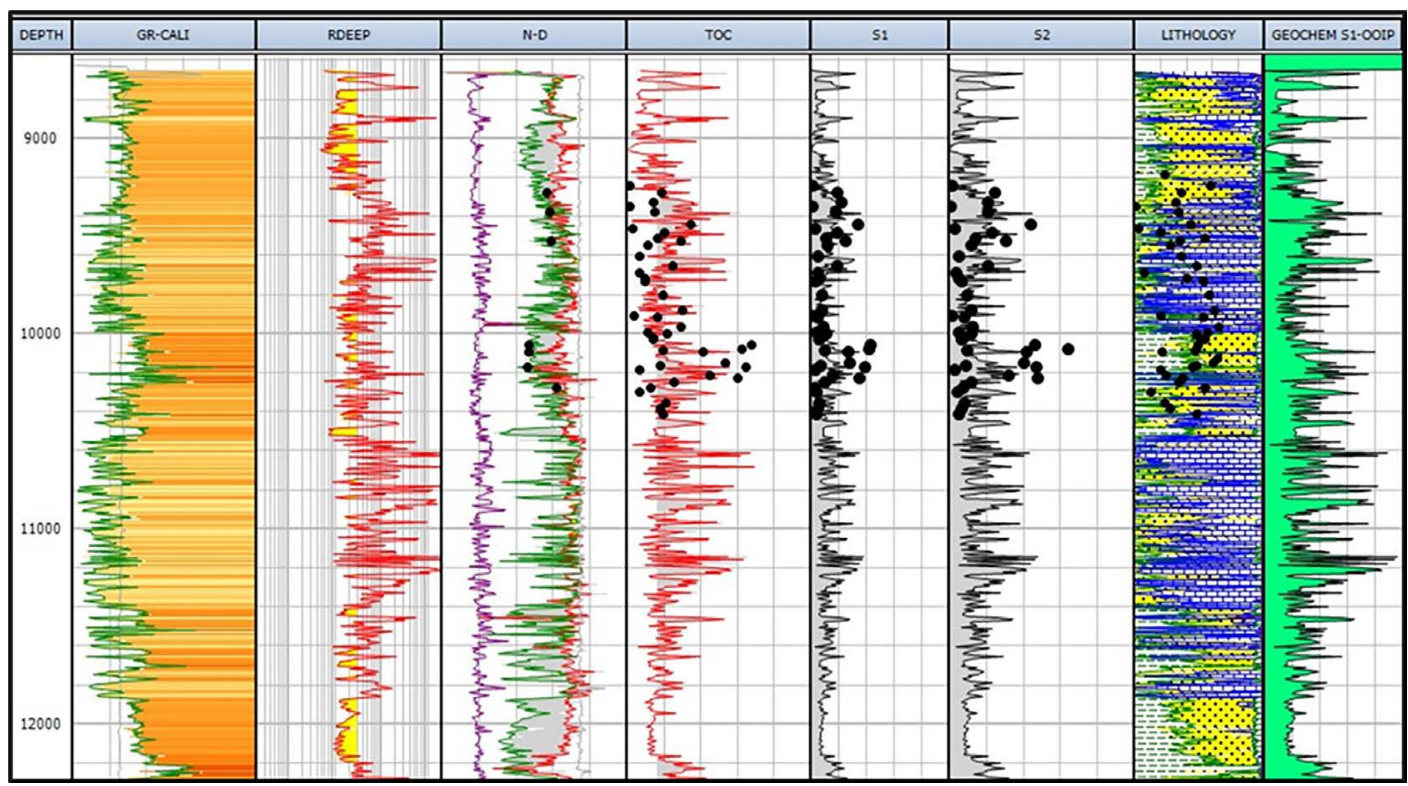

Figure 33. Petrophysical display integrating source rock total organic carbon and programmed pyrolysis data to generate a geochemically derived/calibrated original oil-in place [see 20]. Utilizing the

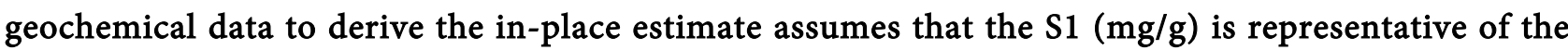
volatile fraction and, since it is measured in an as-received state, that no fluid shrinkage factors need to be applied, such as would be the case when utilizing PVT data instead. The methodology here does not require a formation volume factor (Bo) input. Equations applied are noted. 


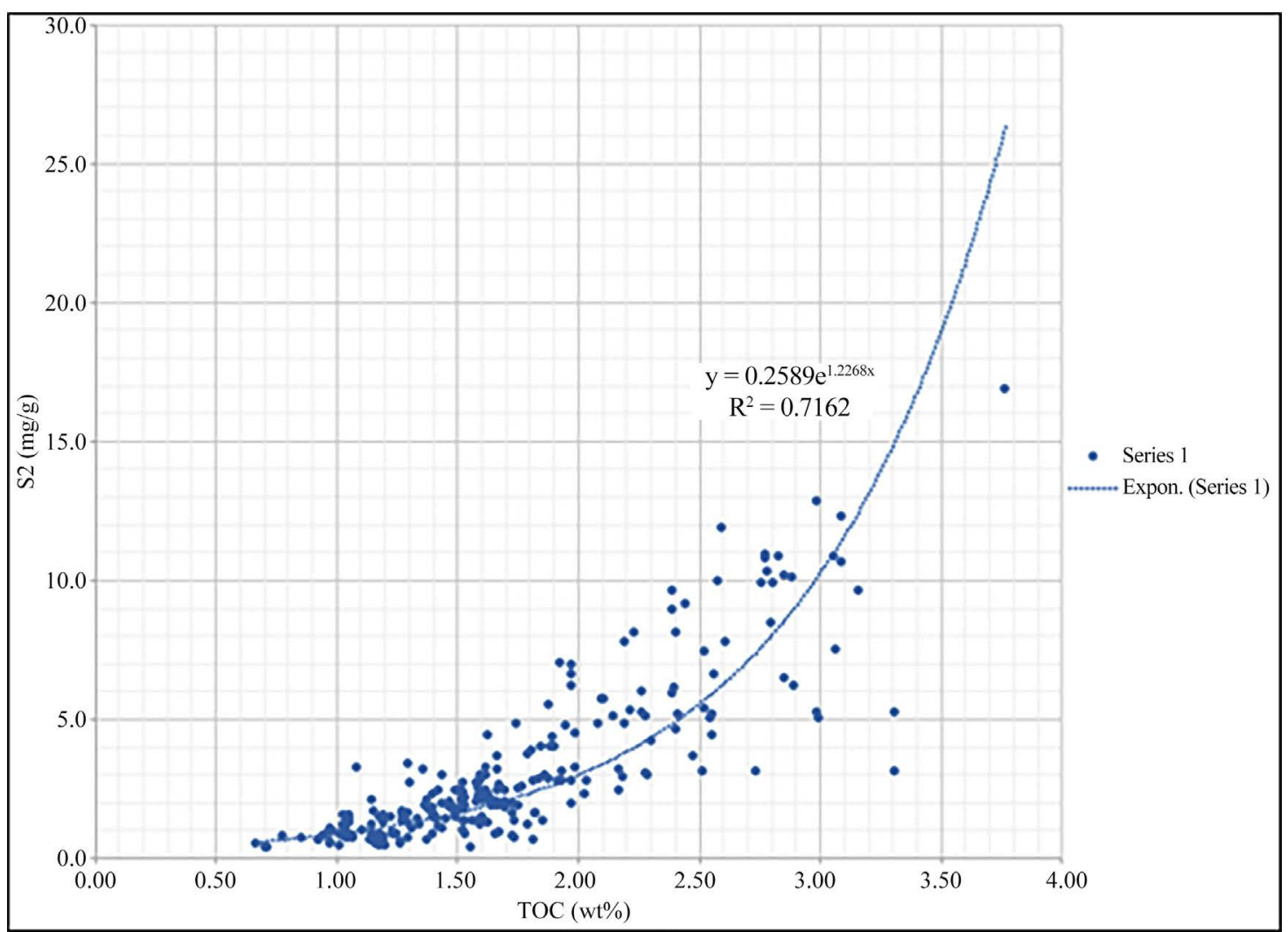

Figure 34. Cross-plot showing correlation between total organic carbon (weight \%) and programmed pyrolysis $\mathrm{S} 2(\mathrm{mg} / \mathrm{g})$.

In this model the following minerals were resolved: Quartz, Clay (independently solved and therefore an input), Kerogen (converted from independently solved total organic carbon as an input), Limestone, Dolomite. The model was calibrated to available $\mathrm{x}$-ray diffraction data (Figure 35). Uncertainty in total clay interpretation is $\pm 5 \%$. Uncertainty in total organic carbon interpretation is $\pm 2 \%$.

\subsection{Petrophysical Properties}

For this study total porosity was approached from multiple calculations including deterministic and inversion-based approaches. Multiple calculations are shared as a part of this study to ensure the scientist can investigate any portion of the stratigraphic stack including the conventional sandstones where an investigator would want to utilize the density porosity solution on a $2.65 \mathrm{~g} / \mathrm{cc}$ matrix (DPHIT_SS) versus unconventional stratigraphy where the application of the multi-mineral model solution results in a variable matrix density on the 0.5 foot for total porosity (PT_PHIT) (Figure 36).

Resulting curves include:

Density Porosity (DPHIT) = Rhomatrix - Rhobulkdensitylog/Rhomatrix - Rhofluid

Sonic Porosity $($ SPHIT $)=$ DeltaTlog - DeltaTmatrix - DeltaTfluid - DeltaTmatrix

- DPHI_SS: Assumes $2.65 \mathrm{~g} / \mathrm{cc}$

- DPHI_268: Assumes $2.68 \mathrm{~g} / \mathrm{cc}$

- DPHI_LS: Assumes $2.71 \mathrm{~g} / \mathrm{cc}$

- SPHI_SS: Assumes 55 us/ft

- SPHI_DS: Assumes $40 \mathrm{us} / \mathrm{ft}$

- RhoFluid (Water-Based): 1 to $1.1 \mathrm{~g} / \mathrm{cc}$ or $189 \mathrm{us} / \mathrm{ft}$

- RhoFluid (Oil-Based): $0.85 \mathrm{~g} / \mathrm{cc}$ 
- PT_PHIT (P50): Does not use a constant matrix value. Derived from the multi-mineral model variable matrix solution.

The derivations allow for "quick-look" exploration basin analysis, down to detailed per stratigraphic zone calibrated development-scale evaluation. Overall, the Best Fit (otherwise defined as the P50 solution), is the PT_PHIT resulting from the calibrated multi-mineral model (Figure 37).

In addition, the correlation between total porosity and permeability in the major formations in the basin were established. Cross-plots of routine and crushed rock core analysis were constructed and utilized to derive the two porosity-permeability transforms that result and can then be applied to interpret a log-based continuous permeability curve. One curve derived from the relationship between routine core analysis (intact plug assumptions) measurements at net confining stress therefore corrected for slippage and reported as Klinkenberg results (KKLINK mD), "ROUTINE_PERM". The second derived from the correlation of crushed rock analysis results "CRUSHED_PERM" (Figure 38). There is a lot of debate in the industry and amongst disciplines to define what the most "accurate" and representative permeabilities are for a formation. In this applied study we highlighted the way to approach or to provide the solution to both techniques with an understanding of their applications and challenges/limitations. The investigator must be cognizant of the solution they utilize as applied to the formation of interest.

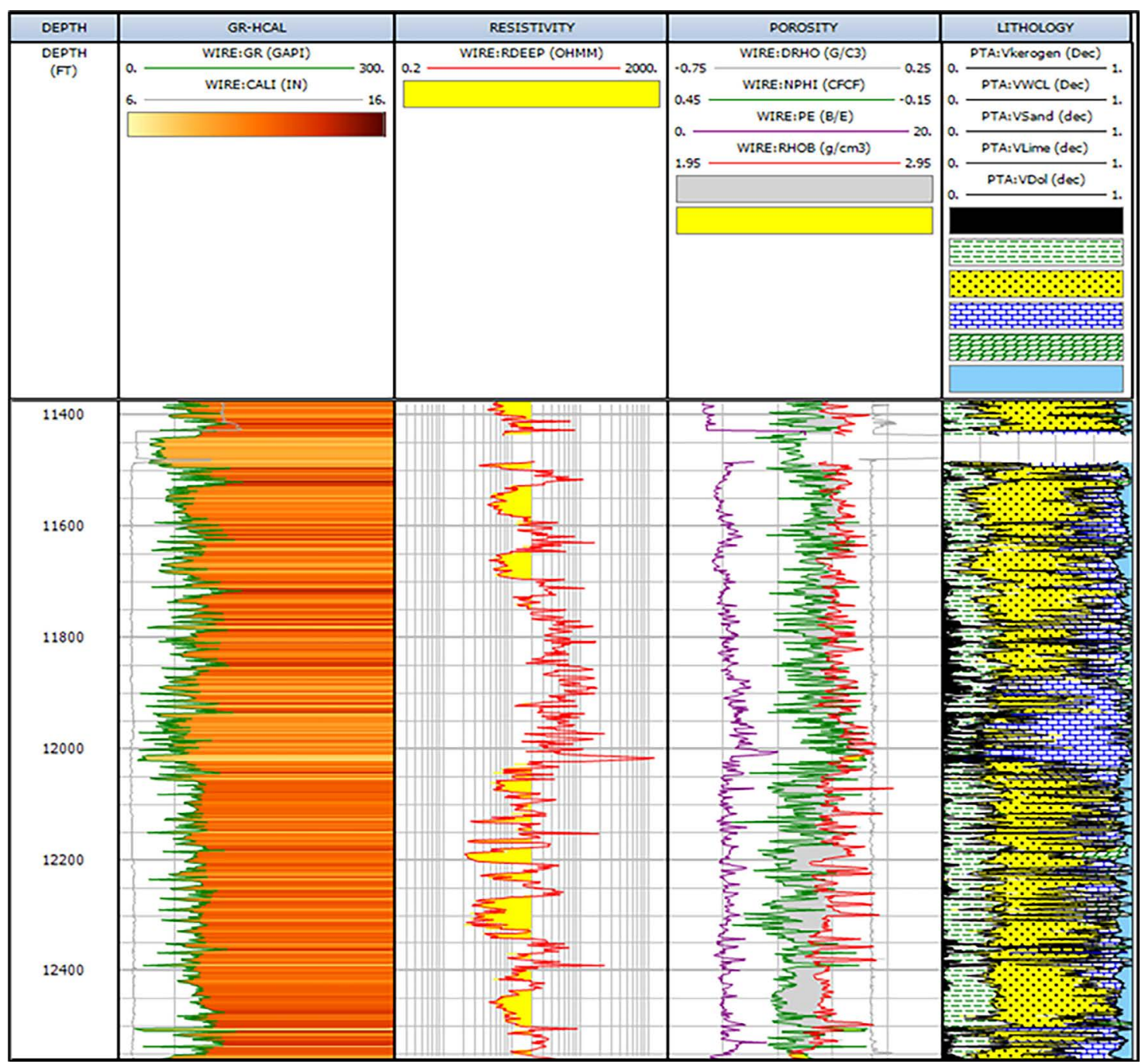

Figure 35. Petrophysical example of a derived multi-mineral model. Here, this model solves for volume of clay, quartz, calcite, dolomite and kerogen. 
Petrophysicists use water salinity and compositional data for many purposes. The application of the United States Geological Survey public water data [13] interpreted in this study for petrophysical derivatives and purposes did not consider the impacts of the basin history and therefore hydrodynamics beyond that of a recognition of water-injection into the Teckla through time. Water analyses were utilized at a high-level simply to constrain gross changes in trends of salinity varying outside of a $\pm 20 \mathrm{kppm}$ variance around a given mean in a map-based product. The raw data and maps were utilized to "guide" the petrophysical resistivity of water $(\mathrm{Rw})$ regarding knowing that an adjustment might need to be invoked in then determining total water saturation.

1) Example below is a plot of total dissolved solids (ppm) in the Powder River Basin versus depth. The onset of increased salinity correlates to increases in maturity as well as top overpressure regionally (Figure 39).

2) The main purpose of water salinity is to constrain a critical input parameter known as Rw (resistivity of water) for total water saturation evaluation (SWT).

Petrophysicists use water salinity and compositional data for many purposes.

* $\mathrm{Rw}$ is a critical parameter to constrain because it determines where (based on resistivity) a petrophysicist will interpret a formation to be primarily oil- versus water-prone or filled.

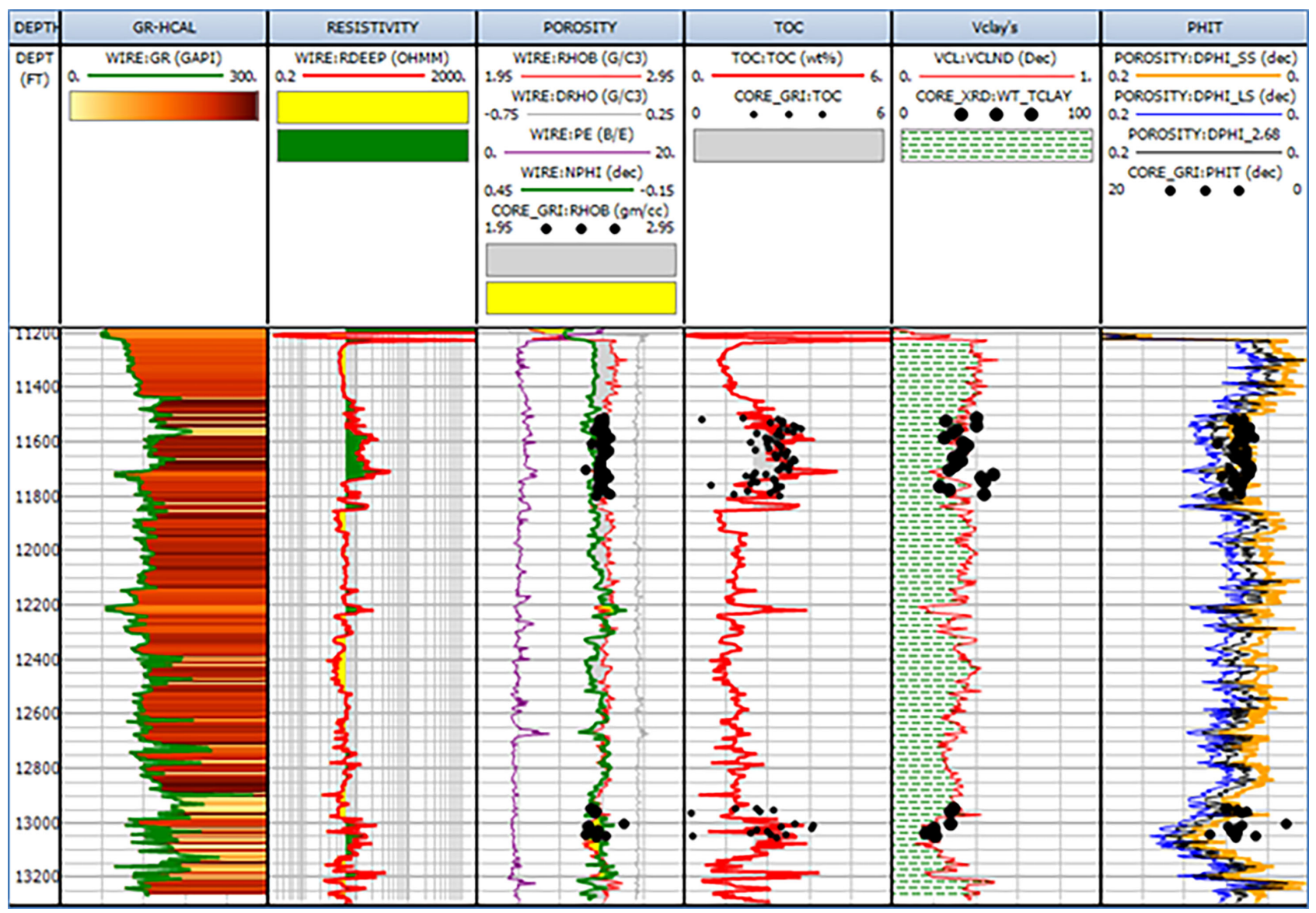

Figure 36. Wireline display of the Niobrara through Mowry formations. Tracks from left to right, displaying different calculations: GR (gapi), RDEEP (ohms)-N, PE-interpreted TOC (wt\%), and interpreted VCL (wt\%)-PHIT. The last track on the right displays three deterministic solutions for density-based total porosity, where matrix assumptions vary from $2.65 \mathrm{~g} / \mathrm{cc}$ (orange) to $2.68 \mathrm{~g} / \mathrm{cc}$ (black) to $2.71 \mathrm{~g} / \mathrm{cc}$ (blue). Core constraint for bulk density (g/cc), total organic carbon (wt\%), volume of clay (wt\%), and total porosity (\%) are shown as black circles. 


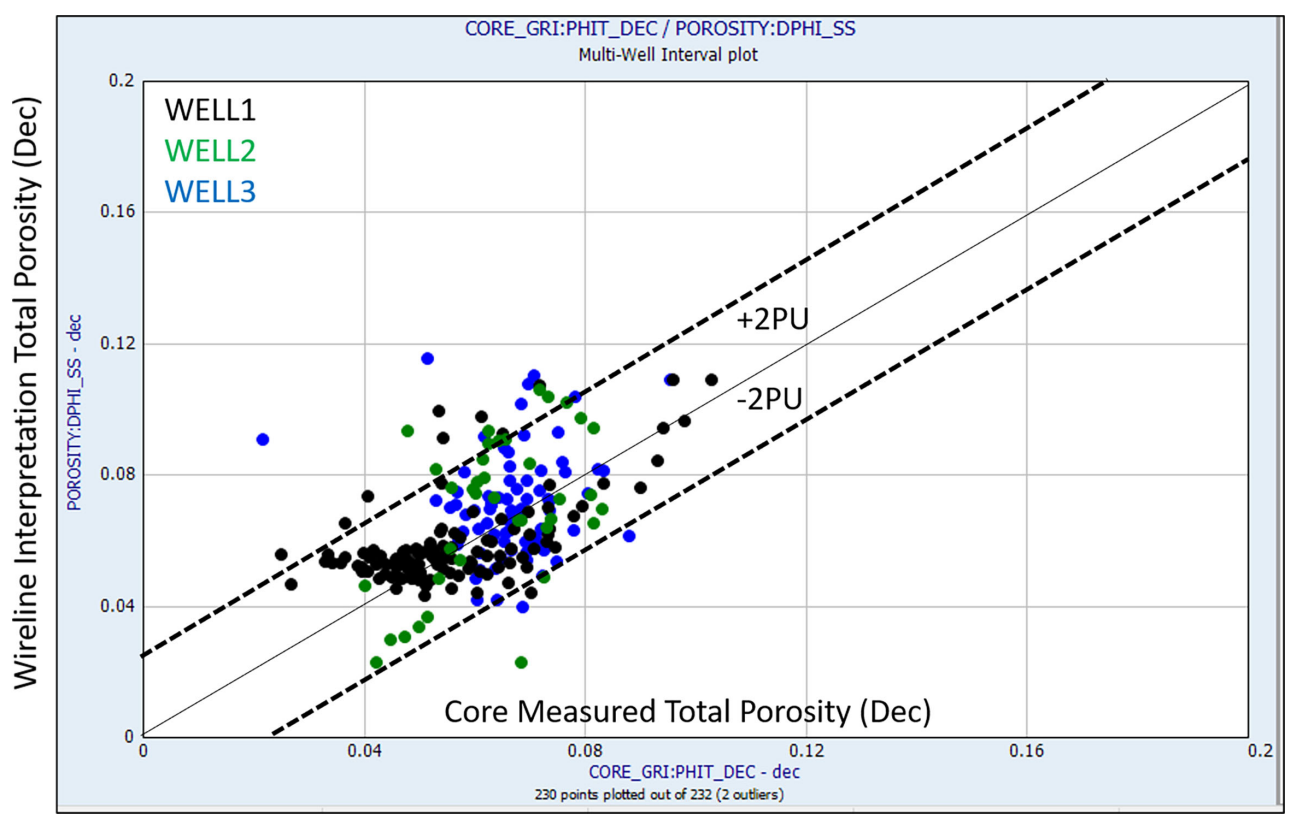

Figure 37. Cross-plot of core measured total porosity $(\mathrm{dec})$ versus wireline-derived total porosity (dec). A 1:1 line is drawn for reference, and the scatter about that 1:1 is demonstrated to define the uncertainty or error between the petrophysical calibrations. In this study, total porosity (PHIT) has a $\pm 2 \%$ uncertainty and should be maintained when geological maps are constructed, and in-place estimates considered.

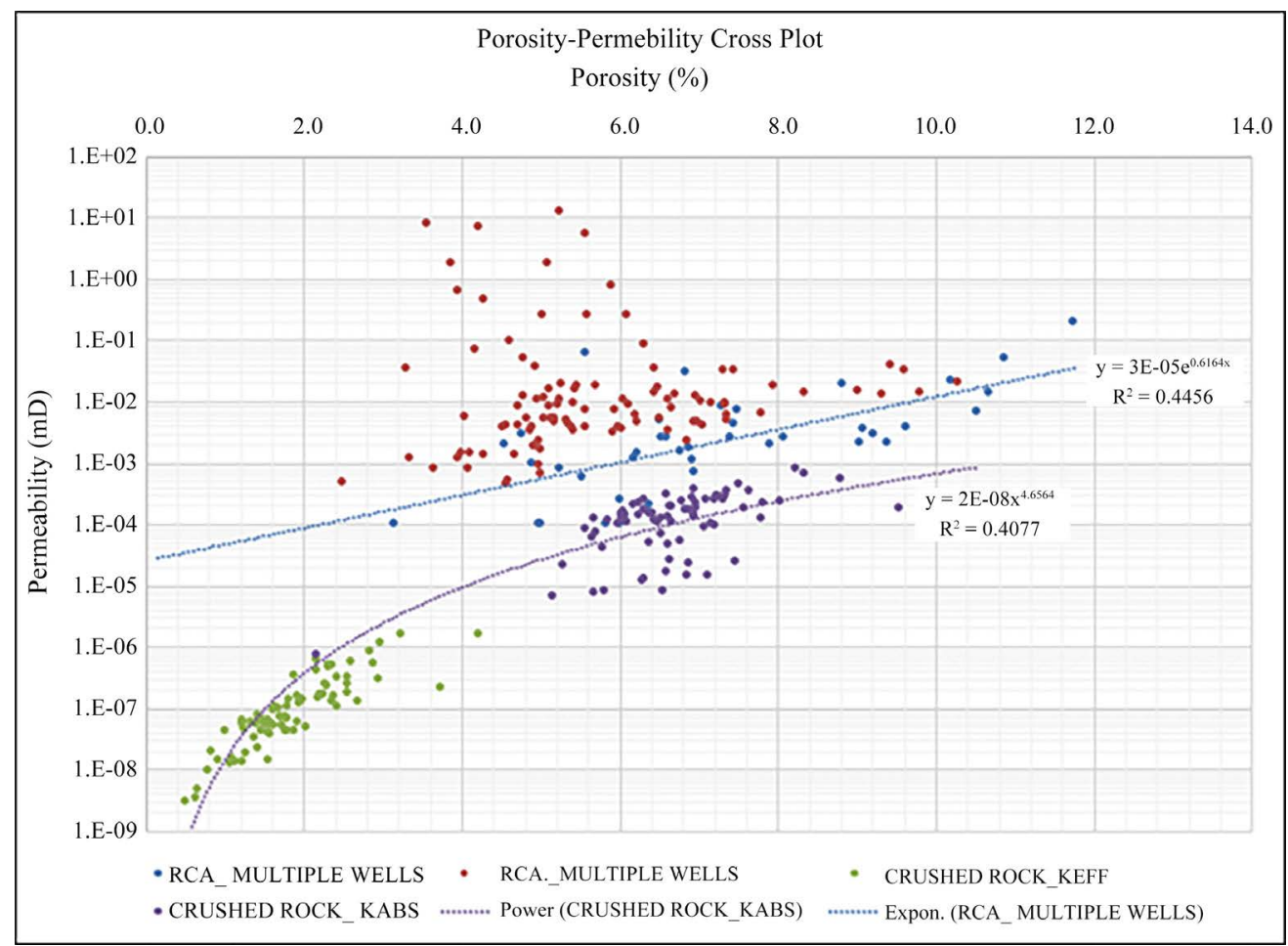

Figure 38. Cross-plot of measured total porosity (\%) on the $\mathrm{X}$-axis and measured permeability (mD) on the Y-axis. Routine core plug measured permeabilities (Klinkenberg corrected) are distinguished from crushed rock permeabilities for reference [principles in 21]. 


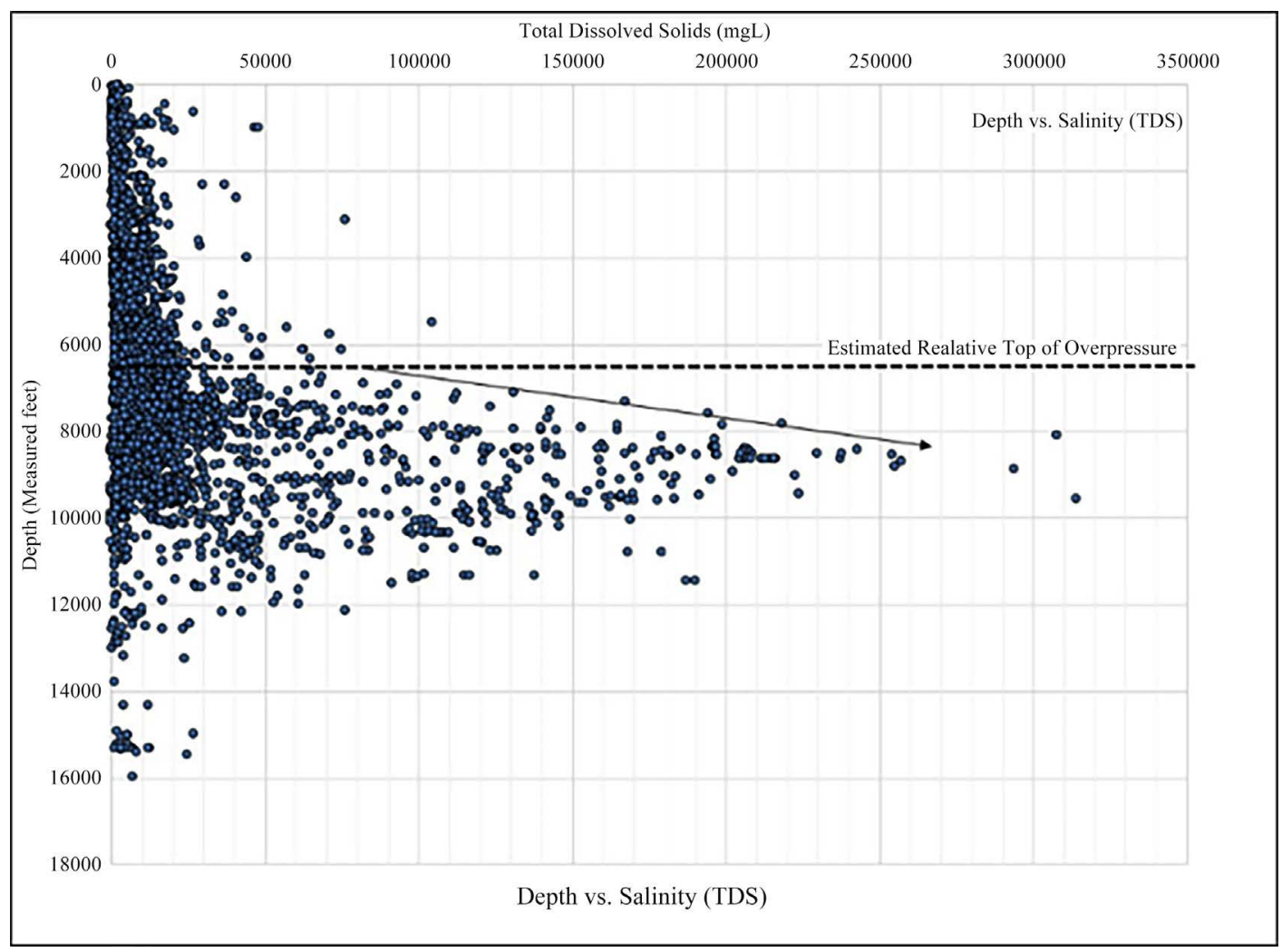

Figure 39. Cross-plot of TDS from water-based analyses versus depth [13]. Qualitative assessment of the overpressure window is assessed by petrophysics, where the salinity of the stratigraphy starts to increase greatly. The fundamental correlation is overly simplistic; however, it can be a good qualitative indicator for consideration.

* Particularly challenging are low resistivity, low contrast pay play types. These formations are where the Rw is lower than expected based on salinity and Pickett plot constraints and a petrophysicist can very easily mis-evaluate these plays as all water-filled, when, they have oil-prone potential.

Below is the equation to convert water salinity to formation resistivity given a known temperature gradient.

$$
\text { Resistivity of water }=010123+1 / 2.74 \times 10^{-4} \text { (NACL ppm equivalent) }
$$

An example of integrating total dissolved solids (TDS in ppm) data in the Powder River Basin in a map-based product for the Mowry formation (Figure 40). Maps such as these will guide a petrophysicist to tell them where their Rw parameter in Archie's equation must be adjusted [14].

General theory states that an increase in resistivity against a baseline, is a direct indication of hydrocarbon presence. A decrease in resistivity is an indication of water-filled pore volume. Archie's theory states that an interpreted baseline should be established to interpret the $100 \%$ water-filled pore volume zone. From there, based on the above equation, total water saturation in the formation can be determined. The interpretation depends on knowing the resistivity of a $100 \%$ water saturated zone (Rw), total porosity (phi), the cementation exponent $(\mathrm{m})$, true resistivity of the formation (Rt), and $\mathrm{n}$ (saturation exponent). The tortuosity exponent is often typically included (a). The formation true resistivity can be complicated by an overprint from lithology such as higher resistivity due to tight carbonates or low resistivity, low contrast pay (Figure 41).

Water Saturation raised to the Lithological Factor $\left(\mathrm{Sw}^{\wedge} \mathrm{n}\right)=$ Resistivity of water/(Total Porosity^Cementation Exponent $\times$ True Resistivity (from measured log) [14] 


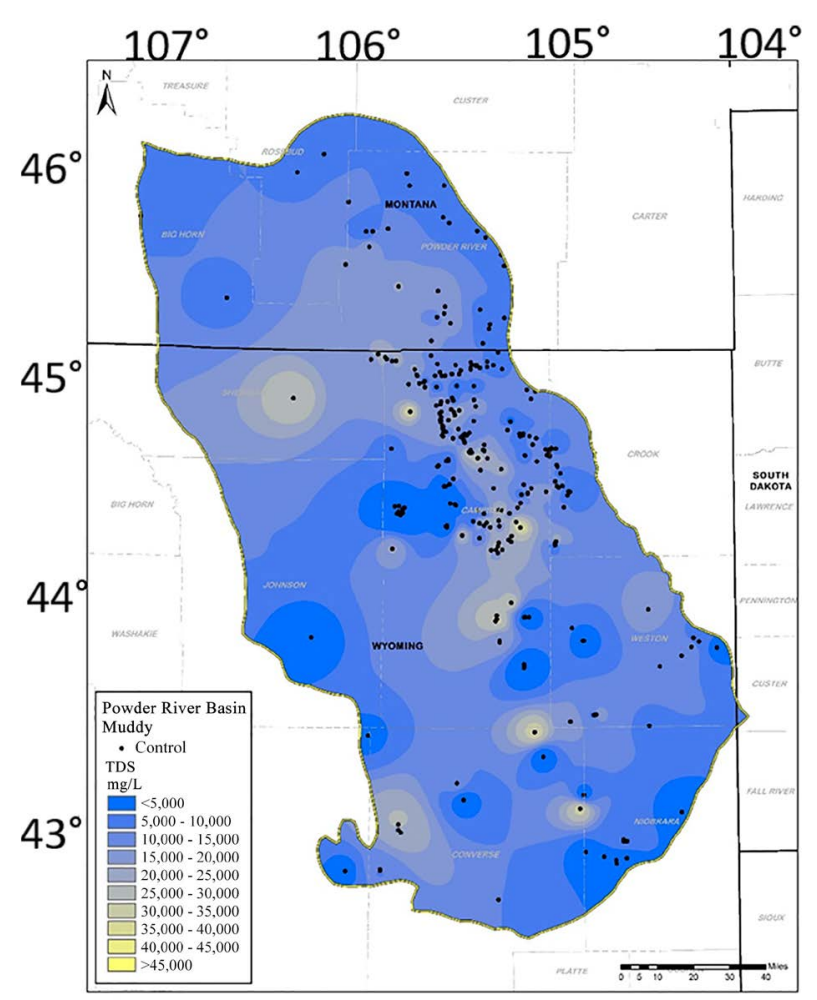

Figure 40. Unites States Geological Survey [13] public database filtered and redefined by depth, interpreted formation and first production total dissolved solids measured factors. Then total dissolved solids (TDS), and mapped for general trends flexed to defined isopachs for a given interval. Map is an interpreted derivative product.

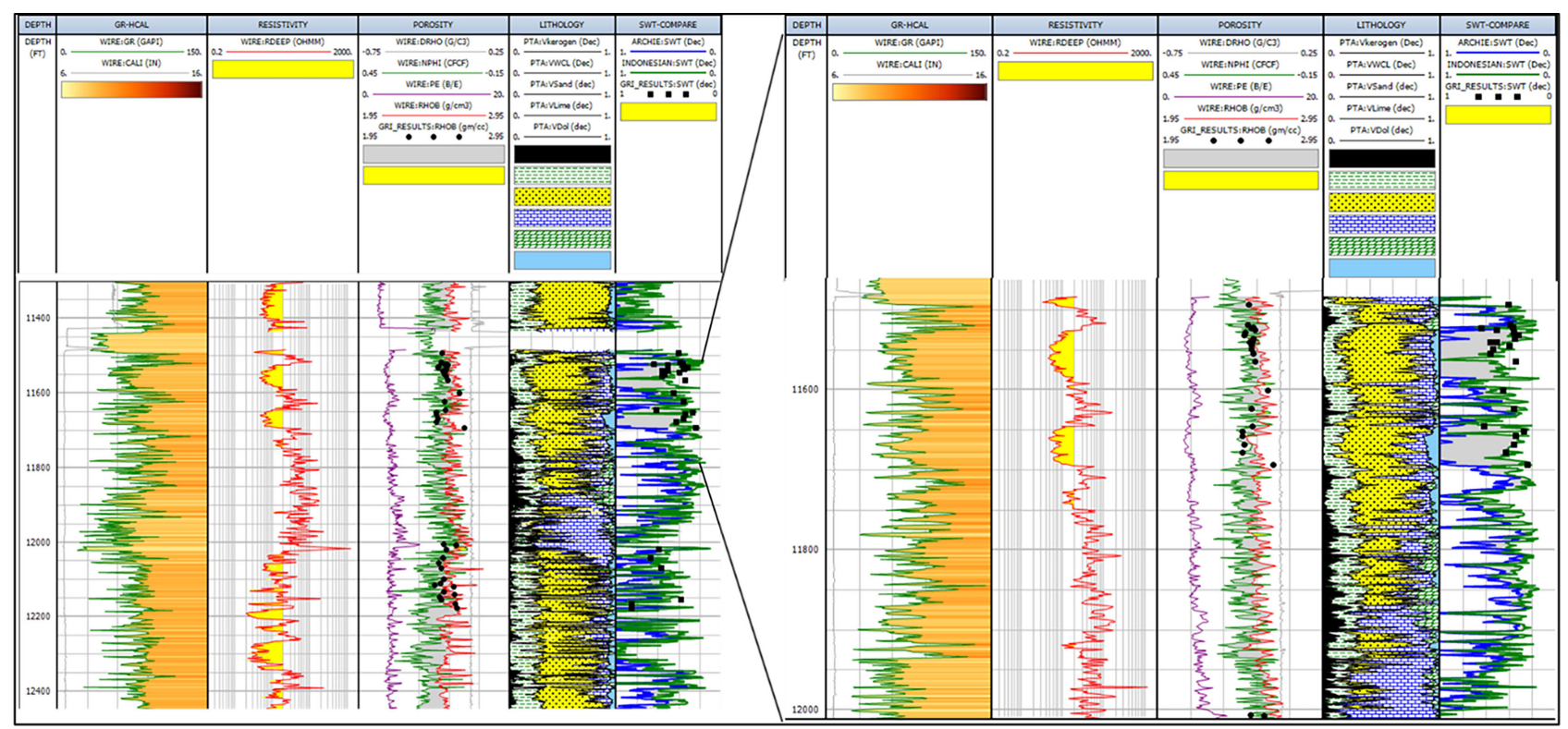

Figure 41. Comparing an Archie-solution [14] versus silty-shale total water saturation evaluation approach. The last track, displayed in blue, is an Archie based total water saturation, assuming a $\mathrm{Rw}$ of $0.08, \mathrm{MN}$ of 2, and $\mathrm{A}$ of 1 . For comparison, the silty-shale solution is demonstrated in green, where Rw is $0.08, \mathrm{MN}$ of $2, \mathrm{~A}$ of 1 , and ResClay of 2 . 
Archie's equation is based on measured principles from sandstones in the Gulf of Mexico and resulting characteristic responses that allow a petrophysicist to calibrate and utilize the known equation [14]. In unconventionals, or silty-sands or shaley-silts etc., excess conductivity related to the cation exchange capacity of clays impacts the basic principles of Archie's equation. The impact of the total water saturation calculation in a clay-rich zone can be observed.

In this study, total water saturation was evaluated several various ways to ensure the client has the most representative SWT (\%) for the formation of interest they are trying to evaluate hydrocarbon-prone potential in.

A conventional Archie total water saturation approach was executed [14] as well as shaley-sand models interpreted across the stratigraphic column. For all the below applied equations and evaluations the total water saturation parameters were held constant and did not vary by stratigraphic zone in every well with depth. Calibration for total water saturation interpretation was utilized from core and rotary sidewall core-based measurements. In addition, to those measurements, Pickett plots were utilized to cross-check and constrain the Rw, M (cementation factor), N (lithology factor) and A (tortuosity) (Figures 42(a)-(c)). Last, to ensure calibration, core based Rw measurements were utilized. Archie based application; Interpreted three ways to represent a low side, P50 and high side solution (Figure 43 and Figure 44).

Archie_SWT_Higher Towards 0\% (Increasing So) - Rw $=0.04, \mathrm{MN}=1.7, \mathrm{~A}=1$

Archie_SWT_P50 - Rw $=0.07, \mathrm{MN}=1.8, \mathrm{~A}=1$

Archie_SWT_Lower Towards 100\% (Decreasing So) - RW $=0.11, \mathrm{MN}=2, \mathrm{~A}=1$

In addition to the Archie based solutions, shaley-sand models were applied for both a total water saturation solution and as effective water saturation solution. These equations consider the cation exchange capacity (CEC) responsible for resulting in excess conductivity and therefore low resistivity associated with the presence of certain clay volumes (often species dependent). As such, for the low resistivity, low contrast potential pay the shaley-sand solutions were applied with the following parameters:

- $\quad$ Simandoux Rw = 0.07, MN 1.8, Res Clay 2, A = 1

- Indonesian $\mathrm{Rw}=0.07, \mathrm{MN} 1.8$, Res Clay 2, $\mathrm{A}=1$

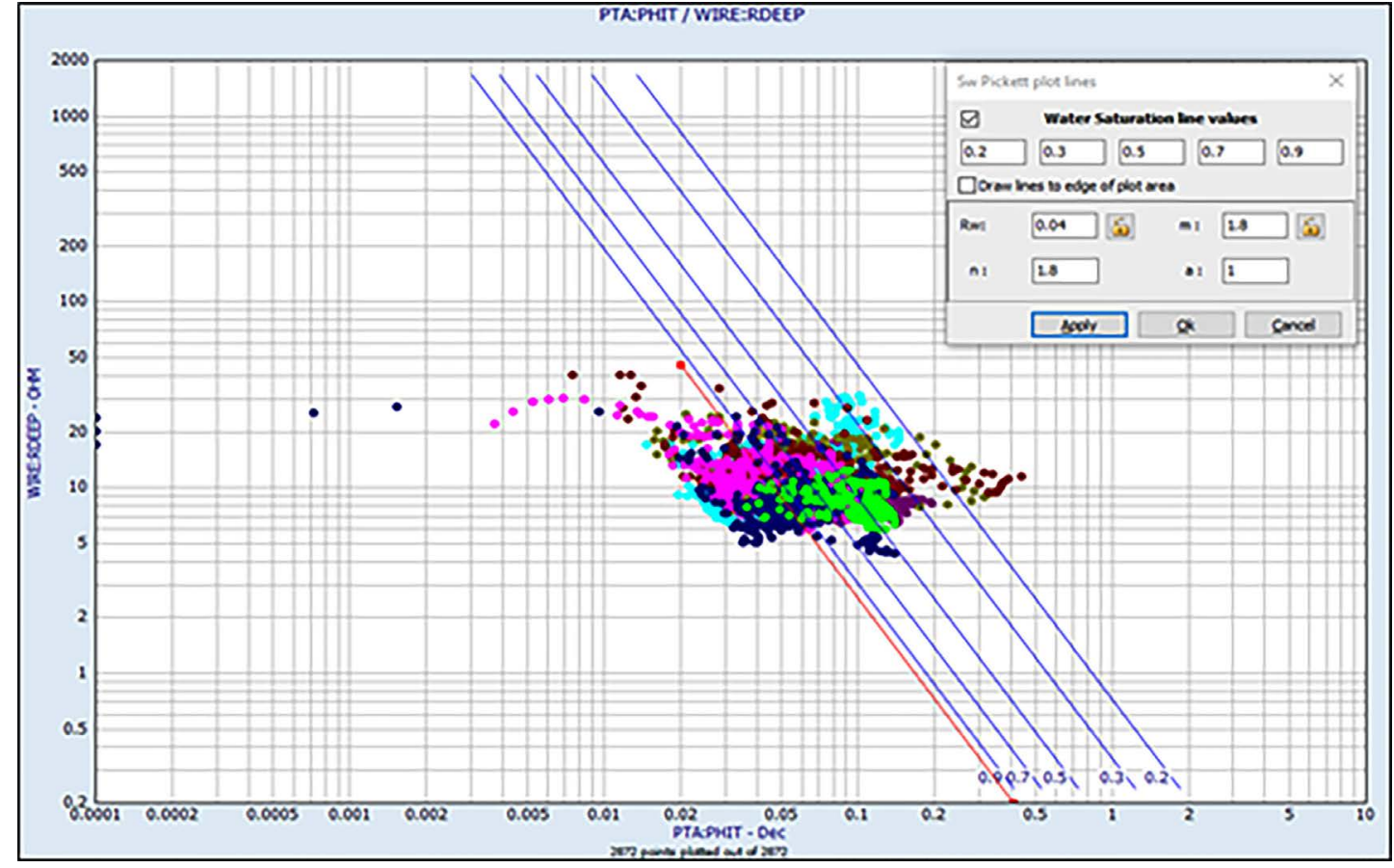

(a) 


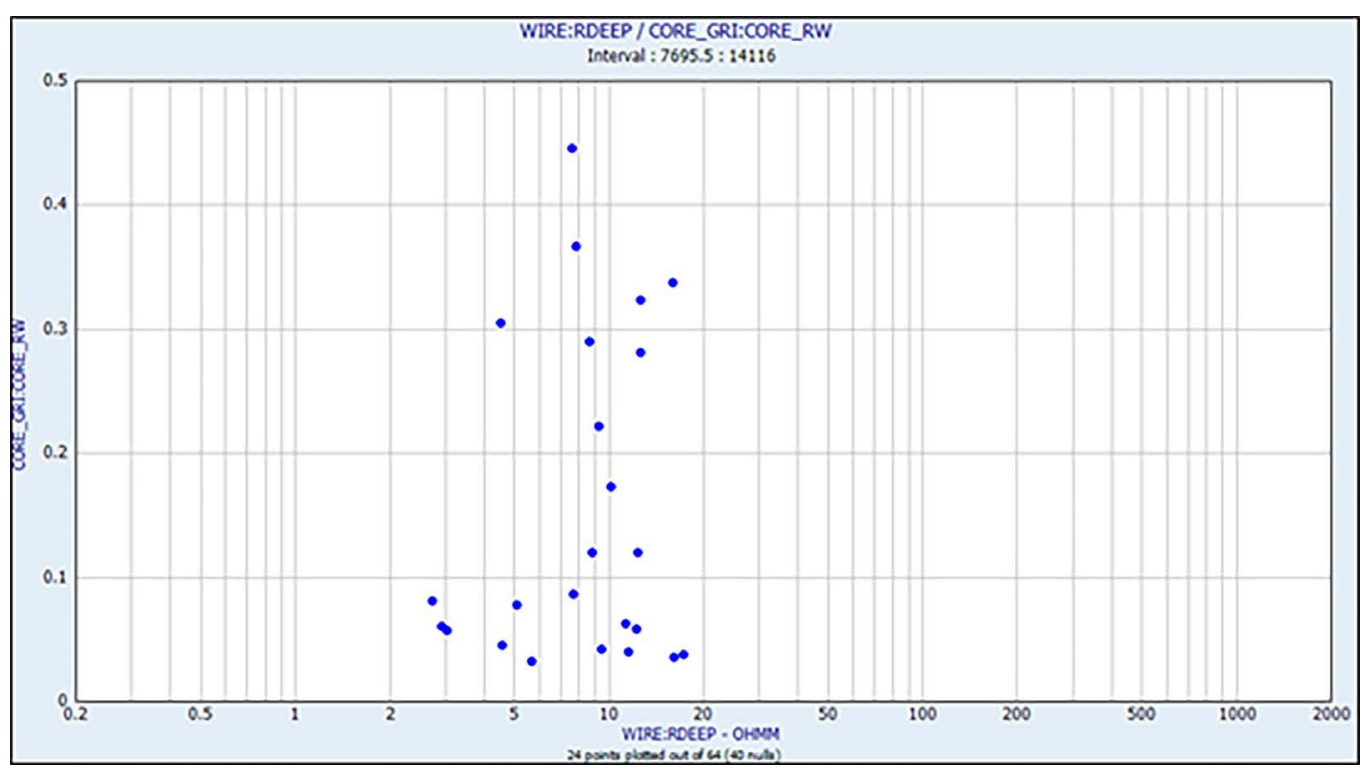

(b)

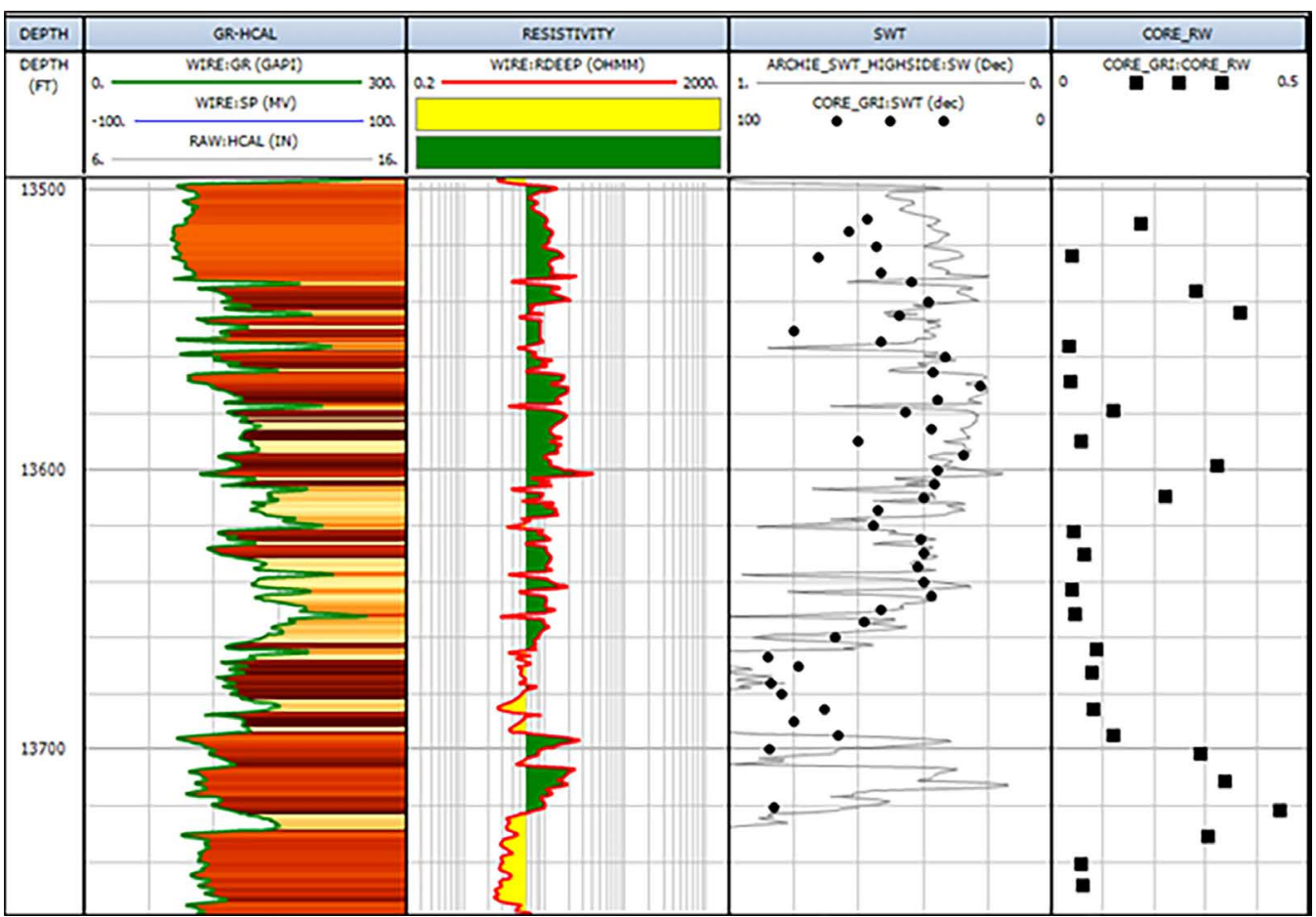

(c)

Figure 42. (a) Cross-plot example of total porosity (dec) and deep resistivity (ohms). Pickett plot overlay lines are displayed, where $\mathrm{Rw}, \mathrm{M}-\mathrm{N}$, and A variables are constraining the $100 \%$ water-saturated line, relative to a $\mathrm{Rw}$ with $\mathrm{M}$ and $\mathrm{N}$ constraining the slope and width of the water-saturation equivalent correlations; (b) Cross-plot of core measure Rw@70F versus wireline deep resistivity (ohms) for reference. Data are utilized in constraining the Rw parameter in the total water saturation equation and solution; (c) Wireline display of total water saturation solution as calibrated to core measurements. Rw from core measurements show variability along the formation correlating primarily with deep resistivity. 
These equations were kept constant and applied across the entire stratigraphic stack. Fine-tuning of adjusting these parameters per formation was not conducted as the solutions are meant to provide the client with a high-level look and quantification (Figure 43). Last, the best fit solution for total water saturation interpretation provided to the client is derived from the multi-mineral model and does vary $\mathrm{Rw}$, $\mathrm{MN}$ and A across the stratigraphic column as needed (Figure 44).

An extension of our understanding of the partitioning of waters beyond the scope of just a total water saturation solution involves the utilization of nuclear magnetic resonance acquired data. Correlation between nuclear magnetic resonance bound water fraction, as defined by applying a $10 \mathrm{~ms}$ cut-off threshold on the open hole wireline data where the tool was run in a $0.2 \mathrm{TE}$ and $2 \mathrm{MHz}$ acquisition setting is applied in this case study (Figure 45). The resulting bound water fraction can be correlated to the volume of clay and an empirical relationship defined. Then that correlation can be extrapolated across the regional setting to provide petrophysical interpretation that allows the investigator to map So (1-SWT), BFV (bound water fraction) and by taking the difference in summation adding to 1 of these fluid fractions, the remaining pore-filled volume is free water (Figure 46(a) and Figure 46(b)). Maps can be generated of each of these fluid fractions. Open retort laboratory data will aid in the constraint and therefore correlation of the bound versus free water interpretation.

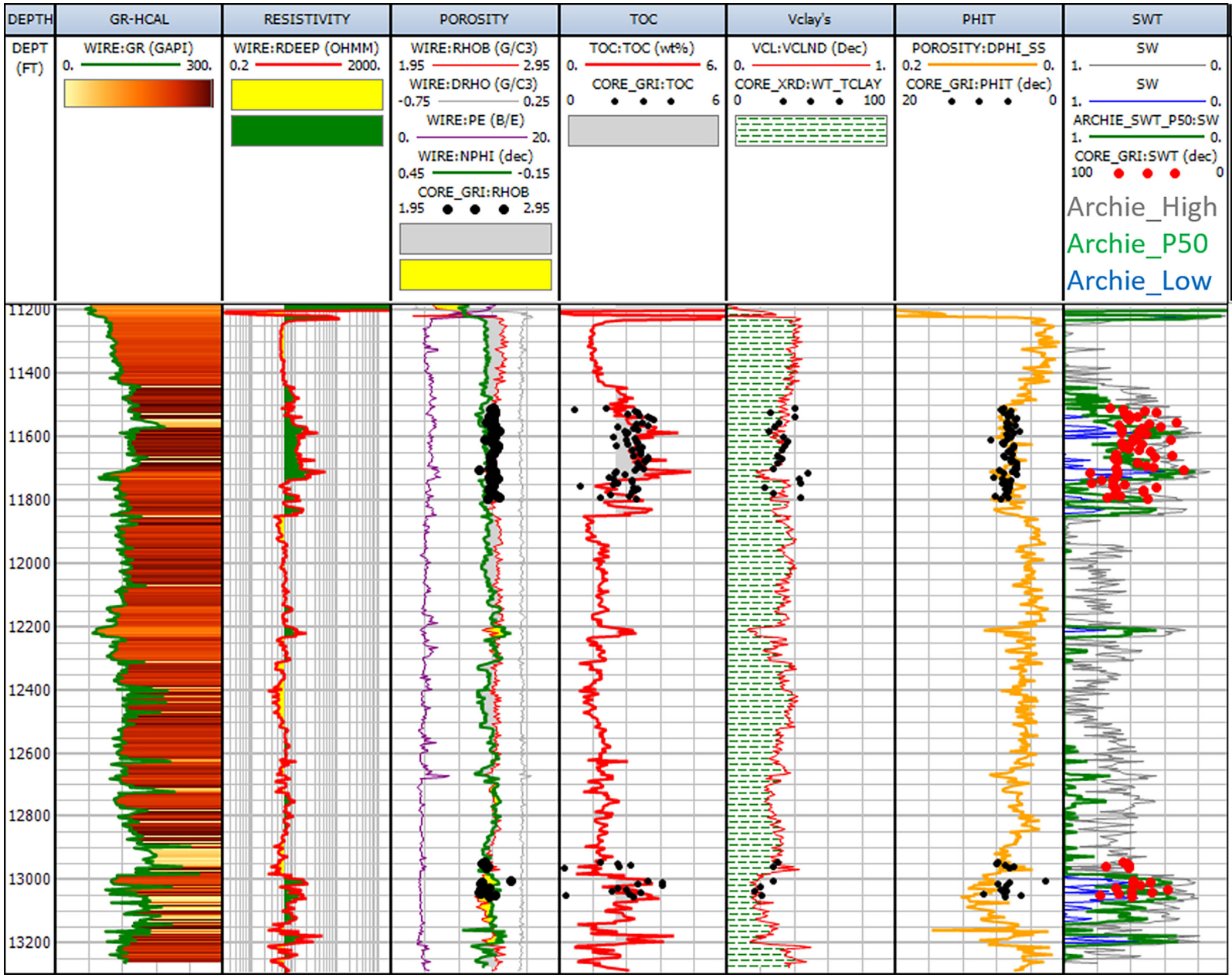

Figure 43. Petrophysical interpretation showing total organic carbon (wt\%), volume of clay (wt\%), total porosity (\%), and total water saturation (\%). The last track displays three Archie-based total water saturation solutions to constrain the uncertainty in the variability across the basin. A low side, P50, and high side solution are provided in every well, where applicable. 


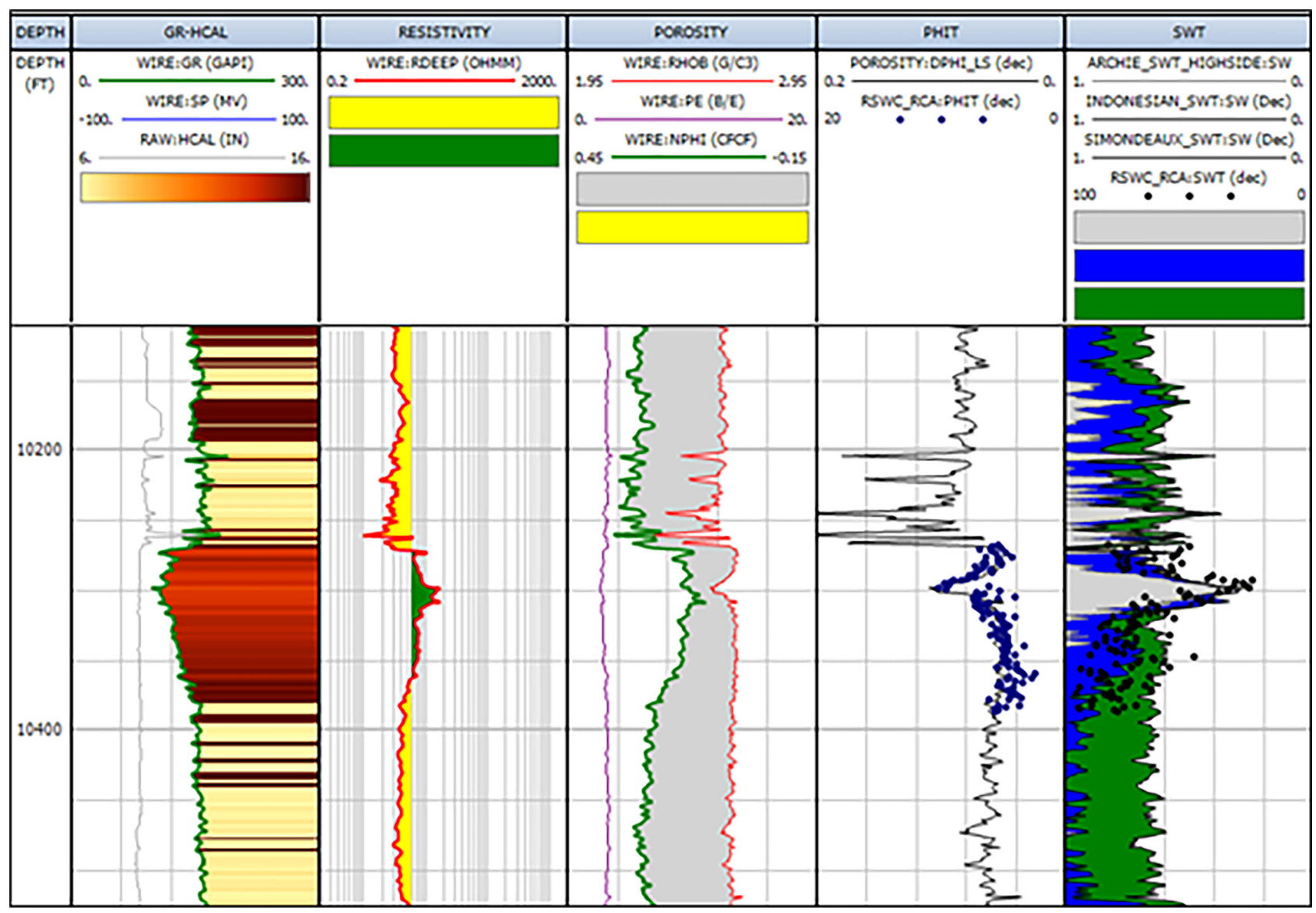

Figure 44. Petrophysical display of variability in a total water saturation solution comparing an Archie-based total water saturation (grey), a Simandoux total water saturation (blue), and an Indonesian effective total water saturation (green).

One of the most critical roles of a petrophysicist is to constrain and provide an original oil-in place quantification. All the work all leads up to that understanding and volumetric assessment. Previously we presented one way of calculating a continuous wireline based original oil in-place (OOIP) just from the geochemistry data alone. The more common way to calculate and assess the OOIP is with the integration of pressure-volume-temperature (PVT) data as well.

Formation volume factor (FVF or Bo) in the basin ranges from $\sim 1-1.5$ based on various PVT measurements across the stratigraphic column. A petrophysicist can assume an equation of state model to be applied and with the fluid gravity specifics reported in a PVT report as well as the resulting Bo, interpret a continuous wireline-based Bo. That variable Bo with depth can then be used as the input to the denominator in the OOIP equation. Else in the lack of the ability to generate a continuous curve, a constant value for Bo may be assumed and utilized (Figure 47).

Original Oil-In Place $($ OOIP $)=7758 \times$ Total Porosity $\times(1$-Total Water Saturation $) \times$ Area $\times$ height (thickness in feet)/Formation Volume factor (Bo)

For this study and the regionally calculated OOIP, a Bo of 1 was assumed for final calculations. However, below is an example of a PVT constraint in the Mowry formation where the petrophysics was constrained and a continuous interpretation could be generated. Last, below is a petrophysical interpretation of OOIP (assumes 640 acres as the area of investigation and 0.5 for the height of the given calculation) (Figure 48). 


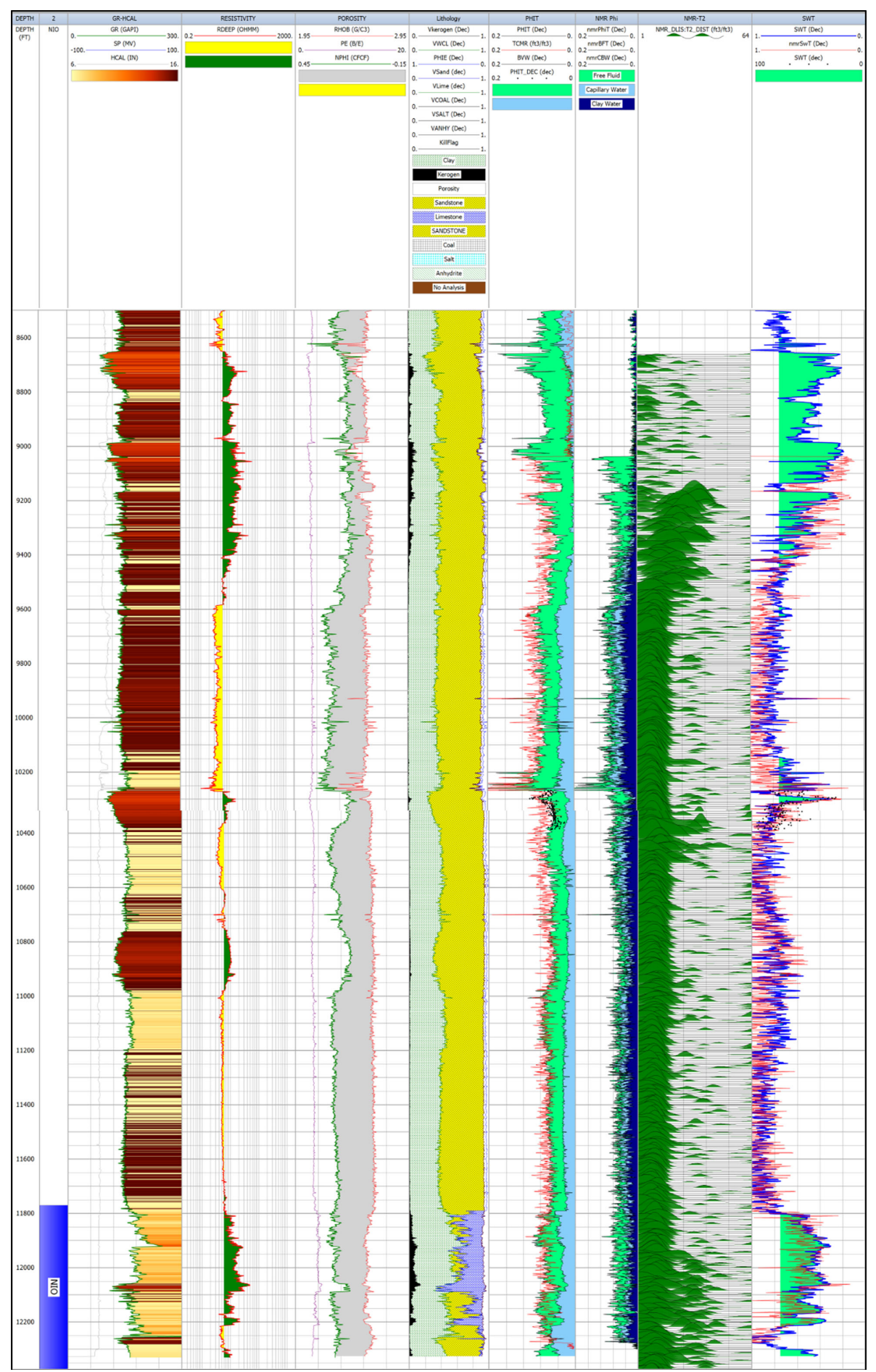

Figure 45. Petrophysical evaluation and integration of nuclear magnetic resonance (NMR) and measured core data over the Shannon, Sussex and Niobrara intervals in the Powder River basin. Note the variation in NMR T2 pore body distributions correlated to the volume of fluid-filled porosity in the Shannon and Sussex (reservoir) versus Niobrara (source and reservoir) intervals. The longer time decays and therefore inverted T2's indicate larger pore bodies and fluid-filled volume. Interconnectivity should be complimented by assessing pore throat distributions through mercury injection capillary pressure measurements. 


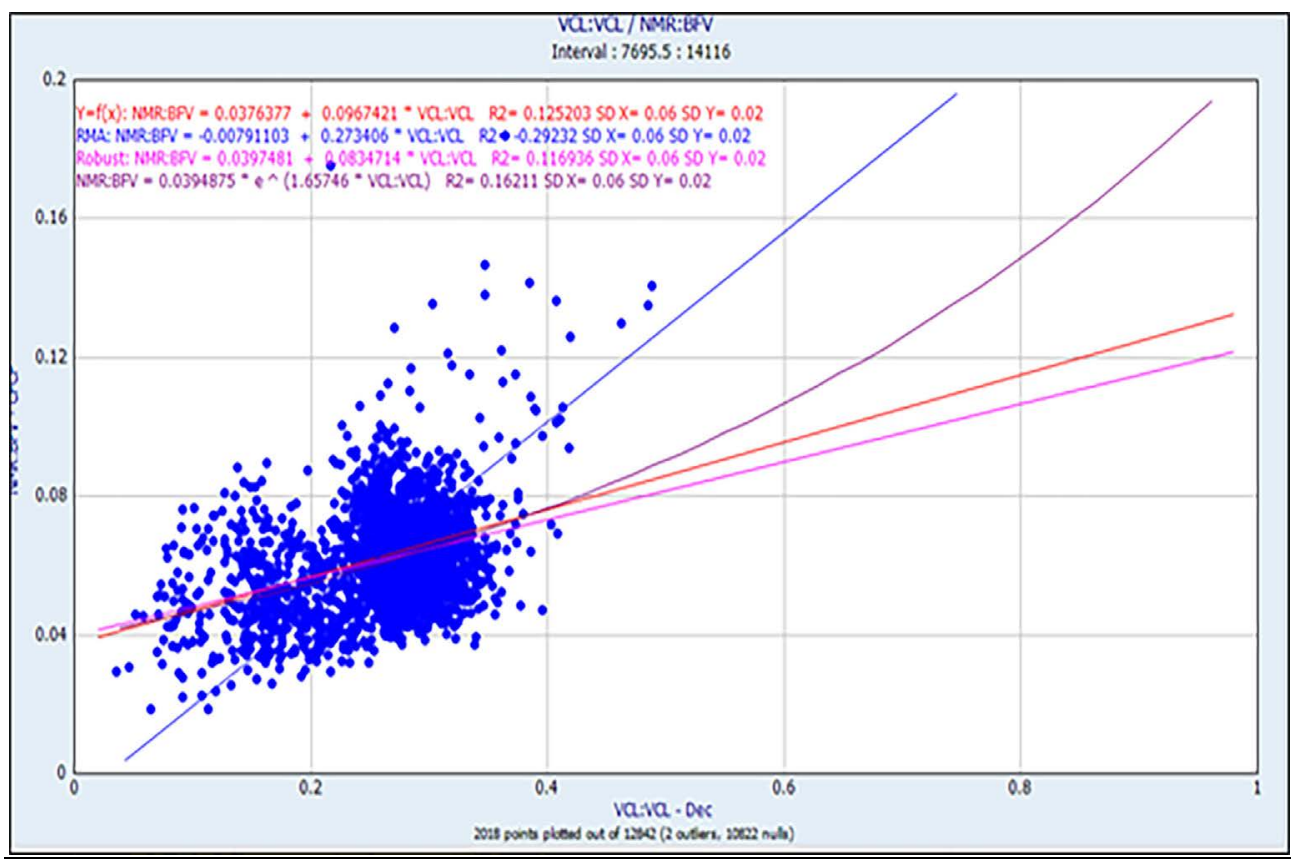

(a)

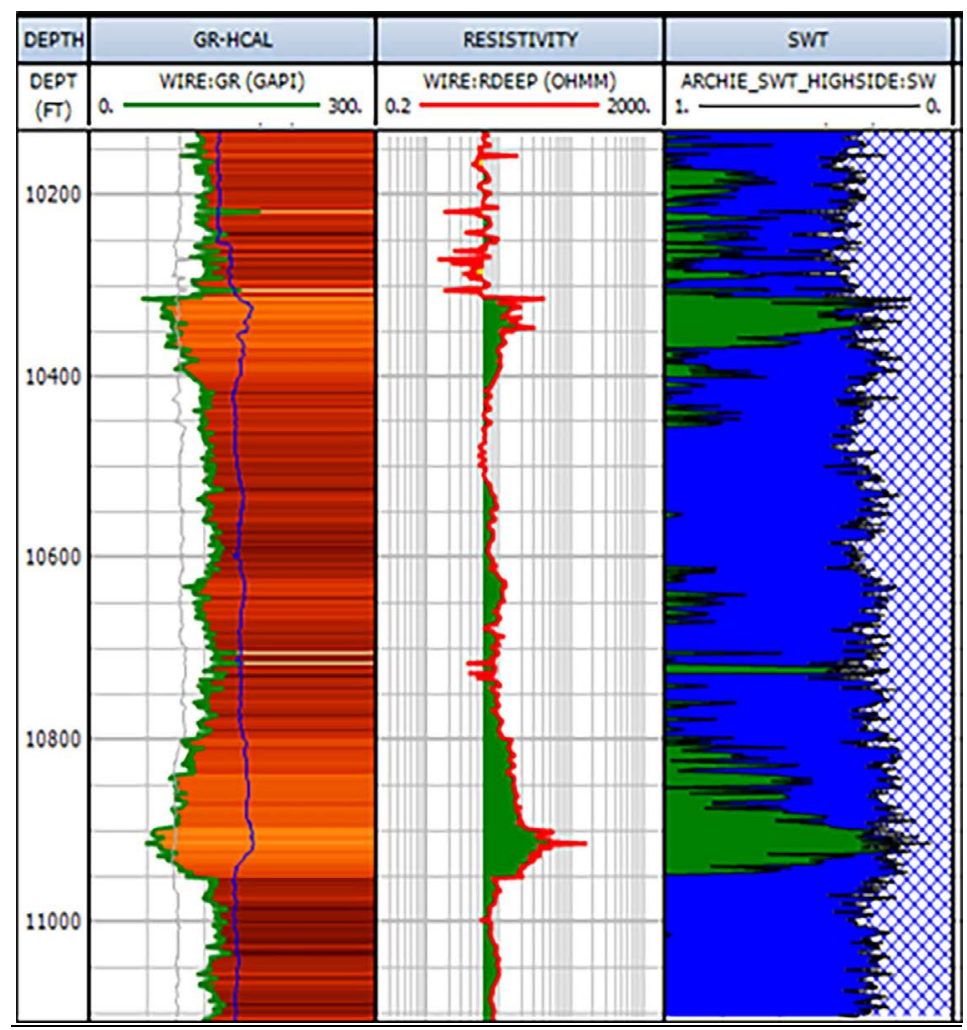

(b)

Figure 46. (a) Cross-plot of the volume of clay on the X-axis versus the NMR defined bound water volume on the $\mathrm{Y}$-axis. Correlation allows for bound water interpretation to be extrapolated away from constraint. (b) Petrophysical interpretation wireline display of the partitioning of free water (blue) versus bound water (hashed) in the Shannon and Sussex formations in the PRB. 


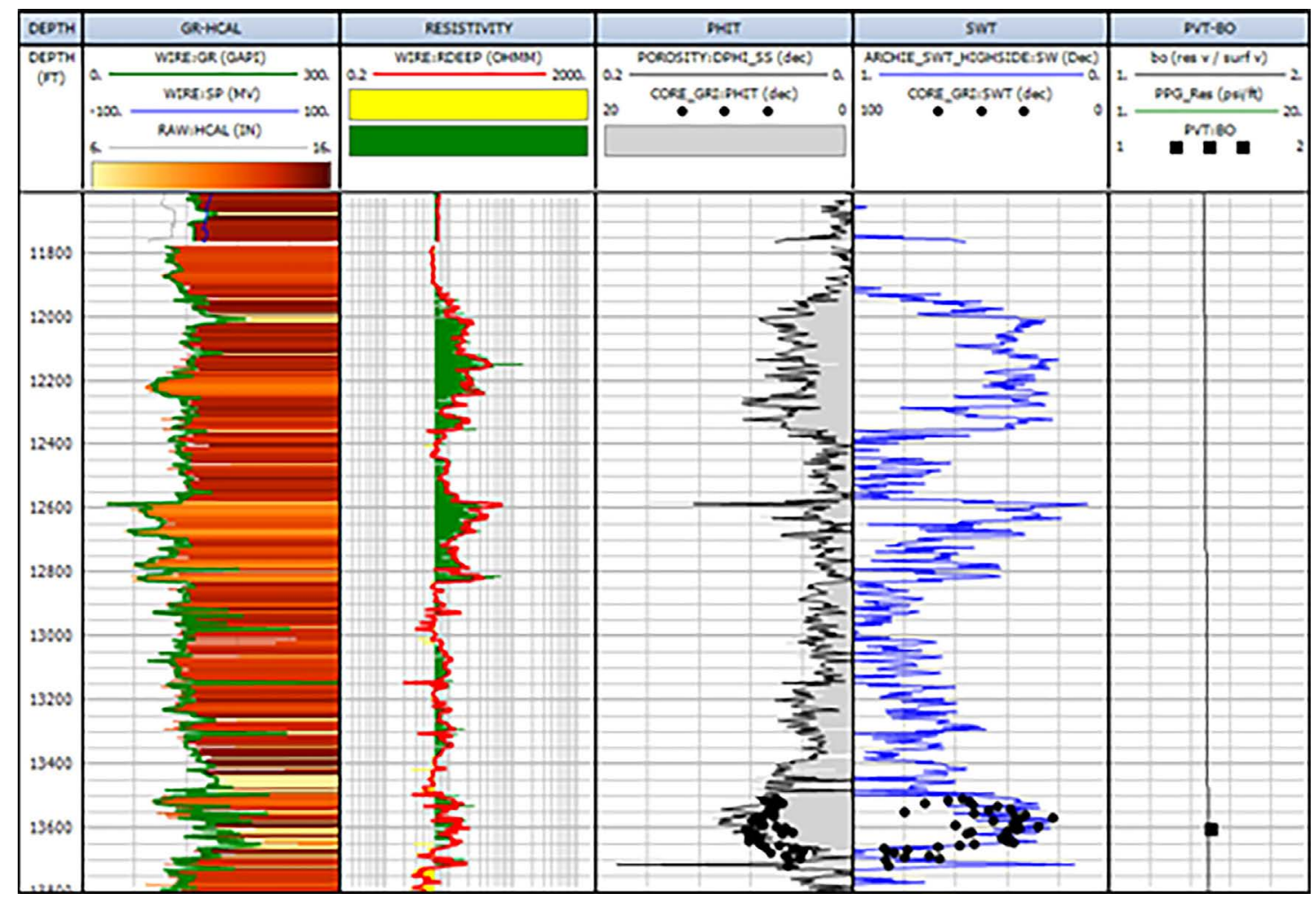

Figure 47. Example of a PVT constraint in the Mowry formation. Note the calibration of Bo/Formation Volume Factor (FVF) to wireline derived input.

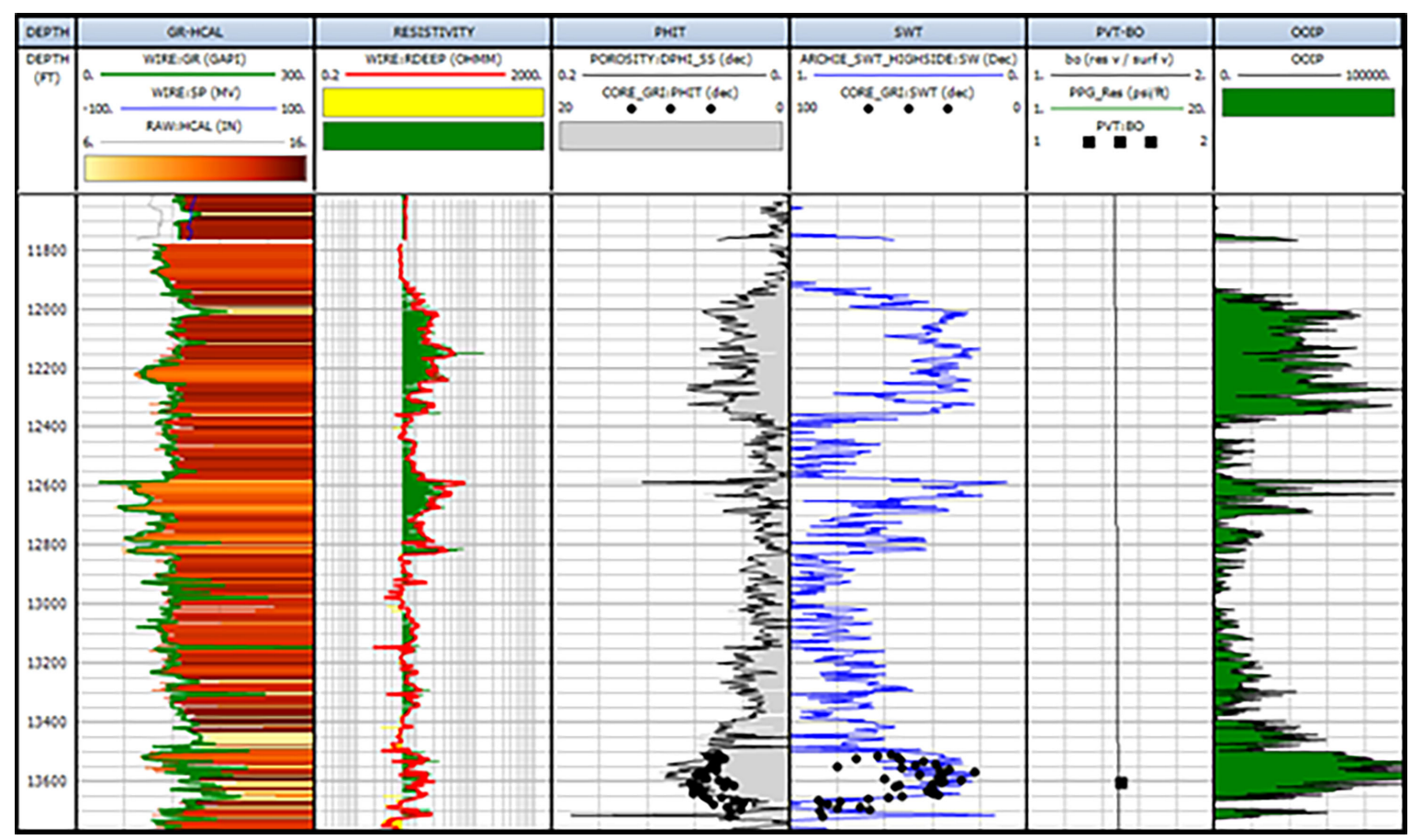

Figure 48. A petrophysical interpretation of original oil in-place (OOIP). Tracks left to right; Depth, Gamma Ray (gapi), Resistivity (ohms), total porosity (v/v), total water saturation (v/v), Formation Volume Factor, and last calculated OOIP. 


\subsection{Geomechanics and Pore Pressure}

For unconventional opportunities, the importance of the rock's stress and strain behavior is critical to understand. In this study we took the approach to evaluate dynamic Poisson's Ratio and Young's Modulus as derived from wireline log application. The dynamic to static relationship was not established so no vertical versus horizontal isotropic or anisotropic models were developed.

Utilizing the bulk density $(\mathrm{g} / \mathrm{cc})$ and compressional and shear velocities, dynamic geomechanical properties can be interpreted. In other words, the stress and strain tendency of a given rock volume. Or Poisson's Ratio (PR and Young's Modulus (YM psi) [15]. These properties relate to the stiffness and elasticity (or ability to rebound) and are commonly used to understand how parameters for a stimulated completion may force the rock to behave $[16,17]$. Where raw logs of DTC (compressional) and DTS (shear) were not available, the established pseudo-DTC and DTS were used as inputs to derive additional PR and YM coverage (Figure 47).

Assume the following principles:

$\mathrm{V}=$ Poisson's Ratio = Strain in each direction perpendicular to the axial load/Strain in the direct direction of the axial load

Compressional and shear velocities can be interpreted for a $\mathrm{VpVs}$ ratio as well as sonic-based porosities on either a sandstone, limestone or dolostone matrices. Also, from these calculations and raw $\log$ trends, top overpressure or formational overpressure can be qualitatively and quantitatively interpreted [18, 19]. Along with the qualitative approach to the observation and definition of overpressure (Figure 49), a more quantitative approach can also be executed. For this study a few select wells were chosen to evaluate pore pressure derived from resistivity and acoustic logs along the stratigraphic column. Limited DFIT data was available for calibration so the evaluation should be used with caution. Further work to constrain via leak-off test (LOT), formation integrity test (FIT) and DFIT data would be advised and welcome. In general, a pore pressure versus depth trend can be established and written in the linear relationship form to then derive on all wells in each basin. While that straight-forward solution does not consider the basin history or complexity, it can qualitatively aid in evaluating the top overpressure window spatially.

For each well investigated a workflow series of calculations was performed.

Step 1: Density Estimation via Gardner, Bellotti and Lindseth methods was applied with constants inputs as follows: Gardner "a" $=0.23$ and " $b "=0.25$, Bellotti consolidated formation Rho $=3.28-\mathrm{DT} / 89$ and where Rho $=(\mathrm{Vp}-3460) /(0.308 \mathrm{XVp})$. Where density estimation did not have to be performed and raw values could be utilized this was preferred as the input to Steps 2 and 3.

Step 2: Overburden Gradient Calculation where the KB height must be known, Water depth must be known, and density must be known. For this study, a density of water of $1 \mathrm{~g} / \mathrm{cc}$ was utilized. Intervals where density was missing, or estimation was not performed an Amoco compaction relationship was assumed. straints

Step 3: Overburden, Fracture Gradient and Pore Pressure Calculations Required Inputs and Con-

Volume of Clay, KB, Water Depth, Water Density, Resistivity or Sonic curve, applied method-For this study we applied a modified Eaton's method where the Eaton constant was held at 1.2. We note that measured Biot's coefficient in this basin does range from 0.8 to 1.1 and should be used to tune pore pressure calculations appropriately.

The resulting analysis provides a continuous fracture gradient and pore pressure predicted curve across the stratigraphic column for a given well. A geologist can then use this resistivity and acoustic derived deliverable to map and supplement any DFIT or point analysis they may have in each basin (Figure 50).

\section{RESULTS AND LESSONS LEARNED}

In general, we can define the hydrocarbon play opportunities into conventional and unconventional definitions by distinguishing unconventional as $<\sim 12 \%$ total porosity and $>1 \mathrm{mD}$ of permeability where 


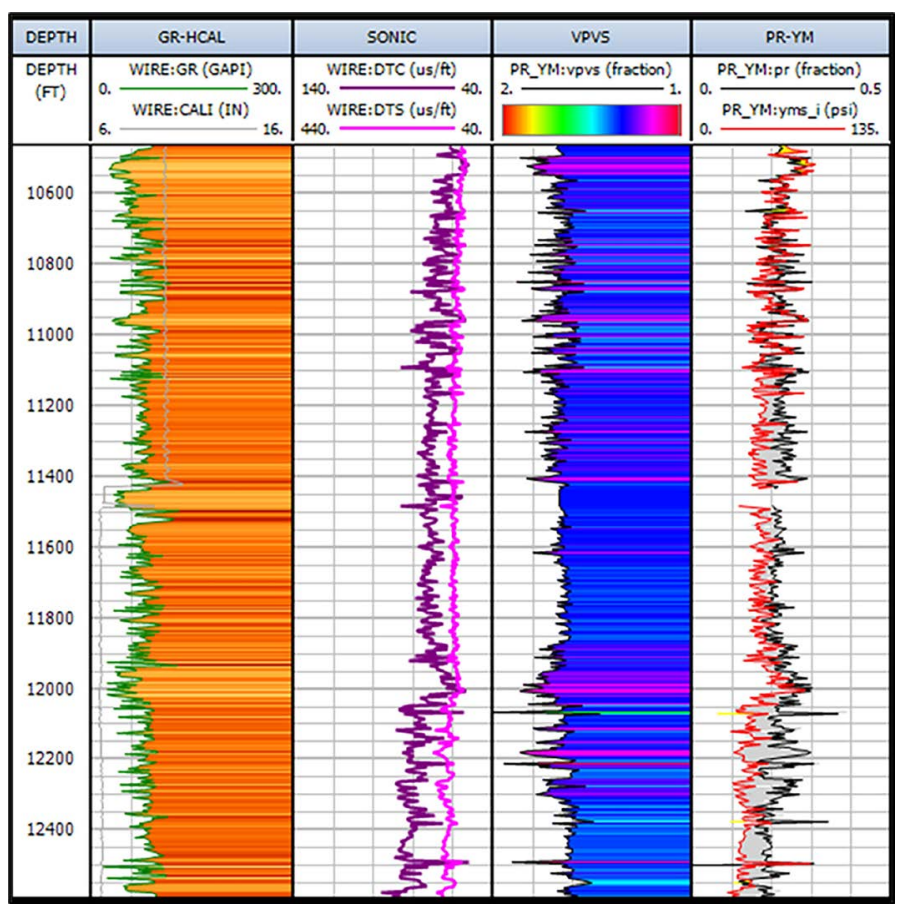

(a)

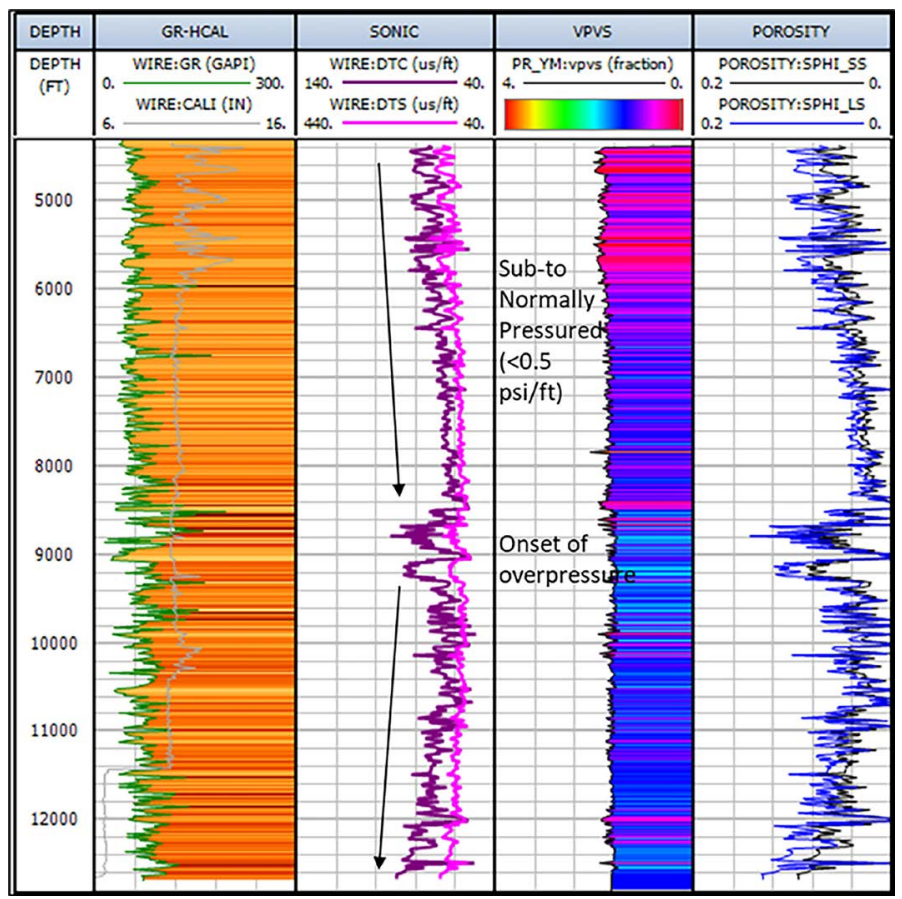

(b)

Figure 49. (a) Wireline display of acoustic compressional and shear velocities, with the VPVS ratio plotted and color filled. The last track is interpreted dynamic Poisson's ratio and Young's Modulus (psi) from the raw wireline inputs; (b) Example of utilizing the raw wireline compressional and shear logs to identify the major slope change associated with the qualitative assessment of the onset of overpressure. Top overpressure in a basin can be quickly identified and mapped with these observations. 


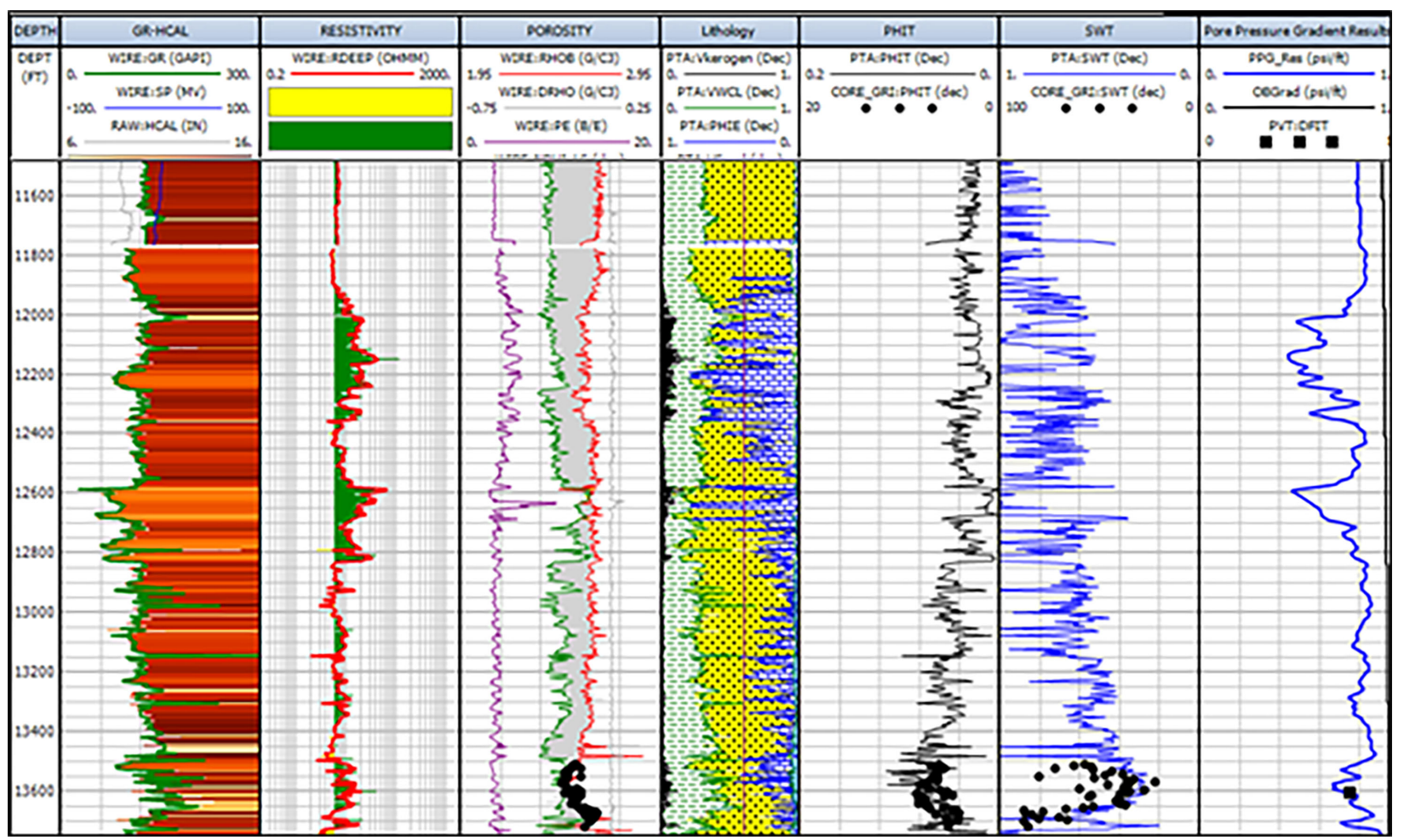

Figure 50. Petrophysical evaluation, where we focus on the last track. A DFIT was acquired in this Mowry example well, where the closure stress and, therefore, interpreted pore pressure is $\sim 0.76$ $\mathrm{psi} / \mathrm{ft}$. Given the constraint and input parameters to pore pressure modeling, a continuous pore pressure curve is interpreted (blue).

horizontal drilling application and stimulated fractured completions are needed to increase deliverability/flow of producible hydrocarbons to a given wellhead. Conventional opportunities as requiring vertical or deviated drilling application with no to only near wellbore acid stimulation or no stimulation with natural flow of producible hydrocarbons to a given wellhead. Conventional opportunities primarily being defined as reservoirs with $>12 \%$ total porosity and $>1-5 \mathrm{mD}$ of permeability where generated hydrocarbons have charged and migrated either locally or a long-distance from the source rock responsible for the hydrocarbon generation. In the Powder River Basin there are several reservoirs that remain as potential conventionally defined targets where the best reservoir quality rock of a given stratigraphic unit might have already been drilled and produced, but an explorationist could consider the decreasing reservoir quality rock as potentially having additional hydrocarbon potential, also known as "halo", opportunities. The Teckla, Teapot, Parkman, Shannon, and Sussex stratigraphic formations present this opportunity. Through a combination of the petrophysically generated volume of clay, total porosity and deep resistivity mapped trends, one could consider additional potential based on the integration of the mapped properties with the wireline signature understanding. Taking an example from the Shannon and Sussex formations, we observe that a deep resistivity threshold of $4 \mathrm{ohmms}$ in combination with the presence of $>6 \%$ total porosity correlates with known production (Figure 51).

Taking these petrophysical property definitions and applying to a map-based application, we can observe regionally where Shannon and Sussex total porosity demonstrate the same trends and can thereby identify potential spatial locations where the rock-based properties favor potential in-place hydrocarbon potential (Figure 52). Critical to integrate is the fluid understanding as well and based on the maturity trends mapped from the petrophysical evaluation we observe the increase of in situ maturity in southern Converse county as well as a related hot spot in Johnson county. If we define the transition from liquid-prone to gas-prone fluid potential as a 1 Vro equivalent, we can then understand that as the reservoir total porosity 


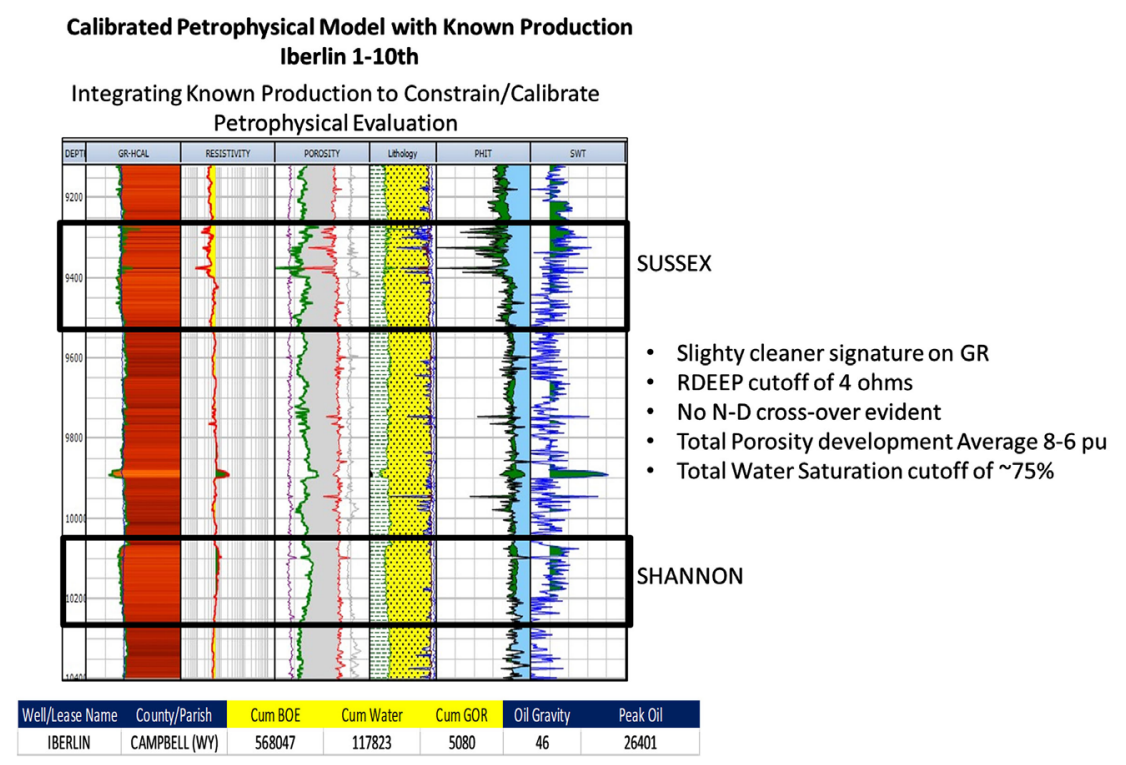

Figure 51. Wireline display and petrophysical evaluation of the Shannon and Sussex stratigraphy in the Powder River Basin. Wireline observations and correlation to known production are critical to use as ancillary calibration of total porosity and total water saturation especially where low resistivity character can be challenging.
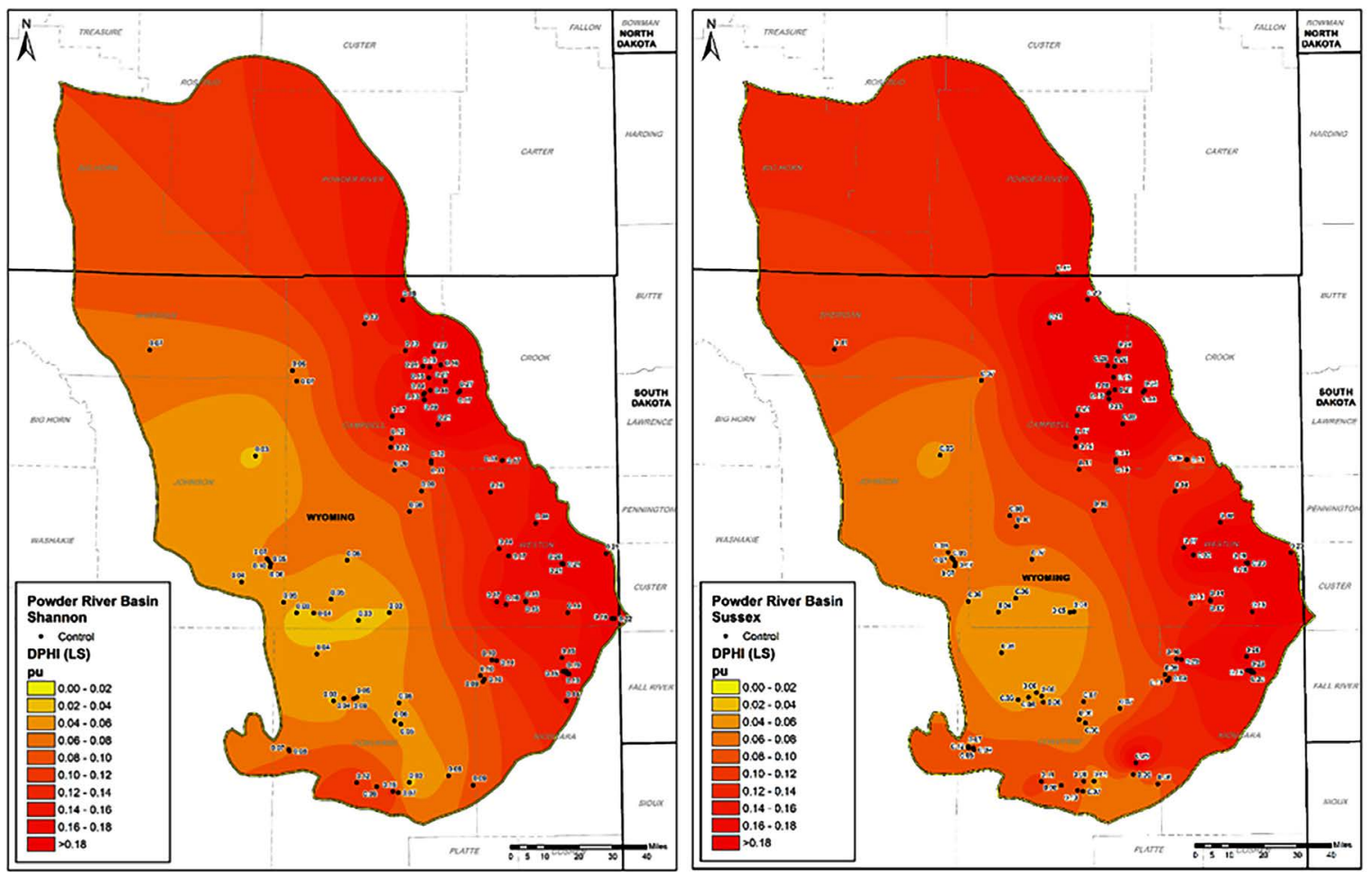

Figure 52. Total density-based porosity of the Shannon and Sussex stratigraphic formations. The main unconventional production trend as well as known conventional fields traverses through Campbell and Converse counties. Note the increase in total porosity to the eastern side of the basin. The effect is driven by the unloading or under compaction of the sediment and therefore impacts the quality of the bulk density $(\mathrm{g} / \mathrm{cc}$ ) logs that the total porosity is then derived from. 
decreases into Campbell and Converse county, the fluid type also becomes more gas-prone. Basic fluid principles would then allow us to assume that gas has increased buoyancy and an increased ability to migrate vertically and horizontally. Therefore, even though total porosity may decrease, the fluid type offsets that challenge by being able to produce from tighter pore throats.

One very significant challenge petrophysically in the Powder River Basin is the trend in bulk density and sonic out of the basin depositional center (through Johnson, Campbell, and Converse counties) off to the eastern flank where the Cretaceous log signature indicates a lack of compaction due to unloading of the basin stratigraphy during the Laramie Orogeny. This impact causes very low bulk density and very slow sonic responses that do not correlate to organically enriched stratigraphy or better reservoir quality apart from the Muddy sandstone interval (Figure 53). There is significance to the trends related to the existing Finn Shirley Turner sandstone defined field. In general, the main conventional and unconventional potential exist where deep resistivity can be mapped on average greater than $4 \mathrm{ohmms}$ indicating source and reservoir quality presence, as well as fluid-filled stratigraphy (Figure 54).

Unconventional trends can be observed in the basin center where the deep resistivity if greater than 4 ohmms and the sonic and bulk density indicate "tighter", total porosity $<12 \%$ and permeability $<1-5$ $\mathrm{mD}$. In addition, petrophysical evaluation of present day total organic carbon trends demonstrate the organically enriched potential that remains as well as indicates where the organic-matter has reached a maturation window where it has converted into hydrocarbon in-place (Figure 55). The Mowry and Niobrara are the identified unconventional source rocks in the basin with the Turner-Frontier-Wall Creek, Belle Fourche, Muddy and Shannon and Sussex being identified as unconventional reservoir targets as they have been horizontally drilled and exploited in the basin. Petrophysically mapped Poisson's Ratio and Young's Modulus aid in where the unconventional stratigraphy may have greater stress-strain contrast on a local or near wellbore scale to consider when planning stimulated completions. Of note but not investigated in this study is the significance of any natural fracture systems and basin-scale faulting. Mapping and understanding the distribution and influence on drill paths and potential uplift to production by providing increased pathways in the subsurface for hydrocarbon to flow through are of importance to consider and understand. When defining the Mowry formation wireline-signature one should observe and understand the presence of low bulk density, high neutron porosity spikes or correlations. This response indicates the presence of bentonites through the stratigraphic section of which the impact to horizontal drilling and stimulated completions should be considered. If the bentonites also have a quality of faster formational rebound/relaxation after stimulation, we could interpret that the vertical connected height of a Mowry formation well will be limited in the short-term production potential as the bentonites relax to their natural state closing off any potential connectivity to the organically enriched (defined as $>2 \%$ total organic carbon content), higher total porosity Mowry stratigraphy (Figure 55).

The Niobrara demonstrates the most petrophysical consistency in the basin in terms of the presence of organic-enrichment, total porosity, and oil-filled saturation (inverse of total water saturation where 1 -SWT $=$ So). However, the Niobrara does transition from mainly carbonate-dominated in southern Campbell and Converse counties to increasingly clastic-prone into Johnston and northern Campbell counties. The transition from carbonate to clastic dominated will impact the types of pore bodies and therefore related pore throat radii of the stratigraphy (Figure 56). Utilizing wireline nuclear magnetic resonance to understand and map where this transition occurs is critical to further exploration and appraisal of the $\mathrm{Ni}^{-}$ obrara stratigraphy (see Figure 45). Variation in that source-reservoir quality should lead any investigator to ask how a stimulated completion may need to be changed or how the hydrocarbon production may be impacted by the geological and petrophysical observations.

Integrating all the above lessons learned, food for thought, trends, observations and understanding, an attribute map-based visual illustration can be generated (Figure 57). Combining all the subsurface geological and petrophysical constraint provides a thorough in situ understanding of the rock and fluid properties for any stratigraphic formation investigated. By placing all the critical rock and fluid attributes on one map, an investigator can then define and understand where, when and how the properties transition and whether increased uncertainty in the stratigraphic potential can be interpreted as too risky to potentially test for hydrocarbon presence and production. 

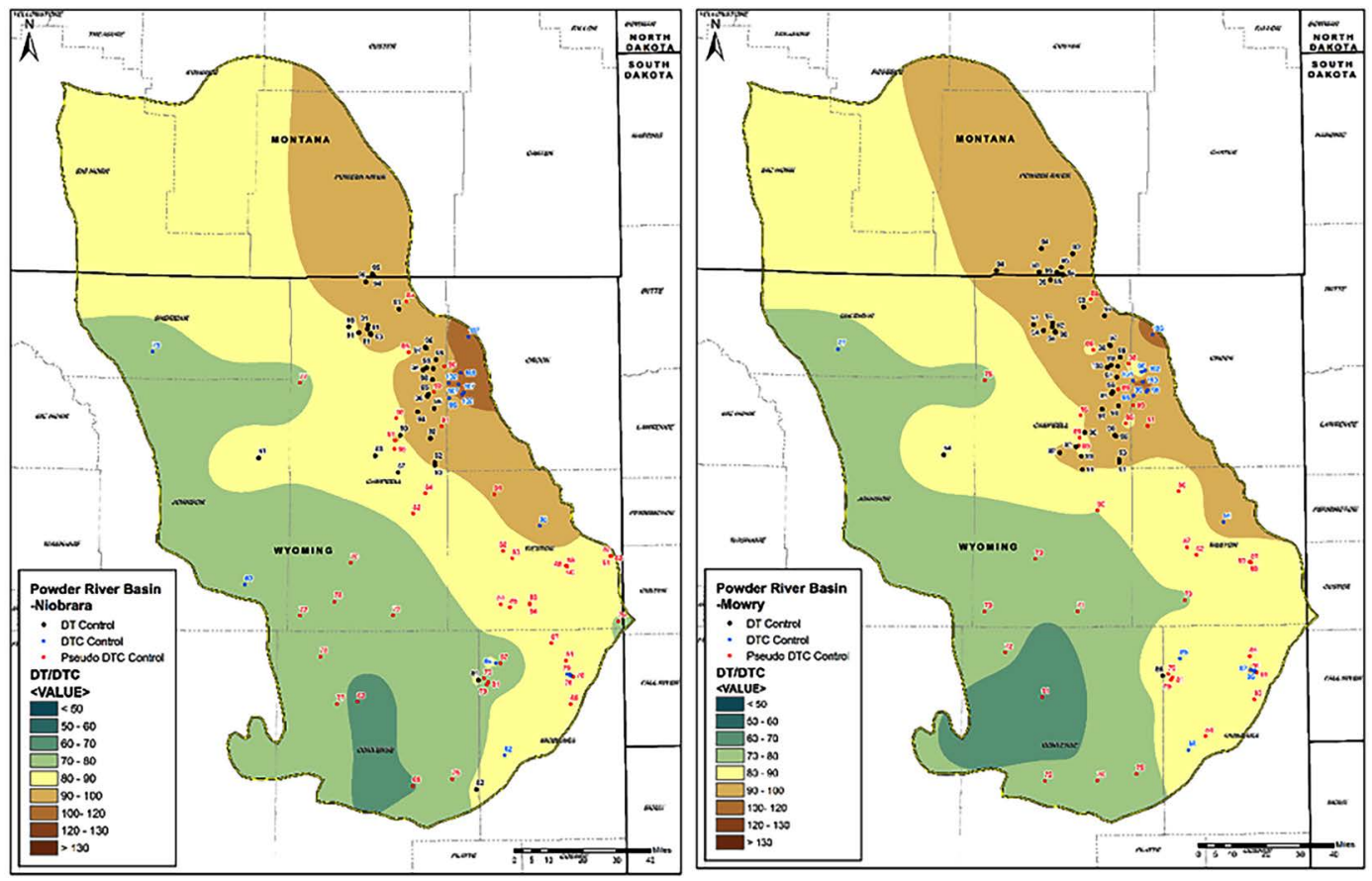

Figure 53. Left: Niobrara average sonic transit time (DT us/ft) map. Right: Mowry average sonic transit time map. The lower the DT values the more dominated the log response is and is driven by two mechanisms including tighter the fluid-filled pore volume, the more converted the potential organically-enriched stratigraphy. The slower the DT values the more impacted the logs by remaining organically-enriched section, gas effect, increase in fluid-filled pore volume, or the presence of overpressure.
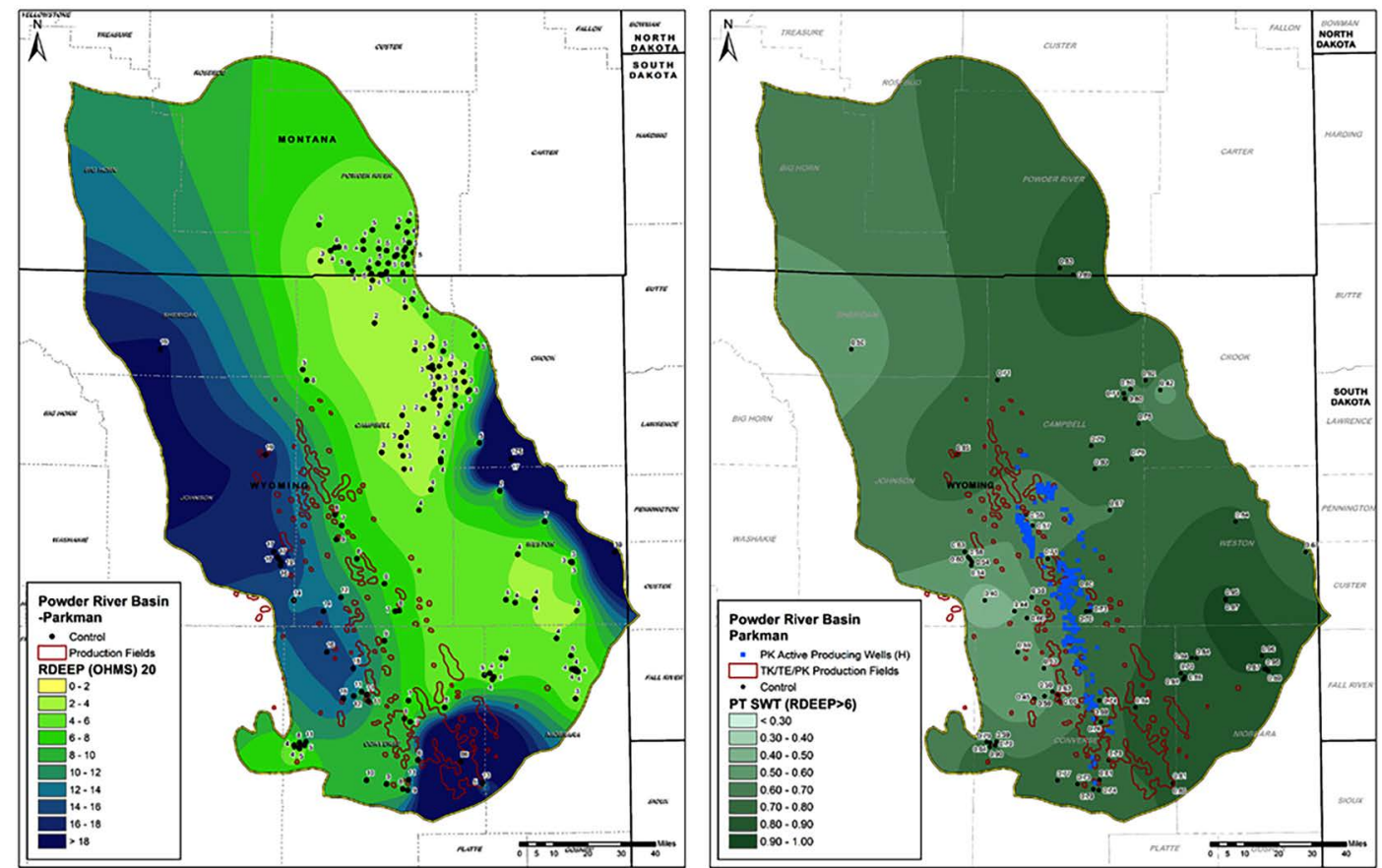

Figure 54. Left: Deep resistivity average map for the Parkman stratigraphic interval. Right: Petrophysical total water saturation with known conventional fields and active producing horizontals overlaid. 

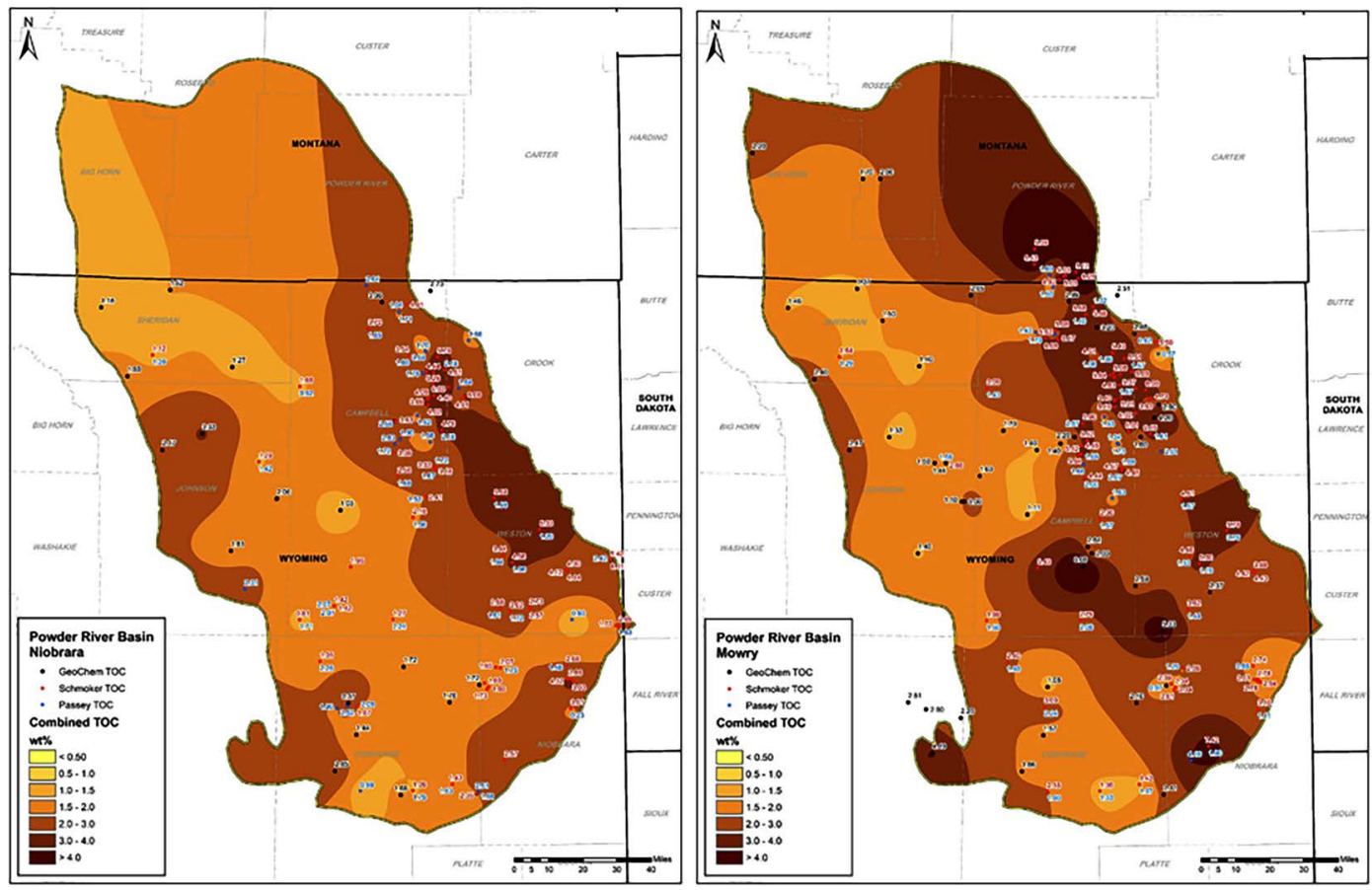

Figure 55. Left: Niobrara wireline derived total organic carbon (wt\%) taking both a Schmoker and Passey $[10,11]$ approach to the evaluation. Right: Mowry wireline derived total organic carbon (wt\%). Increase in present day total organic carbon (wt\%) is both an impact of lighter bulk density on the eastern margin of the basin as well as decreased maturity.

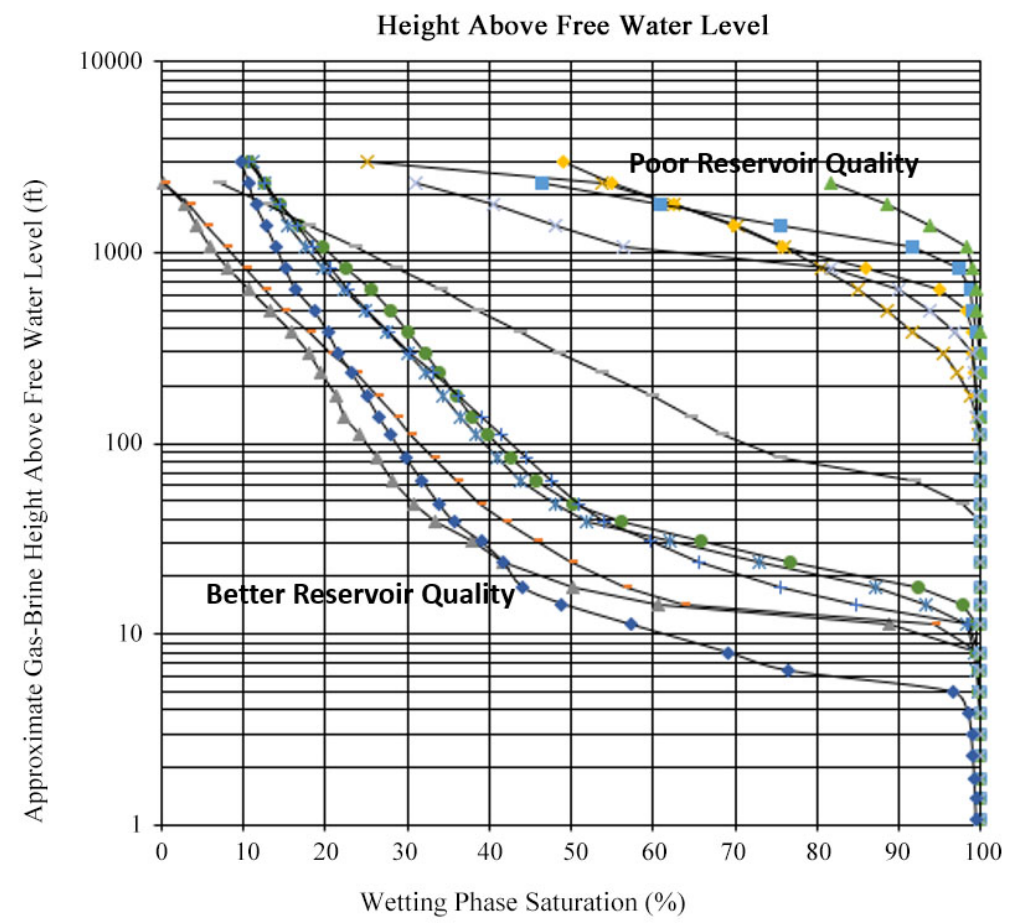

Figure 56. Mercury injection capillary pressure data [22] from the Powder River basin. Better reservoir quality indicates the more clastic-dominated facies in the stratigraphy versus the poor reservoir quality indicating more source rock or tight carbonate dominated facies [modified from 5]. 
Bringing Together All Defined Properties In One Space

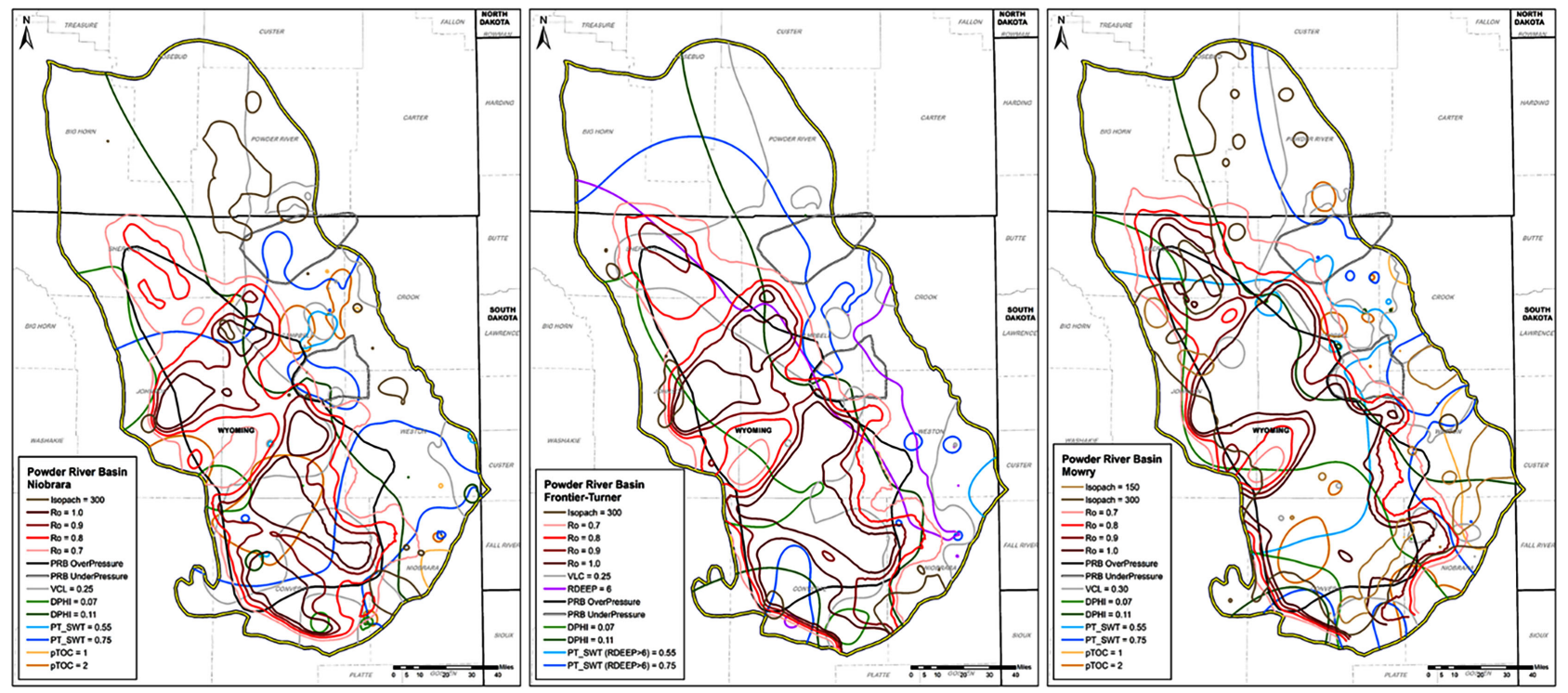

Figure 57. Maps of petrophysically driven attributes that allow subsurface integration and evaluation of potential, uncertainty and associated geological chance of success (risk). Example of bringing evaluated properties into spatial context to identify viable areas for potential hydrocarbon viability.

\section{CONCLUSION}

We presented here a comprehensive tutorial, applied lessons learned and interpretations resulting in impactful subsurface understanding for a case study in the Powder River Basin. Utilizing a multi-faceted petrophysical approach from raw log value to interpreted properties we share regionally based spatial trends for critical fluid-filled storage trends in context of the stratigraphy they are relevant to. We share insights and additional ways to approach and understand the two main, prolific source rocks in the Powder River basin, the Mowry and Niobrara formations. We share recommendations and insights into log values and approaches for both geologists and petrophysicists to consider when investigating the conventional to unconventional sandstone or silty-sandstone reservoirs present in the basin. We shared a detailed petrophysical approach to the Powder River basin for the scientific community to then utilize and expand upon when continuing to unravel the basins oil and gas potential as well as overall complexity.

\section{CONFLICTS OF INTEREST}

The authors declare no conflicts of interest regarding the publication of this paper.

\section{REFERENCES}

1. Glaze, F., Robert, E. and Keller, E.R. (1965) Geologic History of the Powder River Basin. AAPG Bulletin, 49, 1893-1907. https://doi.org/10.1306/A6633874-16C0-11D7-8645000102C1865D

2. Anna, L.O. (2010) Geologic Assessment of Undiscovered Oil and Gas in the Powder River Basin Province Wyoming and Montana. In: Total Petroleum Systems and Geologic Assessment of Oil and Gas Resources in the Powder River Basin Province, Wyoming and Montana, U.S. Geological Survey Series DDS-69-U, USGS, Reston, Chap. 1, 97 p. https://doi.org/10.3133/ds69U

3. Craddock, W.H., Drake, R.M., Mars, J.C. and Merrill, M.D. (2012) Geologic Framework for the National Assessment of Carbon Dioxide Storage Resources-Powder River Basin Wyoming, Montana, South Dakota, and Nebraska Chapter B. In: Geologic Framework for the National Assessment of Carbon Dioxide Storage Resources, 
USGS, Reston, Open File Report 2012-1024-B. https://doi.org/10.3133/ofr20121024B

4. Bottjer, R., Hendricks, M.L., Stright, D.H. and Bettridge, J.A. (2014) Sussex Sandstone, Hornbuckle Trend, Powder River Basin, Wyoming: Lithofacies and Reservoir Properties in a Tight Oil Play. AAPG Rocky Mountain Section Meeting, Denver, 20-22 July 2014, Search and Discovery Article \#10665.

5. Heger, A. (2016) Stratigraphy and Reservoir Characterization of the Turner Sandstone, Southern Powder River Basin, Wyoming. Colorado School of Mines MS Submission and Archive.

6. Sonnenberg, S. (2011) The Niobrara Petroleum System, a Major Tight Resource Play in the Rocky Mountain Region. AAPG Rocky Mountain Section Meeting, Cheyenne, 15-18 September 2019, Search and Discovery Article \#10355.

7. Slack, P.B. (1981) Paleotectonics and Hydrocarbon Accumulation, Powder River Basin. AAPG Bulletin, 65, 730743. https://doi.org/10.1306/2F9199BD-16CE-11D7-8645000102C1865D

8. Wyoming Oil and Gas Conservation Commission. WYOGC Scanned Log Database [LAS Files]. http://pipeline.wyo.gov/legacywogcce.cfm

9. Passey, Q.R., Creaney, S. and Kulla, J.B. (1990) A Practical Model for Organic Richness from Porosity and Resistivity Logs. AAPG Bulletin, 74, 1777-1794.

https://doi.org/10.1306/0C9B25C9-1710-11D7-8645000102C1865D

10. Schmoker, J. (1979) Determination of Organic Content of Appalachian Devonian Shales from Formation-Density Logs: Geologic Notes. AAPG Bulletin, 63, 1504-1509.

https://doi.org/10.1306/2F9185D1-16CE-11D7-8645000102C1865D

11. Passey, Q.R., Bohacs, W.L. and Klimentidis, W.L. (2010) From Oil-Prone Source Rock to Gas Producing Shale Reservoir-Geologic and Petrophysical Characterization of Unconventional Shale Gas Reservoirs. International Oil and Gas Conference and Exhibition, Beijing, 8-10 June 2010, 29. https://doi.org/10.2118/131350-MS

12. Jarvie, D.M. (2017) Perspectives on Shale Resource Plays, the Role of Organic Petrology in the Exploration of Conventional and Unconventional Hydrocarbon Systems. In: Suarez-Ruiz, I. and Filho, J.G.M., Eds., Geology. Current and Future Developments, Bentham Science Publishers, Sharjah, Vol. 1, 316-343.

13. United States Geological Survey, Core Research Center: U.S. Geological Survey. CRC Well Catalog [Database]. https://my.usgs.gov/crcwc

14. Archie, G.E. (1952) Classification of Carbonate Reservoir Rocks and Petrophysical Considerations. AAPG Bulletin, 36, 218-298. https://doi.org/10.1306/3D9343F7-16B1-11D7-8645000102C1865D

15. Belyadi, H., Fathi, E. and Belyadi, F. (2019) Rock Mechanical Properties and in Situ Stresses. In: Belyadi, H., Fathi, E. and Belyadi, F., Eds., Hydraulic Fracturing in Unconventional Reservoirs, Second Edition, Elsevier, Amsterdam, 215-231. https://doi.org/10.1016/B978-0-12-817665-8.00013-8

16. Poplavko, Y.M. (2019) Mechanical Properties of Solids. In: Poplavko, Y.M., Ed., Electronic Materials, Elsevier, Amsterdam, Chapter 2, 71-93. https://doi.org/10.1016/B978-0-12-815780-0.00002-5

17. Zhang, J.J. (2019) Rock Physical and Mechanical Properties. In: Zhang, J.J., Ed., Applied Petroleum Geomechanics, Chapter 2, Elsevier, Amsterdam, 29-83. https://doi.org/10.1016/B978-0-12-814814-3.00002-2

18. Couzens-Schultz, B.A., Axon, A., Azbel, K., Hansen, K.S., Haugland, M., Sarker, R., Tichelaar, B., Wieseneck, B., Wilhelm, R., Zhang, J. and Zhang, Z. (2013) Pore Pressure Prediction in Unconventionals. International Petroleum Technology Conference, Beijing.

19. Gong, C. and Rodriguez, L. (2017) Challenges in Pore Pressure Prediction for Unconventional Petroleum Systems. Unconventional Resources Technology Conference, Austin, 24-26 July 2017, Search and Discovery Article \#402018.

20. Downey, M.W., Garvin, J., Lagomarsino, R.C. and Nicklin, D.F. (2010) Quick Look Determination of Oil-in- 
Place in Oil Shale Resource Plays. AAPG Annual Convention, Houston, Search and Discovery Article \#40764.

21. Luffel, D.L., Hopkins, C.W. and Shettler, P.D. (1993) Matrix Permeability Measurements of Gas Productive Shales. SPE Annual Technical Conference and Exhibition, Houston, 3-6 October 1993, SPE 26633. https://doi.org/10.2118/26633-MS

22. Swanson, B.F. (1981) A Simple Correlation between Permeabilities and Mercury Injection Capillary Pressures. Journal of Petroleum Technology, 33, 2498-2504. https://doi.org/10.2118/8234-PA 


\section{APPENDIX}

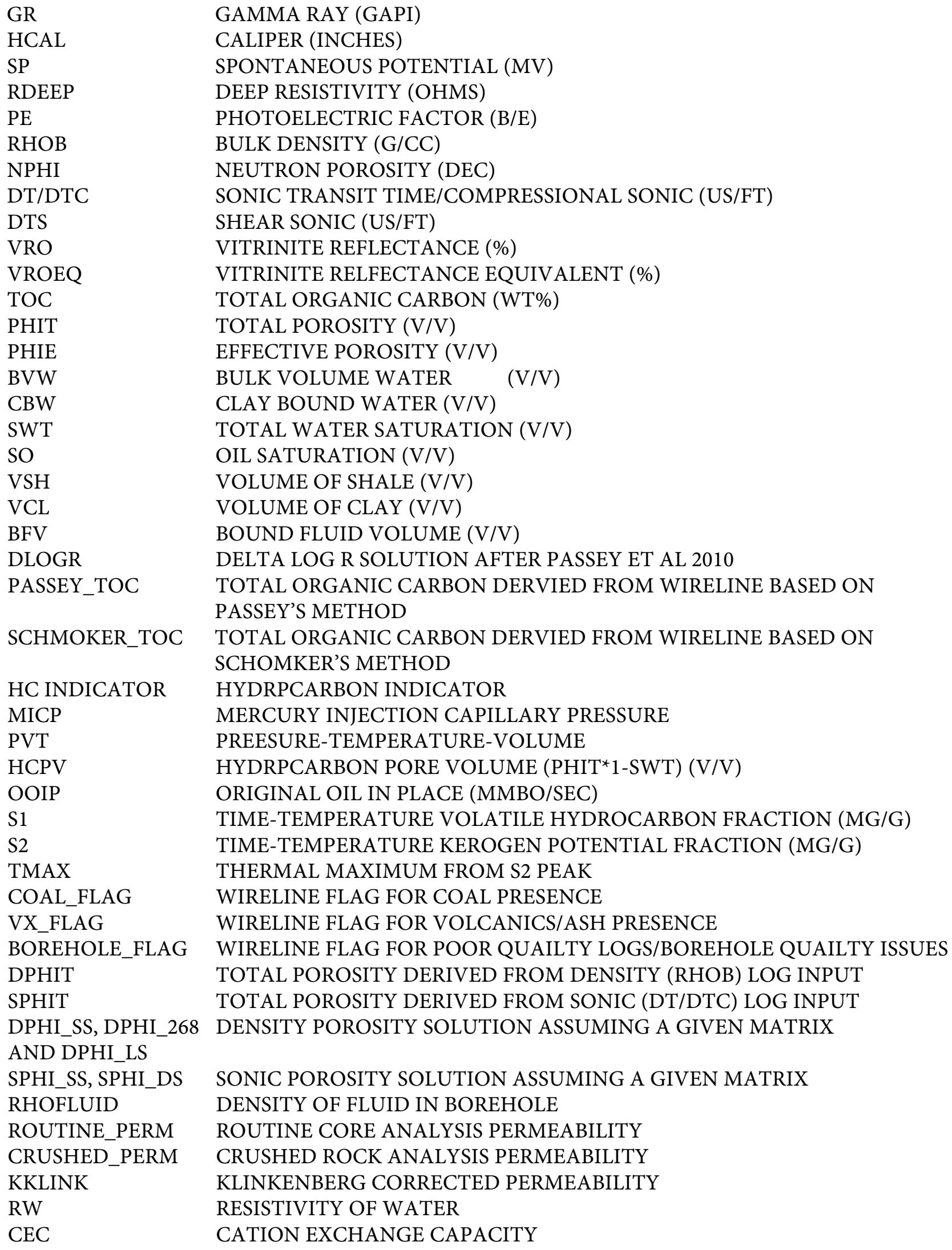




$\begin{array}{ll}\mathrm{PR} & \text { POISSONS RATIO } \\ \text { YM } & \text { YOUNGS MODULUS (PSI) } \\ \text { FIT } & \text { FORMATION INTEGRITY TEST } \\ \text { LOT } & \text { LEAK OFF TEST } \\ \text { KB } & \text { KELLY BUSHING } \\ \text { FVF/BO } & \text { FORMATION VOLUME FACTOR-SHRINKAGE FACTOR } \\ \text { TE } & \text { INTER-ECHO TIME (MS) } \\ \mathrm{MHz} & \text { MEGAHERTZ } \\ \mathrm{VpVs} & \text { COMPRESSION VERSUS SONIC VELOCITY RATIO } \\ \% & \text { PERCENT } \\ ><= & \text { GREATER THAN, LESS THAN, EQUALS } \\ \star & \text { MULTIPLY BY } \\ + & \text { ADDITION OF } \\ +/- & \text { PLUS OR MINUS } \\ \wedge & \text { RAISED TO THE EXPONENT } \\ / & \text { DIVIDED BY }\end{array}$

